MARIA RAPHAELLA DOS SANTOS VASCONCELOS

\title{
PROSPECÇÃO DE FUNGOS DERIVADOS DE ESPONJAS MARINHAS NA DEGRADAÇÃO/DESCOLORAÇÃO DE POLUENTES AMBIENTAIS
}

Tese apresentada ao Programa de Pós-Graduação Interunidades em Biotecnologia USP/Instituto Butantan/IPT, para obtenção do Título de Doutor em Biotecnologia. 
MARIA RAPHAELLA DOS SANTOS VASCONCELOS

\section{PROSPECÇÃO DE FUNGOS DERIVADOS DE ESPONJAS MARINHAS NA DEGRADAÇÃO/DESCOLORAÇÃO DE POLUENTES AMBIENTAIS}

Tese apresentada ao Programa de PósGraduação em Microbiologia do Instituto de Ciências Biomédicas da Universidade de São Paulo, para obtenção do Título de Doutor em Ciências.

Área de concentração: Biotecnologia

Orientadora: Profa. Dra. Lara Durães Sette

Versão original 
DADOS DE CATALOGAÇÃO NA PUBLICAÇÃO (CIP)

Serviço de Biblioteca e Informação Biomédica do

Instituto de Ciências Biomédicas da Universidade de São Paulo

reprodução não autorizada pelo autor

Vasconcelos, Maria Raphaella dos Santos.

Prospecção de fungos derivados de esponjas marinhas na degradação/descoloração de poluentes ambientais / Maria Raphaella dos Santos Vasconcelos. -- São Paulo, 2014.

Orientador: Profa. Dra. Lara Durães Sette.

Tese (Doutorado) - Universidade de São Paulo. Instituto de Ciências Biomédicas. Programa de Pós-Graduação Interunidades em Biotecnologia USP/IPT/Instituto Butantan. Área de concentração: Biotecnologia. Linha de pesquisa: Degradação de poluentes ambientes por micro-organismos marinhos.

Versão do título para o inglês: Prospecting of fungi derived from marine sponges in the degradation/decolorization of environmental pollutants.

1. Biorremediação 2. Poluentes ambientais 3. Hidrocarbonetos policíclicos aromáticos 4. Delineamento experimental 5. Fungos filamentosos 6. Enzimas ligninoliticas I. Sette, Profa. Dra. Lara Durães II. Universidade de São Paulo. Instituto de Ciências Biomédicas. Programa de Pós-Graduação Interunidades em Biotecnologia USP/IPT/Instituto Butantan III. Título. 


\section{UNIVERSIDADE DE SÃO PAULO \\ Programa de Pós-Graduação Interunidades em Biotecnologia}

Universidade de São Paulo, Instituto Butantan, Instituto de Pesquisas Tecnológicas

Candidato(a):

Maria Raphaella dos Santos Vasconcelos.

Título da Tese:

Prospecção de fungos derivados de esponjas marinhas na degradação/descoloração de poluentes ambientais.

Orientador(a):

Profa. Dra. Lara Durães Sette.

A Comissão Julgadora dos trabalhos de Defesa da Tese de Doutorado, em sessão pública realizada a .................., considerou
( ) Aprovado(a)
( ) Reprovado(a)

$\begin{array}{ll}\text { Examinador(a): } & \text { Assinatura: } \\ & \text { Nome: ....... } \\ & \text { Instituição: } \\ \text { Examinador(a): } & \text { Assinatura: } \\ & \text { Nome: ....... } \\ & \text { Instituição: } \\ \text { Examinador(a): } & \text { Assinatura: } \\ & \text { Nome: ........ } \\ & \text { Instituição: } \\ \text { Examinador(a): } & \text { Assinatura: } \\ & \text { Nome: ........ } \\ & \text { Instituição: } . . \\ & \text { Assinatura: } \\ \text { Presidente: } & \text { Nome: ........ } \\ & \text { Instituição: ... }\end{array}$


Dedico este trabalho ao Deus da minha vida, à minha família, especialmente aos meus sobrinhos queridos, Carlosman Neto, Ana Elise, Maria Izabella, João Gabriel e João Miguel, que fizeram a minha alegria e renovaram as minhas forças a cada ida à minha casa! Amo-os imensamente! 


\section{AGRADECIMENTOS}

À Universidade de São Paulo - USP (Campus da Capital);

Ao Conselho Nacional de Pesquisa (CNPq) pela bolsa DTI-2, a qual subsidiou o início dos meus estudos do Doutorado;

À Coordenação de Aperfeiçoamento de Pessoal de Nível Superior (CAPES) pela bolsa de Doutorado dispensada a mim pelo Programa de Pós-Graduação Interunidades em Biotecnologia (PPGIB) da Universidade de São Paulo (20112012);

À Fundação de Amparo à Pesquisa do Estado de São Paulo (FAPESP), pela bolsa de Doutorado e recursos de reserva técnica (2012-2015);

Ao Centro de Pesquisa Química, Biológica e Agrícola (CPQBA), especialmente à Divisão de Recursos Microbianos (DRM), meu laboratório querido, onde convivi com pessoas agradáveis e cooperativas, por toda infra-estrutura, na pessoa da Dra.

Valéria Maia (coordenadora da DRM);

À profa. Dra. Lara Durães Sette, pela grande oportunidade de novos conhecimentos que me concedeu no aceite da minha orientação, pela responsividade às soluções para os problemas do trabalho e pela liberdade de pensamento e na condução dos experimentos; isso favoreceu ainda mais o meu crescimento e amadurecimento, muito obrigada!;

À profa. Dra. Rafaella Costa Bonugli Santos, pela preciosa co-orientação e pela paciência em me passar seus conhecimentos;

Às pesquisadoras Marili Rodrigues e Vera Garcia, da Divisão de Química Orgânica e Farmacêutica (DQOF/CPQBA) pela exímia colaboração nas análises químicas do presente trabalho e ao Sinésio Boaventura que me auxiliou nos experimentos;

À Milena Binatti, pela sua atenção nos meus primeiros passos na DRM e no início da minha adaptação em SP: muito obrigada pela generosa amizade!;

À Viviane Piccin pelas incansáveis aulas de inglês (sempre muito cuidadosamente preparadas) que foram de grande ajuda e importância, além da ajuda no laboratório de BioMol: grata pela paciência e a disposição em ajudar!;

Aos amigos queridos e a todos do laboratório pelas risadas, pela cooperatividade, pelo café na copa, pelo "bar na sexta", pelas caronas, enfim, por tornar o laboratório um ambiente "no stress", totalmente favorável ao desenvolvimento das nossas 
atividades. Queridos da DRM, vocês são demais!!! Guardarei para sempre esse tempo precioso que passamos juntos!

À minha família que sempre me apoiou nesse caminho do aprendizado, da formação; e à d. Natalina, minha mãe paulista, pelo carinho e apoio. Sem vocês, o caminho não teria sido suavizado e a vitória não teria sido alcançada! Amo-os!

Às minhas amigas lobas Eliana, Simone, Rosângela, Laíse e a minha irmã-amiga Mariana que sempre estiveram na "escuta" durante todo o tempo do meu curso; muito obrigada pela leal e dedicada amizade! Amo-as! 


\section{AGRADECIMENTO ESPECIAL}

Ao Pai do céu, que confiou em mim e me impulsionou a percorrer mais 4 anos na estrada do conhecimento, dessa vez longe de casa! Muito obrigada, Pai querido, sem Ti nada disso valeria à pena! $\mathrm{A} \mathrm{Ti}$, o mais alto agradecimento, $\mathrm{o}$ louvor, a honra e a glória para sempre! Amo-te e sei que sou muito amada! 
“Deus é bom em todo o tempo." 


\section{RESUMO}

VASCONCELOS, M. R. S. Prospecção de fungos derivados de esponjas marinhas na degradação/descoloração de poluentes ambientais. 2014. $101 \mathrm{f}$. Tese (Doutorado em Biotecnologia) - Instituto de Ciências Biomédicas, Universidade de São Paulo, São Paulo, 2014.

Diversos estudos têm demonstrado o potencial de utilização de fungos filamentosos na degradação de poluentes ambientais. Entretanto, estudos de degradação de HPAs, descoloração de corantes sintéticos e produção de enzimas ligninolíticas por fungos de origem marinha ainda são escassos. Neste contexto, o presente trabalho teve como objetivo principal avaliar o potencial biotecnológico de 174 fungos filamentosos isolados a partir de seis diferentes espécies de esponjas marinhas, os quais foram reativados com sucesso e submetidos ao screening em meio sólido contendo corante RBBR e guaiacol. A triagem resultou em 61 isolados positivos $(35,05 \%)$ para lacase, sendo 10 destes avaliados quanto à produção de lacase, manganês peroxidase $(\mathrm{MnP})$ e lignina peroxidase (LiP) em meio líquido utilizando siringaldazina, álcool veratrílico e o vermelho de fenol como substratos enzimáticos, respectivamente. Ensaios sem corante (SC) e com suplementação dos corantes têxteis preto sulfuroso (PS), índigo blue (IB) e reativo black 5 (RB5) foram realizados. Os isolados Trichoderma harzianum CBMAl 1359 (DRG4.3.1), Pleospora sp. CBMAI 1358 (DRAC3) e Arthopyrenia salicis CBMAI 1330 (DRRBBR7.2) foram selecionados como os melhores produtores de enzimas ligninolíticas e foram submetidos aos ensaios de degradação de pireno (Py) e benzo[a]pireno (BaP). Os maiores valores de degradação $(44,01 \%$ para Py e $30,38 \%$ para $\mathrm{BaP}$ ) foram obtidos pelo fungo Pleospora sp. CBMAI 1358 na ausência de salinidade. Diante destes resultados, novos isolados foram selecionados e submetidos aos ensaios de degradação dos HPAs estudados. O fungo Chaunopycnis alba CBMAI 1346 (DRR 7.9) foi capaz de degradar $66,28 \%$ de Py e $61,06 \%$ de BaP e o fungo Xylaria sp. CBMAl 1464 (CeAC2) apresentou degradação de $55,74 \%$ de Py e 88,16 \% de BaP. Para esses dois fungos houve destaque na produção de $\mathrm{MnP}$ na presença de BaP. Nas análises de metabólitos formados na degradação de Py pelo fungo $C$. alba CBMAI 1346 foram detectados íons que sugerem a presença dos compostos monohidroxifenantreno, dihidroxipireno, lactona e hidroxipirenos. Delineamentos experimentais foram realizados para os dois fungos selecionados visando otimização do processo de degradação. No PB20, utilizando 9 variáveis, C. alba CBMAl 1346 alcançou 79,39 \% de degradação, enquanto que Xylaria sp. CBMAl 1464 atingiu o máximo de $46,00 \%$. Um novo PB (PB16) utilizando 5 variáveis foi realizado para o fungo $C$. alba CBMAI 1346, resultando na degradação de $58,28 \%$ de Py. Assim, foi proposto um delineamento fatorial fracionado $2^{4-1}$, com 4 variáveis (FF12), que resultou na degradação de 94,17 \% (ensaio 6) de Py. O experimento de validação do processo de degradação foi realizado pela repetição do ensaio 6 do delineamento FF12, onde foi observado 94,54 \% de degradação de Py em $35 \%$ de salinidade. Nestas condições (validação), C. alba CBMAl 1346 apresentou expressiva produção de $\mathrm{MnP}$ e os metabólitos formados durante o processo degradativo foram identificados como sendo de cadeia aberta (ceteno, hexadecano, octadeceno, 5-eicoseno, eicosano e álcool behênico), sugerindo o ataque à molécula do HPA pelo fungo estudado. Os resultados do presente trabalho 
evidenciam o potencial biotecnológico do fungo C. alba CBMAI 1346 para aplicação em processos de degradação de poluentes ambientais em condições salinas.

Palavras-chave: Poluentes ambientais. Fungos filamentosos marinhos. Enzimas ligninolíticas. Delineamento experimental. Degradação de pireno. 


\section{ABSTRACT}

VASCONCELOS, M. R. S. Prospecting fungi derived from marine sponges on degradation/decolorization of environmental pollutants. 2014. $100 \mathrm{f}$. Ph. D thesis (Biotechnology) - Instituto de Ciências Biomédicas, Universidade de São Paulo, São Paulo, 2014.

Several studies have shown the potential use of filamentous fungi in the degradation of environmental pollutants. However, studies related to PAHs degradation, synthetic dyes decolorization and ligninolytic enzymes production by fungi from marine origin are still scarce. In this context, the present work aimed to evaluate the biotechnological potential of 174 filamentous fungi isolated from six different species of marine sponges, which were successfully reactivated and submitted to a screening on solid medium containing RBBR dye and guaiacol. The screening resulted in 61 laccase positive isolates (35.05\%), being 10 isolates submitted to the evaluation of laccase, manganese peroxidase (MnP) and lignin peroxidase (LiP) production in liquid medium using syringaldazine, veratryl alcohol and phenol red as enzymatic substrates, respectively. Assays without dye (SC) and with supplementation of sulfur black (PS), indigo blue (IB) and reactive black 5 (RB5) textile dyes were performed. The isolates Trichoderma harzianum CBMAI 1359 (DRG4.3.1) Pleospora sp. CBMAI 1358 (DRAC3) and Arthopyrenia salicis CBMAl 1330 (DRRBBR7.2) were selected as the best producers of ligninolytic enzymes and were subjected to the experiments related to pyrene (Py) and benzo[a]pyrene (BaP) degradation. The highest degradation (44.01\% to $30.38 \%$ for Py and $\mathrm{BaP}$ ) were obtained by the fungus Pleospora sp. CBMAI 1358 in the absence of salinity. Based on these results, new isolates were selected and subjected to the experiments of PAHs degradation. The fungus Chaunopycnis alba CBMAI 1346 (DRR 7.9) was able to degrade $66.28 \%$ of Py and $61.06 \%$ of BaP and the fungus Xylaria sp. CBMAI 1464 (CeAC2) showed $55.74 \%$ and $88.16 \%$ of degradation for $\mathrm{Py}$ and $\mathrm{BaP}$, respectively. For both fungi $\mathrm{MnP}$ was specially produced in the presence of $\mathrm{BaP}$. In the analyses of metabolites formed during Py degradation by the fungus $C$. alba CBMAl 1346 were detected ions that suggest the presence of monohydroxy-phenanthrene, dihydroxy-pyrene, lactone and hydroxypyrene compounds. Experimental designs were performed for the two selected fungi in order to optimize the degradation process. In PB20 using nine variables, C. alba 1346 CBMAl reached $79.39 \%$ of degradation, while Xylaria sp. CBMAI 1464 reached $46.00 \%$. A new PB (PB16) was performed using five variables for the fungus C. alba CBMAI 1346, resulting in degradation of $58.28 \%$ of Py. Thus, was proposed a $2^{4-1}$ fractional factorial design with four variables (FF12) that resulted in the degradation of $94.17 \%$ of Py (assay 6). The validation experiment related to the degradation process was carried out by repeating the assay 6 of FF12 design, where was observed $94.54 \%$ of Py degradation under $35 \%$ of salinity. Under these conditions (validation), C. alba CBMAl 1346 showed significant production of MnP and the metabolites formed during the degradation process were identified as aliphatic compounds (ketene, hexadecane, octadecene, eicosene-5, eicosane and behenic alcohol), suggesting that the studied fungus attacked the HPA molecule. 
Results from this work highlight the biotechnological potential of the fungus $C$. alba CBMAI 1346 for application in degradation processes of environmental pollutants in saline conditions.

Keywords: Environmental pollutants. Marine filamentous fungi. Ligninolytic enzymes. Experimental design. Pyrene degradation. 


\section{LISTA DE FIGURAS}

Figura 1. Possível mecanismo de oxidação do guaiacol pela lacase (SHLEEV et al., 2006)

Figura 2. Estruturas químicas dos hidrocarbonetos policíclicos aromáticos (HPAs). A) Pireno (Py). B) Benzo[a]pireno (BaP).

Figura 3. Equação geral de reação biocatalítica executada pelas enzimas da superfamília P450 (BRINK et al. 1997). .28

Figura 4. Vias propostas para o catabolismo microbiano de hidrocarbonetos policíclicos aromáticos (HPAs) (HARITASH e KAUSHIK, 2009).

Figura 5. Principais estruturas da lignina. A) Éter aril-glicerol- $\beta$-aril, B) Fenilcoumarina, C) Resinol. $R_{1}$ é $\mathrm{H}$ para a estrutura guaiacil e $\mathrm{OCH}_{3}$ para a estrutura siringil. $\mathrm{R}_{2}$ é $\mathrm{H}$ para estruturas fenólicas, $\mathrm{CH}_{3}$ para estruturas fenólicas metiladas, e lignina para estruturas não fenólicas.

Figura 6. Número de gêneros distintos de fungos derivados de ambiente marinho baseado em diferentes fontes (Fonte: BUGNI e IRELAND, 2004).

Figura 7. Mapa com a localização dos pontos de coleta (em amarelo) em São Sebastião e Ilhabela (SP).

Figura 8. Screening de produção de lacase em meio B\&K acrescido de guaiacol: (A) experimento controle - crescimento dos fungos em B\&K sem guaiacol. (B) Formação do composto marrom escuro na presença de guaiacol.

Figura 9. Atividade enzimática de lacase $\left(U \mathrm{~L}^{-1}\right)$ pelos fungos Pleospora sp. CBMAI 1358, Trichoderma harzianum CBMAI 1359 e Arthopyrenia salicis CBMAI 1330, no $3^{\circ}$ e $7^{\circ}$ dia de cultivo em meio líquido $\mathrm{MA} \%+3 \% \mathrm{NaCl}$. Tratamentos: Meio sem corante (SC), suplementados com corante preto sulfuroso (PS) e com o corante índigo blue (IB).

Figura 10. Atividade enzimática de $\mathrm{MnP}\left(\mathrm{U} . \mathrm{L}^{-1}\right)$ pelos fungos Pleospora sp. CBMAI 1358, Trichoderma harzianum CBMAI 1359 e Arthopyrenia salicis CBMAI 1330, no $3^{\circ}$ e $7^{\circ}$ dia de cultivo em meio líquido $\mathrm{MA}+3 \% \mathrm{NaCl}$. Tratamentos: Meio sem corante (SC), suplementados com corante preto sulfuroso (PS) e com o corante índigo blue (IB)

Figura 11. Atividade enzimática de LiP $\left(U . \mathrm{L}^{-1}\right)$ pelos fungos Pleospora sp. CBMAI 1358, Trichoderma harzianum CBMAI 1359 e Arthopyrenia salicis CBMAI 1330, no 3ํㅜ $7^{\circ}$ dia de cultivo em meio líquido $\mathrm{MA}+3 \% \mathrm{NaCl}$. Tratamentos: Meio sem corante (SC), suplementados com corante preto sulfuroso (PS) e com o corante índigo blue (IB)

Figura 12. Degradação de pireno e benzo[a]pireno $\left(2 \mathrm{mg} \cdot \mathrm{mL}^{-1}\right)$ pelos fungos Pleospora sp. CBMAI 1358, Trichoderma harzianum CBMAl 1359 e Arthopyrenia salicis CBMAI 1330 em meio $\mathrm{MA} 2 \%+3 \% \mathrm{NaCl}$ (condição salina) e MA2\% (condição sem sal), após 7 dias de cultivo a $28^{\circ} \mathrm{C}$ e $140 \mathrm{rpm}$

Figura 13. Degradação de pireno $\left(2 \mathrm{mg}^{-1} \mathrm{~mL}^{-1}\right)$ pelos isolados DRAC1-9, DRR7-9, CeAC 2 e DRR4.1-6 em meio MB2\% após 7 dias de cultivo a $28^{\circ} \mathrm{C}$ e $140 \mathrm{rpm}$. 
Figura 14. Análise filogenética de ITS-rDNA de Xylaria sp. CBMAI 1464 e de sequências de ITS-rDNA de fungos que apresentaram alta similaridade de sequência do marcador taxonômico utilizado. As distâncias evolutivas e a construção da árvore foram realizadas pelo método Maximum Likelihood. Valores de bootstrap (1000 replicatas) estão mostrados na forma de \%.

Figura 15. Degradação de benzo[a]pireno $\left(2 \mathrm{mg} \mathrm{mL}^{-1}\right)$ pelos fungos Chaunopycnis alba CBMAI 1346 e Xylaria sp. CBMAI 1330 em meio MB2\%, após 7 dias de cultivo a $28^{\circ} \mathrm{C}$ e 140 rpm.

Figura 16. Adsorção (\%) dos HPAs pireno e benzo[a]pireno pelos micélios dos fungos Chaunopycnis alba CBMAI 1346 e Xylaria sp. CBMAI 1464. .59

Figura 17. Atividade enzimática de lacase, MnP e LiP dos fungos Chaunopycnis alba CBMAI 1346 e Xylaria sp. CBMAI 1464, no meio líquido sem corante (SC), na presença dos corantes preto sulfuroso (PS) e índigo blue (IB), no $3^{\circ}$ e $7^{\circ}$ dia de cultivo em meio MB2 \% $\left(28^{\circ} \mathrm{C}\right.$ e $\left.140 \mathrm{rpm}\right)$. A) Lacase, B) MnP, C) LiP.

Figura 18. Atividade enzimática de lacase, MnP e LiP $\left(\mathrm{U}^{-1}\right)$ de Xylaria sp.CBMAl 1464 e Chaunopycnis alba CBMAI 1346 em meio MB2\%, A) adicionado com Py $\left.\left(2 \mathrm{mg}^{-1} \mathrm{~mL}^{-1}\right), \mathrm{B}\right)$ adicionado de BaP (2 mg. $\mathrm{mL}^{-1}$ ) e C) sem a presença dos HPAs, após 7 dias de cultivo a $28^{\circ} \mathrm{C}$ e $140 \mathrm{rpm}$.

Figura 19. Cromatograma expandido no intervalo de $t_{R} 10$ min a 24 min no modo Scan, na degradação do pireno pelo fungo $C$. alba CBMAI 1346 após 7 dias de cultivo a $28^{\circ} \mathrm{C}$ e 140 rpm.

Figura 20. Estruturas químicas de compostos resultantes da degradação de pireno pelo fungo $C$. alba CBMAI 1346, após 7 dias de cultivo a 28ㄷ $\mathrm{C}$ e $140 \mathrm{rpm}$.

Figura 21. Cromatograma modo SIM dos metabólitos formados na degradação de pireno pelo fungo C.alba CBMAl 1346, após 7 dias de cultivo a 28ํㅡ e 140 rpm.

Figura 22. Perfil cromatográfico dos metabólitos formados pela degradação do pireno por $\mathrm{C}$. alba CBMAI 1346 após 7 dias de cultivo ( $\left.t_{R} 38,321 \mathrm{~min}\right)$......

Figura 23. Perfil cromatográfico dos metabólitos formados pela degradação do pireno por $C$. alba CBMAI 1346, após 7 dias de cultivo ( $\left.t_{R} 38,530 \mathrm{~min}\right)$.

Figura 24. Efeito das variáveis estudadas no delineamento de Plackett-Burman (PB20) sobre o processo de degradação do fungo C. alba CBMAI 1346.

Figura 25. Efeito das variáveis estudadas no delineamento de Plackett-Burman (PB20) sobre o processo de degradação do fungo Xylaria sp. CBMAI 1464.

Figura 26. Efeito das variáveis estudadas no delineamento de Plackett-Burman (PB16) sobre o processo de degradação do fungo C.alba CBMAI 1346.

Figura 27. Efeito das variáveis estudadas no delineamento fatorial fracionado $2^{4-1}$ sobre 0 processo de degradação do fungo C. alba CBMAl 1346.

Figura 28. Evolução da degradação (\%) de pireno pelo fungo C. alba CBMAI 1346 nos ensaios propostos antes e após os delineamentos experimentais. 86 
Figura 29. Cromatograma expandido ( $t_{R}$ de $8 \mathrm{~min}$ a $18 \mathrm{~min}$ ) modo $S c a n$ do produto de degradação do pireno pelo fungo $C$. alba CBMAI 1346, após 7 dias de cultivo, nas condições do ensaio validado

Figura 30. Espectro de massas do composto estudado pireno $-M M=202\left(\mathrm{C}_{6} \mathrm{H}_{10}\right)$ e sua respectiva estrutura química.

Figura 31. Espectro de massas do composto hexadecano - $M M=226\left(\mathrm{C}_{6} \mathrm{H}_{34}\right)$, composto encontrado como metabólito formado a partir da degradação de pireno pelo fungo $C$. alba CBMAI 1346, após 7 dias de cultivo, na condição validada, e sua respectiva estrutura química

Figura 32. Espectro de massas do composto 5-eicoseno $-\mathrm{MM}=280\left(\mathrm{C}_{20} \mathrm{H}_{40}\right)$, composto encontrado como metabólito formado a partir da degradação de pireno pelo fungo $C$. alba CBMAI 1346, após 7 dias de cultivo, na condição validada, e sua respectiva estrutura química

Figura 33. Espectro de massas do composto eicosano $-M M=282\left(\mathrm{C}_{20} \mathrm{H}_{42}\right)$, composto encontrado como metabólito formado a partir da degradação de pireno pelo fungo $C$. alba CBMAI 1346, após 7 dias de cultivo, na condição validada, e sua respectiva estrutura química.

Figura 34. Espectro de massas do composto octadeceno - $M M=224\left(\mathrm{C}_{18} \mathrm{H}_{36}\right)$ composto encontrado como metabólito formado a partir da degradação de pireno pelo fungo $C$. alba CBMAI 1346, após 7 dias de cultivo, na condição validada, e sua respectiva estrutura química.

Figura 35. Espectro de massas do composto ceteno (1-hexadeceno) - $M M=224\left(\mathrm{C}_{16} \mathrm{H}_{32}\right)$, composto encontrado como metabólito formado a partir da degradação de pireno pelo fungo C. alba CBMAl 1346, após 7 dias de cultivo, na condição validada, e sua respectiva estrutura química.

Figura 36. Espectro de massas do composto álcool behênico (1-docosanol) - $M M=308$ $\left(\mathrm{C}_{22} \mathrm{H}_{46} \mathrm{O}\right)$, composto encontrado como metabólito formado a partir da degradação de pireno pelo fungo $C$. alba CBMAl 1346, após 7 dias de cultivo, na condição validada, e sua respectiva estrutura química. 


\section{LISTA DE TABELAS}

Tabela 1. Níveis das variáveis estudadas no delineamento de Plackett-Burman com 9 variáveis (PB20), aplicado à degradação de pireno.

Tabela 2. Níveis das variáveis estudadas no delineamento de Plackett-Burman com 5 variáveis (PB16), aplicado à degradação de pireno.

Tabela 3. Níveis das variáveis estudadas no delineamento fatorial fracionado $2^{4-1}$ (FF12), aplicado à degradação de pireno.

Tabela 4. Níveis das variáveis estudadas no Delineamento Composto Central Rotacional (DCCR12)

Tabela 5. Identificação dos fungos derivados marinhos ligninolíticos, número do depósito, código de origem e fonte de isolamento.

Tabela 6. Identificação dos fungos derivados marinhos, número de depósito, código de origem e fonte de isolamento.

Tabela 7. Íons monitorados na detecção dos metabólitos formados na degradação de pireno pelo fungo $C$. alba CBMAI 1346: tempo de retenção e características da espectrometria de massas (MAGRINI, 2012)

Tabela 8. Identificação dos metabólitos da degradação de pireno pelo fungo $C$. alba CBMAI 1346: tempo de retenção $\left(t_{R}\right)$ e características da espectrometria de massas.

Tabela 9. Degradação de pireno (\%), valores reais e codificados da matriz do delineamento de Plackett-Burman com 9 variáveis, no total de 20 ensaios (PB20) para o fungo Chaunopycnis alba CBMAI 1346.

Tabela 10. Erro padrão e significância $(p<0,1)$ das variáveis estudadas no PB20 de $C$. alba CBMAI 1346.

Tabela 11. Degradação de pireno (\%), valores reais e codificados da matriz do delineamento de Plackett-Burman com 9 variáveis, no total de 20 ensaios (PB20) para o fungo Xylaria sp. CBMAI 1464

Tabela 12. Erro padrão e significância $(p<0,1)$ das variáveis estudadas no PB20 de Xylaria sp. CBMAI 1464

Tabela 13. Degradação de pireno (\%) pelo fungo C. alba CBMAl 1346, obtidos pelo planejamento de Plackett \& Burman de 16 ensaios (PB16)

Tabela 14. Erro padrão e significância $(p<0,1)$ das variáveis estudadas no PB16 de $C$. alba CBMAI 1346.

Tabela 15. Degradação, valores reais e codificados da matriz do delineamento Fatorial Fracionado com 4 variáveis, no total de 12 ensaios (FF12), pelo fungo Chaunopycnis alba CBMAl 1346, obtidos pelo delineamento Fatorial Fracionado $2^{4-1}$

Tabela 16. Erro padrão e significância $(p<0,1)$ das variáveis estudadas no delineamento fatorial fracionado $2^{4-1}$ de C. alba CBMAI 1346. 
Tabela 17. Degradação de pireno (\%), valores reais e codificados da matriz do Delineamento Composto Central Rotacional (DCCR) com 2 variáveis, no total de 12 ensaios pelo fungo $C$. alba CBMAI 1346. .84

Tabela 18. Degradação de pireno (\%) e atividade enzimática do fungo C. alba CBMAI 1346, obtidos pelo ensaio validado (ensaio 6 do delineamento fatorial fracionado $2^{4-1}$ ).

Tabela 19. Validação da degradação de pireno (\%) pelo fungo Chaunopycnis alba CBMAI 1346 , obtidos pelo delineamento fatorial fracionado $2^{4-1}$

Tabela 20. Identificação dos metabólitos formados a partir da degradação de pireno pelo fungo Chaunopycnis alba CBMAI 1346 no modo de varredura completa (Full Scan): tempo de retenção $\left(t_{R}\right)$ e características da espectrometria de massas. .88 
1 INTRODUÇÃO

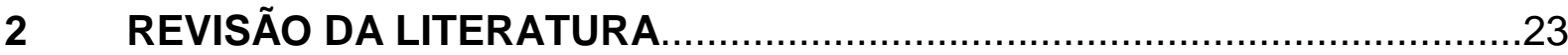

2.1 Fungos filamentosos de origem marinha: recursos utilizados para a biodegradação de corantes e efluentes coloridos.

2.2 Hidrocarbonetos policíclicos aromáticos (HPAs) e os mecanismos envolvidos na sua degradação pelos fungos filamentosos de origem marinha. .26

2.3 Fungos filamentosos marinhos e sua classificação ecológica. .32

2.4 Delineamento experimental como ferramenta utilizada para a otimização

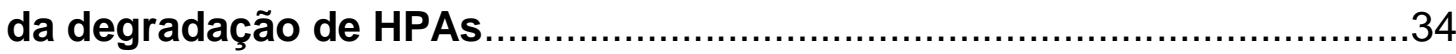

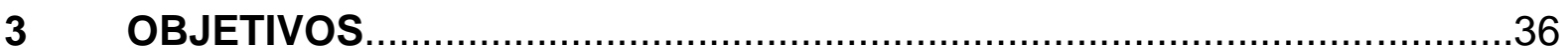

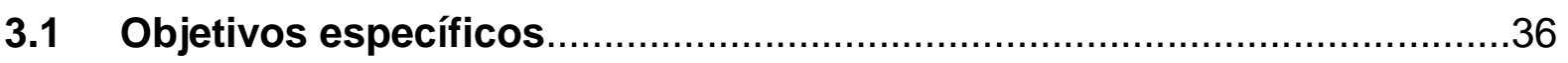

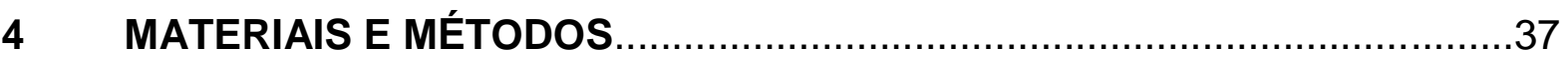

4.1 Reativação de fungos filamentosos isolados a partir de amostras de

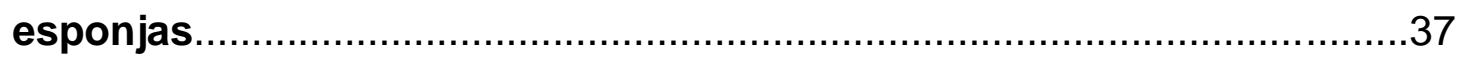

4.2 Seleção de fungos produtores de enzimas ligninolíticas.........................38

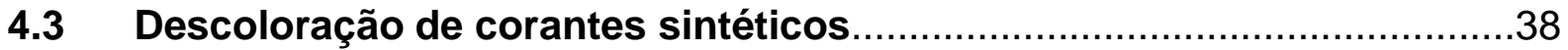

4.3.1 Avaliação do potencial de descoloração......................................................

4.4 Avaliação da produção das enzimas ligninolíticas..................................39

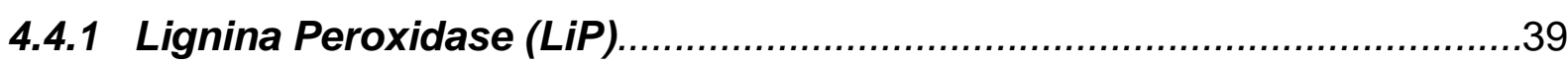

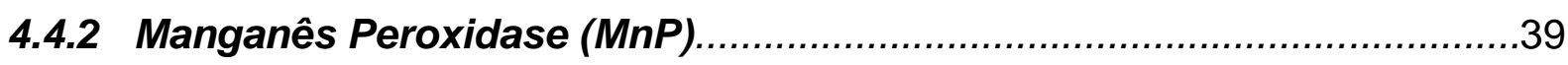

4.4.3 Lacase

4.5 Avaliação da degradação in vitro dos HPAs pireno e benzo[a]pireno....41

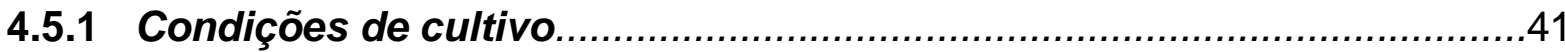

4.5.2 Degradação in vitro dos HPAs pireno e benzo[a]pireno.........................41

4.5.2.1 Extração dos HPAs para análise por Cromatografia Gasosa e Espectrometria

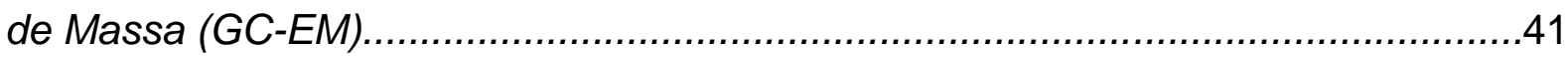

4.5.2.2 Análise quantitativa da degradação dos HPAs por GC-EM.........................42

4.5.2.3 Avaliação da adsorção dos HPAs ao micélio............................................43 
4.5.2.4 Otimização da degradação de HPAs através do delineamento

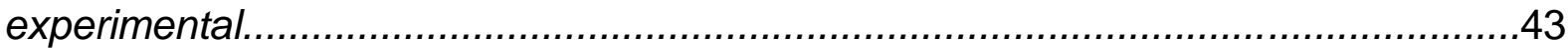

4.5.2.4.1 Delineamentos experimentais de Plackett-Burman (PB).......................43

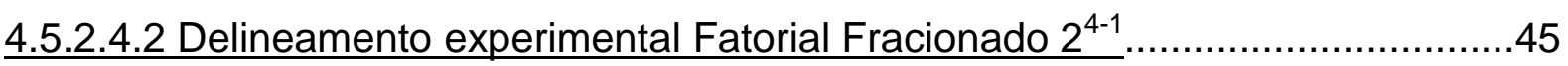

4.5.2.4.3 Delineamento Composto Central Rotacional (DCCR) ..............................46

4.6 Análise qualitativa dos metabólitos formados durante a degradação dos HPAs por Cromatografia Gasosa e Espectrometria de Massa (GC-EM).

4.7 Extração do DNA genômico e amplificação dos genes marcadores taxonômicos para a identificação do isolado CeAC2

4.8 Análises filogenéticas para identificação do isolado CeAC 2................48

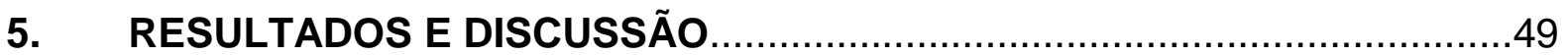

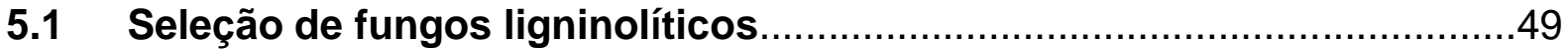

5.2 Avaliação da produção das enzimas ligninolíticas em meio líquido e suplementado com corantes

5.3 Degradação dos HPAs pireno e benzo[a]pireno pelos fungos produtores de enzimas ligninolíticas .54

5.4 Identificação molecular do isolado CeAC 2.

5.5 Degradação do HPA benzo[a]pireno pelos fungos Chaunopycnis alba CBMAl 1346 e Xylaria sp. CBMAl 1464

5.6 Avaliação da adsorção dos HPAs pireno e benzo[a]pireno pelos fungos Chaunopycnis alba CBMAl 1346 e Xylaria sp. CBMAl 1464. .58

5.7 Avaliação da produção das enzimas ligninolíticas pelos fungos Chaunopycnis alba CBMAl 1346 e Xylaria sp. CBMAl 1464 em meio líquido suplementado com corantes.

5.8 Atividade enzimática dos fungos Chaunopycnis alba CBMAl 1346 e Xylaria sp. CBMAl 1464 na presença de pireno e benzo[a]pireno

5.9 Identificação de metabólitos formados durante a degradação de pireno pelo fungo Chaunopycnis alba CBMAl 1346.

5. 10 Delineamento experimental de Plackett-Burman para a otimização da degradação de pireno pelos fungos Chaunopycnis alba CBMAl 1346 e Xylaria sp. CBMAI 1464. 
5.11 Delineamento experimental Fatorial Fracionado $2^{4-1}$ utilizado para a otimização da degradação de pireno pelo fungo Chaunopycnis alba CBMAI 1346

5.12 Identificação dos metabólitos formados durante a degradação de pireno pelo fungo Chaunopycnis alba CBMAl 1346 em condição otimizada pelo

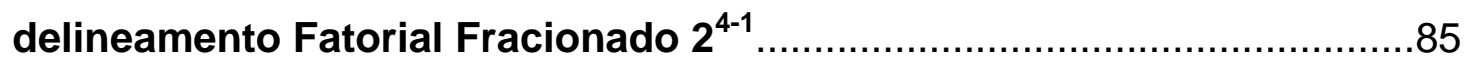

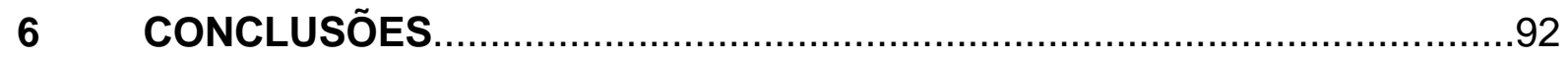

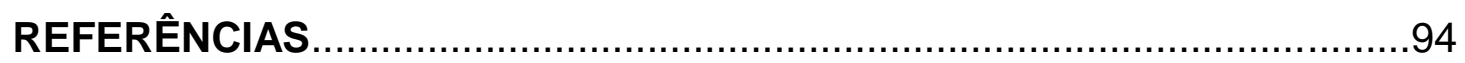




\section{INTRODUÇÃO}

O interesse pela avaliação do potencial biotecnológico de micro-organismos pertencentes a nichos ecológicos pouco explorados, como os fungos filamentosos derivados de ambientes marinhos, tem crescido nos últimos anos. Isto se deve principalmente ao fato da micologia marinha ser uma ciência recente e de pouco se conhecer sobre a biodiversidade e recursos genéticos dos micro-organismos que habitam esses ecossistemas. De acordo com Bugni e Ireland (2004) e Saleem et al. (2007) os compostos bioativos produzidos por fungos derivados de ambiente marinho podem apresentar diferenças estruturais consideráveis quando comparados com os seus parceiros terrestres devido ao fato destes micro-organismos estarem adaptados a altas pressões e salinidade deste ambiente. Assim, os fungos de origem marinha podem ser considerados estratégicos para a aplicação biotecnológica em processos industriais ou biorremediação de ambientes salinos, incluindo a degradação de HPAs derivados do derramamento de petróleo em sedimentos e oceanos e o tratamento de efluentes de indústrias têxtil, que são em sua maioria altamente coloridos e contém valores extremos de $\mathrm{pH}$ e sais (RAGHUKUMAR et al., 2008).

Neste contexto, o grupo de pesquisa da Profa. Dra. Lara D. Sette vem desenvolvendo projetos relacionados ao isolamento e à prospecção de enzimas (BONUGLI-SANTOS; DURRANT; SETTE, 2010a, b; PASSARINI, 2008), degradação de poluentes ambientais (BONUGLI-SANTOS et al., 2009; DA SILVA et al., 2008; PASSARINI et al., 2011a; PASSARINI; SETTE; RODRIGUES, 2011b; MAGRINI, 2012), descoloração de corante têxtil (BONUGLI-SANTOS et al., 2012) e estudo da biodiversidade (DA SILVA et al., 2008; MENEZES et al., 2010; PASSARINI, 2008; PASSARINI et al., 2013) de fungos filamentosos associados a macro-organismos marinhos. Existe atualmente cerca de 700 fungos filamentosos derivados de ecossistemas marinhos brasileiros mantidos na coleção de trabalho/pesquisa da Divisão de Recursos Microbianos do CPQBA/UNICAMP onde se encontra alocada a Coleção Brasileira de Microrganismos de Ambiente e Indústria (CBMAl). Estes fungos foram isolados no âmbito dos projetos FAPESP 05/51213-8 intitulado "Fungos derivados de ambientes marinhos: isolamento, caracterização taxonômica e avaliação do potencial biotecnológico" (coordenado pela Dra. Lara Sette) e do Temático FAPESP 05/60175-2 Intitulado "Descoberta e desenvolvimento de 
potenciais agentes quimioterapêuticos a partir de invertebrados marinhos e de micro-organismos associados" (coordenado pelo Dr. Roberto Berlinck da USP-SC), cujos resultados demonstraram o potencial biotecnológico dos fungos filamentosos associados a algas e invertebrados marinhos e têm estimulado o desenvolvimento de novos estudos.

Neste contexto, o presente projeto teve como objetivo selecionar fungos derivados de ambiente marinho da coleção de trabalho/pesquisa da DRM (CPQBA/UNICAMP) visando avaliação da descoloração de corantes sintéticos, produção de enzimas ligninolítica e degradação dos HPAs pireno e benzo[a]pireno. 


\section{REVISÃO DA LITERATURA}

\subsection{Fungos filamentosos de origem marinha: recursos utilizados para a biodegradação de corantes e efluentes coloridos}

Com o desenvolvimento industrial o uso de corantes sintéticos vem se expandindo em diferentes setores, incluindo, entre outros, o farmacêutico, de alimentos, cosméticos, papel, couro e tintas, resultando no despejo anual de toneladas deste composto em águas residuais (HERNANDEZ-LUNA; GUTIÉRREZSOTO; SALCEDO-MARTINEZ, 2008). Uma das principais fontes de poluição com problemas graves em nível mundial é a indústria têxtil por seus efluentes possuírem cerca de 10.000 diferentes tipos de corantes com uma produção estimada em 7.105 toneladas comercialmente disponíveis no mundo inteiro; sendo $30 \%$ destes corantes usados em excesso de 1.000 toneladas por ano, e 90\% dos produtos têxteis utilizados ao nível de 100 toneladas ou menos por ano. No processo de tingimento, $10-25 \%$ dos corantes têxteis são perdidos e $2-20 \%$ são descarregados diretamente como efluentes aquosos em diferentes componentes ambientais. Assim corantes residuais provenientes de fontes diferentes são considerados uma grande variedade de poluentes orgânicos introduzidos nos meios aquáticos naturais ou sistemas de tratamento de águas residuais (ZAHARIA; SUTEU, 2012).

Os corantes pertencem às classes azo, antraquinona, trifenilmetano e estruturas poliméricas heterocíclicas. Entre estes, os corantes azo são a maior e mais versátil classe de corantes e são responsáveis por mais da metade dos corantes sintéticos produzidos anualmente (DIWANIYAN et al., 2010). Segundo Ciullini et al. (2008), azo, antraquinona e índigo são os principais cromóforos encontrados em corantes comerciais e sua descoloração por métodos físicos ou químicos, além de ser financeiramente cara, não é muito eficaz. Nos ecossistemas aquáticos, os corantes podem interferir na fotossíntese, na difusão de gases e por apresentarem toxicidade podem ameaçar a saúde humana (BAUGHMAN; WEBER, 1994; CIULLINI et al., 2008). Estes compostos são comumente recalcitrantes e produzidos para resistir à lavagem, exposição à luz solar e aos tratamentos químicos, tornando difícil e cara a sua remoção de águas residuais (HAO; KIM; CHIANG, 2000). 
Neste sentido, consideráveis esforços têm se concentrado no desenvolvimento de tecnologias eficientes e de baixo custo para o tratamento de águas residuais contento corantes. Assim, apesar da alta eficiência em degradação de corantes relatada para os fungos terrestres, os fungos marinhos podem apresentar vantagens biológicas importantes na descoloração de efluentes industriais coloridos por estarem adaptados a teores elevados de sal e pH extremos (RAGHUKUMAR et al., 2008). Os trabalhos reportados por Raghukumar et al. (1996) e D'Souza et al. (2006) mostram resultados significativos de descoloração de efluentes têxtil e corantes sintéticos como vermelho congo, verde brilhante e RBBR por fungos marinhos. Em adição, os efluentes domésticos contêm grupos sulfonil éster de corantes reativos não ligados sujeitos à hidrólise devido à temperatura elevada e valor de $\mathrm{pH}$ durante processos de tingimento que, mesmo em pequena concentração, tem um grande impacto sobre o meio aquático, devido à DBO, cor e turbidez, além de produtos de degradação que podem ser formados (ZAHARIA; SUTEU, 2012).

Alguns estudos tem concentrado esforços na aplicação de fungos filamentosos na descoloração de corantes sintéticos (ARANTES; MILAGRES, 2007; ASGHER; AZIM; BHATTI, 2009; BONUGLI-SANTOS; DURRANT; SETTE, 2012; CHEN et al., 2014; EICHLEROVÁ et al., 2007; JUNGHHANNS; KRAUSS; SCHOLOSSER, 2008; KARTHIKEYAN et al., 2010), já que seus mecanismos de descoloração envolvem reações oxidativas (Figura 1) que não produzem aminas tóxicas (CIULLINI et al., 2008).
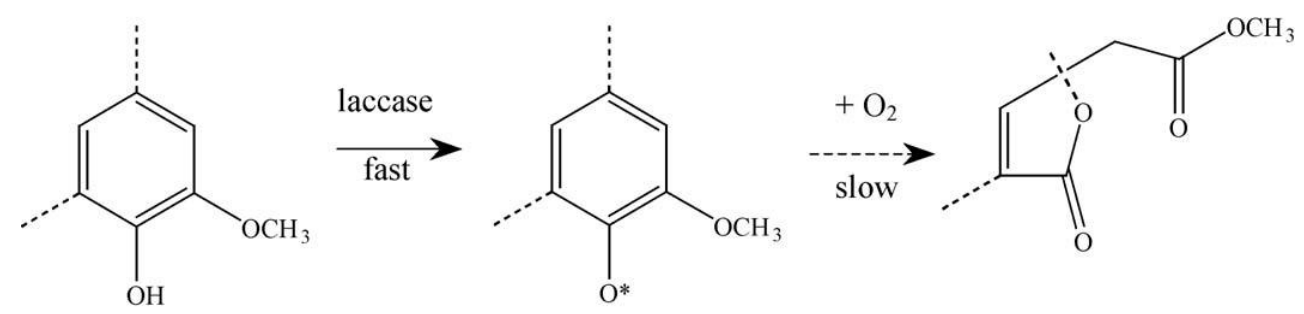

Figura 1. Possível mecanismo de oxidação do guaiacol pela lacase (SHLEEV et al., 2006).

Tauber et al. (2008) demonstraram a descoloração de vários corantes azo pela lacase de Trametes modesta em diferentes taxas e tratamentos, tais como a degradação enzimática para melhorar a degradação total do corante, evitando formação de produtos tóxicos da degradação. Khalid et al. (2011) sugeriram que os 
poluentes tóxicos como os corantes azo, concentrados em resíduos industriais e áreas contaminadas pode, potencialmente, ser eliminado por sistemas de biorremediação de baixo custo, utilizando culturas microbianas. $O$ conhecimento sobre os fatores ambientais ideais poderia ajudar a empregar abordagens biológicas de forma eficiente para limpar a água e o solo poluídos por corantes azo de indústria têxtil.

No estudo reportado por Chen et al. (2014) foi apresentado um sistema de imobilização de células do fungo marinho Pestalotiopsis sp. J63 em meio de cultura contendo outro fungo Penicilium janthinellum P1 e que foi capaz de biorremediar esgoto e descolorir o corante Azure B. Pan et al. (2014) reportaram um tipo de lacase (LCc9) que foi capaz de descolorir corante anil na presença de 2-2'-azino-bis (3-etilbenzotazolina-6-sulfonato) após $1 \mathrm{~h}$ de incubação sob condições catalíticas ótimas. Nutrientes (fontes de carbono e nitrogênio) e parâmetros físicos ( $\mathrm{pH}$, salinidade e temperatura) possuem efeito significativo na descoloração de corante (SINGH et al., 2013) e o mecanismo de descoloração catalisado por lacase pode variar dependendo da estrutura do corante (D'SOUZA et al., 2006).

Verma et al. (2010) testaram dois efluentes têxteis A (TEA) que continha um corante azo e pH de 8,9 e um efluente têxtil $B$ (TEB) com o pH de 2,5 que continha uma mistura de oito corantes reativos, os quais foram submetidos a experimentos de descoloração utilizando consórcios contendo dois ascomicetos e dois basidiomicetos. Cada um destes consórcios descoloriu em 6 dias o efluente TEA por $30-60 \%$ e TEB por $33-80 \%$ quando utilizados em $20-90 \%$ de concentração e salinidade de 15 ppt Em adição, os autores reportaram a redução de toxicidade (LC50 contra larvas de Artemia) de duas a três vezes e redução de $70-80 \%$ na demanda química de oxigênio e fenólicos totais. Análises de espectrometria de massa dos efluentes, após o tratamento com os fungos, revelaram a degradação da maioria dos componentes. O potencial de descoloração de basidiomicetos derivados marinhos também foi testado em condições salinas e não-salinas. A descoloração completa de RBBR (Remazol Brilliant Blue) foi alcançada em meio líquido pelo fungo Tinctoporellus sp. CBMAI 1061 após 3 dias de incubação nas concentrações (500 e $1000 \mathrm{mg} . \mathrm{L}^{-1}$ ), seguido pelo Peniphora sp. CBMAl 1063 (BONUGLI-SANTOS; DURRANT; SETTE, 2012). Em um outro estudo realizado com fungos isolados de cnidários coletados a partir do litoral norte do Estado de São Paulo (Brasil) revelou o potencial de fungos filamentosos de origem marinha para a descoloração de 
corantes têxteis, sendo o Penicillium citrinum CBMAI 853 o fungo mais eficiente alcançando 100\% de descoloração do RBBR após 12 dias, seguido de Aspergillus sulphureus CBMAI 849 (95\%), Cladosporium cladosporioides CBMAI 857 (93\%) e Trichoderma sp. CBMAI 852 (89 \%) (DA SILVA et al., 2008). Assim, fungos derivados marinhos podem ser mais eficazes do que fungos terrestres em tratamento de efluentes coloridos já que são adaptados para trabalhar sob condições extremas de salinidade e pH (RAGHUKUMAR; D'SOUZA-TICLO; VERMA, 2008).

\subsection{Hidrocarbonetos policíclicos aromáticos (HPAs) e os mecanismos envolvidos na sua degradação pelos fungos filamentosos de origem marinha}

Assim como os corantes, os HPAs são compostos químicos tóxicos e poluentes ambientais. A preocupação com o aumento da presença de HPAs no ar, solo, sistemas aquáticos e alimentos é constante e crescente. Estes compostos são constituídos por dois ou mais anéis aromáticos e apresentam propriedades carcinogênicas (Figura 2). O que determina o seu comportamento no ambiente são as propriedades físico-químicas. Devido às suas propriedades hidrofóbicas e baixa solubilidade em água (ARGUMEDO-DELIRA et al., 2010), os HPAs são difíceis de serem degradados e se acumulam no ambiente. Estes compostos são componentes do petróleo e possuem uma afinidade muito alta a solos ricos em matéria orgânica e sedimentos marinhos, com a possibilidade de acumular e de ser transferidos ao homem através da ingestão de organismos marinhos contaminados (ABBONDANZI et al., 2005).
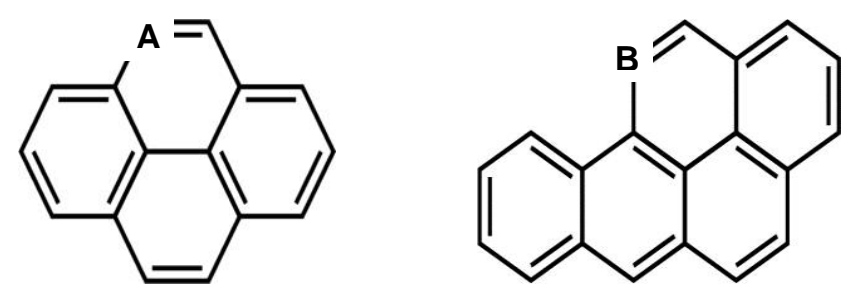

Figura 2. Estruturas químicas dos hidrocarbonetos policíclicos aromáticos (HPAs). A) Pireno (Py). B) Benzo[a]pireno (BaP).

Os HPAs são contaminantes ubíquos derivados de fontes pirogênica e petrogênica (SZLINDER-RICHERT; NERMER; SZATKOWSKA, 2014), podendo ser também produzidos por meio da combustão incompleta de combustível fóssil, de 
processos industriais, na queima da madeira e do cozimento de alimentos defumados e grelhados (CERNIGLIA; HEITKAMP, 1989; JUHASZ; NAIDU, 2000). Embora existam centenas de HPAs, 16 deles foram selecionados pela Agência de Proteção Ambiental dos Estados Unidos (USEPA) como poluentes prioritários por sua elevada toxicidade, persistência no ecossistema e propriedades mutagênicas e carcinogênicas. Dentre eles, o benzo[a]pireno é reconhecido como o composto de maior potencial carcinogênico (JUHASZ; NAIDU, 2000). A preocupação com a saúde em relação aos HPAs está em sua transformação metabólica, pois estes compostos podem se ligar ao DNA e RNA gerando diversos tumores (WILD; JONES, 1995).

Atualmente, a abordagem mais promissora no controle e destruição de compostos orgânicos contaminantes, incluindo os HPAs e os corantes sintéticos, é a exploração da capacidade catabólica de micro-organismos, processo conhecido como biorremediação. As tecnologias utilizadas na remediação de ambientes, como a incineração e o tratamento químico de efluentes, são caras e ineficientes podendo levar a diversas complicações. O princípio da biorremediação se baseia na prospecção de populações microbianas que possuam a habilidade de modificar ou decompor determinados poluentes (PEIXOTO; ROSADO; TAKETANI, 2008). Os processos ideais de biodegradação levam à mineralização completa dos compostos orgânicos, ou seja, à $\mathrm{CO}_{2}$ e $\mathrm{H}_{2} \mathrm{O}$, embora existam as degradações parciais ou ainda simplesmente a biotransformação de um composto aromático em compostos derivados.

O uso de micro-organismos na remediação pode ser considerado como uma atraente alternativa biotecnológica devido à possibilidade de obtenção da mineralização do poluente ou sua transformação em produtos menos tóxicos, de maior solubilidade em água, e que podem ser degradados posteriormente pela ação de outros micro-organismos (CERNIGLIA, 1997; CERNIGLIA; SUTHERLAND, 2001). A base dos diferentes mecanismos conhecidos para o metabolismo aeróbico de HPAs consiste na oxidação do anel aromático, seguida pela separação do composto em metabólitos de HPAs e/ou dióxido de carbono (BAMFORTH; SINGLETON, 2005). Embora o mecanismo subjacente não tenha sido esclarecido em todos os casos, vários autores relataram que diversas espécies de fungos são eficientes na biodegradação não só de HPAs, mas de uma grande variedade de poluentes como compostos fenólicos, corantes, defensivos agrícolas, entre outros 
(ARGUMEDO-DELIRA et al., 2010; HADIBARATA; TACHIBANA; ITOH, 2007; TORTELLA; DIEZ; DURÁN, 2005; WEBB et al., 2000; WESENBERG; KYRIAKIDES; AGATHOS, 2003). O metabolismo dos HPAs por fungos pode ser dividido em dois principais grupos, os mediados por fungos não-ligninolíticos (por meio da utilização da citocromo P450, da epóxido hidrolase) e o metabolizado por fungos ligninolíticos.

Passarini et al. (2011) relataram que o fungo Aspergillus sclerotiorum CBMAI 849 (isolado de cnidário marinho) degradou 99,7\% de pireno e $76,6 \%$ de benzo[a]pireno, após 8 e 16 dias, respectivamente. Degradação de benzo[a]pireno acima de $50 \%$ foi obtida pelo fungo de origem marinha Mucor racemosus CBMAI 847. Análises químicas em HPLC-DAD-MS mostraram que A. sclerotiorum CBMAI 849 e $M$. racemosus CBMAl 847 foram capazes de metabolizar o pireno a pirenilsulfato e foram capazes também de degradar benzo[a]pireno a benzo[a]pirenilsulfato, sugerindo que o mecanismo de hidroxilação é mediado pela citocromo P-450 monooxigenase, seguido da conjugação de íons sulfato. Devido à diversidade enzimática, capaz de catalisar várias reações bioquímicas, os microorganismos marinhos são atraentes alvos para aplicação em biorremediação de ambientes salinos (ROCHA et al., 2012).

$\mathrm{O}$ sistema monooxigenase da $\mathrm{P} 450$ possui um sistema de transferência de elétrons que desempenha um papel importante numa gama de reações de hidroxilação e oxidação de processos que conduzem à degradação, desintoxicação e sínteses de moléculas críticas à vida. Enzimas do sistema citrocromo P450, como as oxidases, são moléculas ideais para estudos evolutivos da biodiversidade e adaptação por várias razões. Em primeiro lugar, as enzimas P450 formam uma superfamília com estruturas semelhantes à heme-tiolato que estão distribuídas extensamente por todas as formas de vida. Em segundo lugar, a superfamília P450 consiste de um grande número de genes, contribuindo com uma ampla gama de funções biológicas nos organismos (DENG; CARBONE; DEAN, 2007). Embora executem uma vasta gama de conversões biocatalíticas, a equação geral da reação é sumarizada na Figura 3:

$$
\mathrm{RH}+\mathrm{NAD}(\mathrm{P}) \mathrm{H}+\mathrm{H}^{+}+\mathrm{O}_{2} \rightarrow \mathrm{ROH}+\mathrm{NAD}(\mathrm{P})^{+}+\mathrm{H}_{2} \mathrm{O}
$$

Figura 3. Equação geral de reação biocatalítica executada pelas enzimas da superfamília P450 (BRINK et al. 1997)

Os elétrons necessários para a inserção de oxigênio no substrato molecular (R) são doados por um elétron separado do sistema doador. O sistema doador de 
elétron ou é um sistema de duas proteínas (adrenoxina e adrenoxina redutase) para P450 mitocondrial e procariótico ou uma proteína (citocromo P450 redutase, CPR ${ }^{2}$ ) para enzimas citocromo P450 que estão localizadas no retículo endoplasmático (RE) (BRINK et al., 1997).

Os genes dentro da superfamília P450 são agrupados em famílias e subfamílias com base principalmente na identidade de sequência de aminoácidos. Os genes são agrupados em famílias quando eles compartilham mais que $40 \%$ de identidade com as sequências de aminoácidos de referência e são atribuídas a subfamílias quando a identidade é maior que $55 \%$ com estas sequências de referência. As famílias são designadas com a sigla CYP e um número, com base em blocos de números reservados para diferentes grupos taxonômicos. Assim, CYP51 à CYP69 e CYP501 à CYP699 são famílias fúngicas (DENG; CARBONE; DEAN, 2007).

Os fungos degradadores da madeira conhecidos como fungos ligninolíticos são taxonomicamente diversos e a maioria deles pertence ao filo Basidiomycota. São comumente divididos em três classes, de acordo com a morfologia da degradação que produzem: fungos de degradação branda, fungos de degradação marrom e fungos de degradação branca, sendo esta última a mais importante, uma vez que comportam fungos altamente ligninolíticos (DURÁN; ESPOSITO, 2008). Estes organismos são poderosos catalisadores capazes de modificar a estrutura e a propriedade tóxica dos contaminantes, podendo mineralizar completamente a molécula do poluente (GIANFREDA; RAO, 2004).

A degradação extracelular (sistema ligninolítico) consiste em um processo multienzimático resultante da ação coordenada de uma série de enzimas do grupo das óxido-redutases. Existem dois principais tipos de enzimas envolvidas na degradação de HPAs por fungos ligninolíticos, as peroxidases e as oxidades. As peroxidases são glicoproteinas que dependem da presença de $\mathrm{H}_{2} \mathrm{O}_{2}$ para suas atividades catalíticas (MESTER; TIEN, 2000) e incluem: i) lignina peroxidase (LiP, EC 1.11.1.14) que ocorre em muitos fungos de degradação branca e foi a primeira enzima ligninolítica a ser descoberta por Tien e Kirk (1984) e, ii) manganês peroxidase (MnP, EC 1.11.1.13), descoberta por Kuwahara et al. (1984), a qual necessita do íon $\mathrm{Mn}^{2+}$ para sua atividade. Em muitos fungos a $\mathrm{MnP}$ exerce um papel essencial na degradação da lignina, uma vez que geram o oxidante $\mathrm{Mn}^{3+}$ (HAMMEL, 1996). As oxidases são representadas pelas lacases (EC 1.10.3.2) que são enzimas 
oxidases multicobre, ou seja, glicoproteínas que contêm cobre em seu sítio ativo e que não requer $\mathrm{H}_{2} \mathrm{O}_{2}$ para sua atividade, catalisando a redução de $\mathrm{O}_{2}$ para $\mathrm{H}_{2} \mathrm{O}$ (HOEGGER et al., 2006). Juntamente com outras oxidases estas três enzimas (LiP, MnP e lacase) constituem os componentes chaves do complexo enzimático ligninolítico usado na biodegradação de poluentes ambientais (KIRK; FARRELL, 1987; HATAKKA, 1994). Na Figura 4 estão apresentadas as vias de catabolismo microbiano na degradação de hidrocarbonetos policíclicos e os respectivos produtos formados.

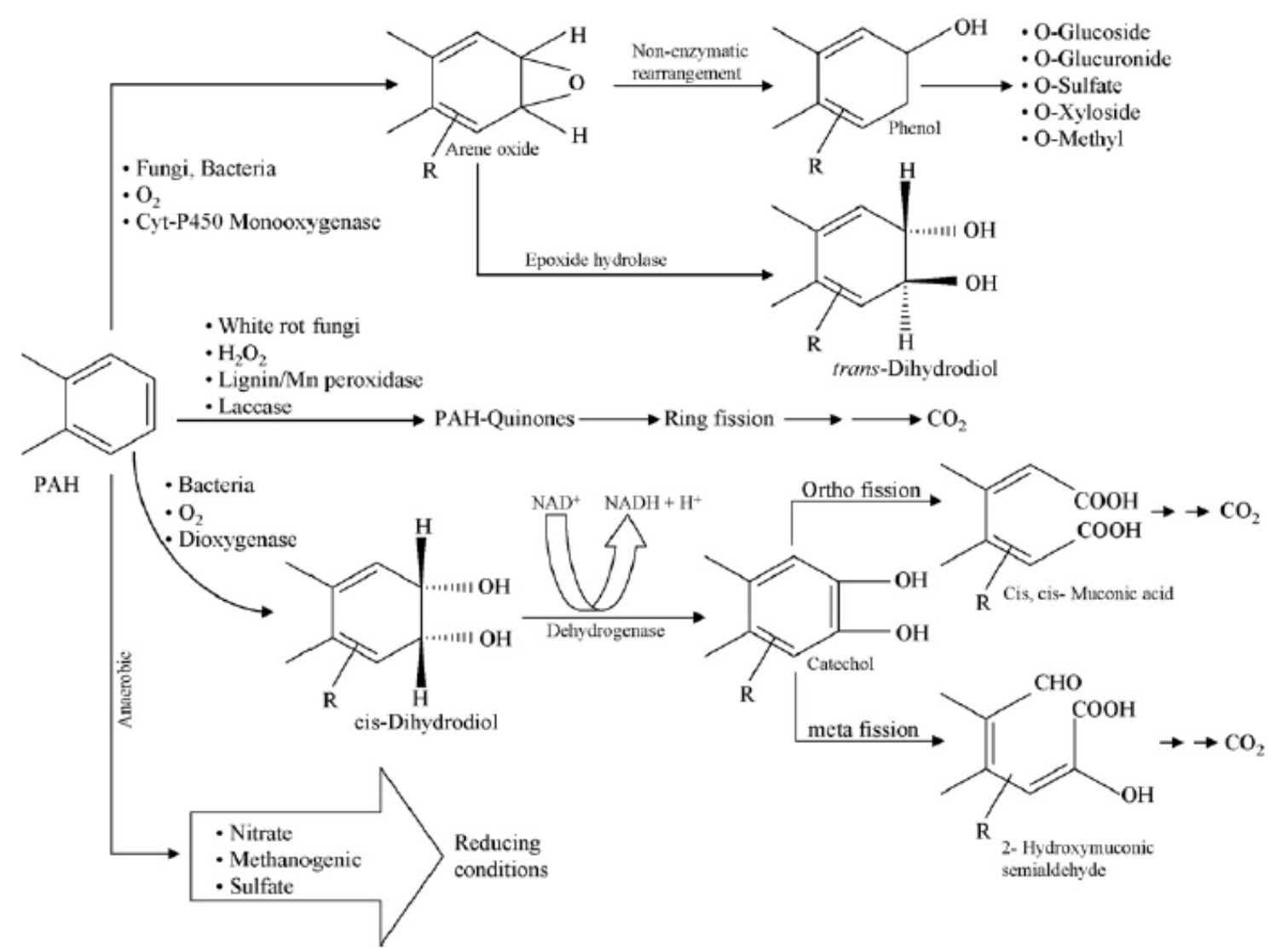

Figura 4. Vias propostas para o catabolismo microbiano de hidrocarbonetos policíclicos aromáticos (HPAs) (HARITASH e KAUSHIK, 2009).

A capacidade ligninolítica dos ascomicetos é mais limitada que a dos basidiomicetos. Uma possibilidade é que os ascomicetos atacam apenas as unidades fenólicas na lignina, que compreendem cerca de $10 \%$ do polímero e são quimicamente mais lábeis que as unidades ligadas a éteres, unidades não fenólicas que compõem o restante (Figura 5). As estruturas fenólicas de lignina são oxidadas e diretamente clivadas por uma variedade de oxidantes biológicos leves, semelhantes a quelatos mangânicos e fenoloxidases. Por outro lado, a clivagem de estruturas de ligninas não fenólicas requer a ação de compostos oxidantes fortes, 
incluindo oxido-radicais produzidos pela ação de peroxidases ou lacases em vários mediadores redoxes. A produção de um sistema ligninolítico mais vigoroso é típico dos basidiomicetos e ainda não foi convincentemente demonstrado nos ascomicetos. No entanto, a produção de fenol oxidases que poderiam agir diretamente sobre a lignina fenólica é generalizada entre os ascomicetos (SHARY; RALPH; HAMMEL, 2007).

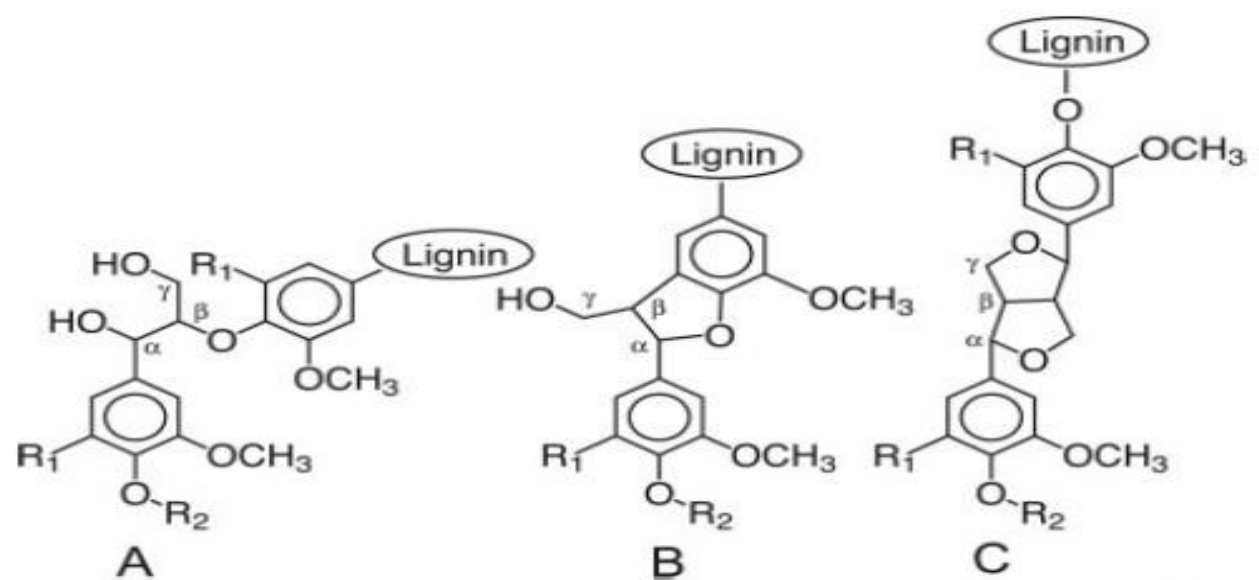

Figura 5. Principais estruturas da lignina. A) Éter aril-glicerol- $\beta$-aril, B) Fenilcoumarina, C) Resinol. $\quad R_{1}$ é $H$ para a estrutura guaiacil e $\mathrm{OCH}_{3}$ para a estrutura siringil. $R_{2}$ é $H$ para estruturas fenólicas, $\mathrm{CH}_{3}$ para estruturas fenólicas metiladas, e lignina para estruturas não fenólicas.

As vantagens do uso de fungos filamentosos na degradação/descoloração de poluentes ambientais estão em sua capacidade de suportar altas concentrações de compostos tóxicos, na baixa especificidade do complexo enzimático ligninolítico e no amplo crescimento das hifas através do substrato, o que juntamente com a difusão das enzimas extracelulares contribuem para o alcance e oxidação dos compostos pouco disponíveis (REDDY, 1995). Além disso, similar ao que ocorre durante a degradação da lignina, a degradação de xenobióticos é acionada pela limitação de nutrientes (CERNIGLIA, 1997). Neste contexto, os fungos derivados de ambientes marinhos podem possuir propriedades únicas, as quais não têm sido suficientemente exploradas na degradação destes poluentes. 


\subsection{Fungos filamentosos marinhos e sua classificação ecológica}

Os fungos marinhos não formam um grupo taxonômico, mas sim ecológico (HYDE; SARMA; JONES, 2000). São chamados fungos marinhos obrigatórios aqueles que crescem e esporulam exclusivamente na água do mar, e seus esporos são capazes de germinar neste ambiente e, fungos marinhos facultativos aqueles terrestres e aquáticos com adaptações que permitem seu desenvolvimento no ambiente marinho (KOHLMEYER; KOHLMEYER, 1979). De acordo com Hyde, Sarma e Jones (2000) aproximadamente 800 espécies de fungos marinhos obrigatórios foram encontrados. Porém, como estes micro-organismos não podem ser definidos somente por critérios fisiológicos, necessitando de um vasto estudo de sua ecologia para serem classificados como fungos marinhos obrigatórios. Como um grande número de fungos isolados de amostras marinhas não foi comprovadamente classificado como micro-organismos marinhos obrigatórios ou facultativos foi criada a expressão "fungos derivados de ambiente marinho" (marine-derived fungi) visando uma classificação mais geral para estes organismos (OSTERHAGE, 2001).

Ecologicamente, os fungos de ambiente marinho são importantes intermediários no fluxo de energia e possuem relevante papel na ciclagem de nutrientes (BUGNI; IRELAND 2004). Os fungos associados a amostras marinhas podem ser obtidos de esponjas, algas, madeiras, tunicados, sedimentos, moluscos, corais, plantas e peixes. A distribuição dos fungos baseada no número de gêneros distintos em diferentes substratos marinhos está graficamente sumarizada na Figura 6 , onde podemos verificar que uma maior diversidade taxonômica de fungos filamentosos é derivada das esponjas marinhas. Devido ao fato das esponjas se alimentarem por filtração, elas são expostas aos poluentes presentes na água e acumulam impurezas dos fitoplânctons ou de outras matérias em suspensão. Portanto, é razoável acreditar que alguns dos micro-organismos associados às esponjas produzem enzimas hidrolíticas para converter estas matérias orgânicas em nutrientes (WANG et al., 2006).

Em um estudo de diversidade microbiana associada com algas, ascídias e esponjas da costa norte do Estado de São Paulo, Brasil, os autores identificaram 144 ribotipos distintos de 256 fungos isolados de esponjas e ascídia (Menezes et al. 2010). Os fungos filamentosos foram distribuídos em 24 gêneros diferentes, pertencentes às classe Ascomycota, Zygomycota e Basidiomycota. Didemnum sp., 
uma ascídia marinha, apresentou 66 isolados e 47 ribotipos, enquanto as esponjas Mycale laxissima (55 isolados e 35 ribotipos), Amphimedon viridis (60 isolados e 43 ribotipos) e Dragmacidon reticulatum (66 isolados e 43 ribotipos) o que indica que os fungos filamentosos também podem ocorrer em abundância e com grande diversidade taxonômica em outros tipos de macro-organismos marinhos.

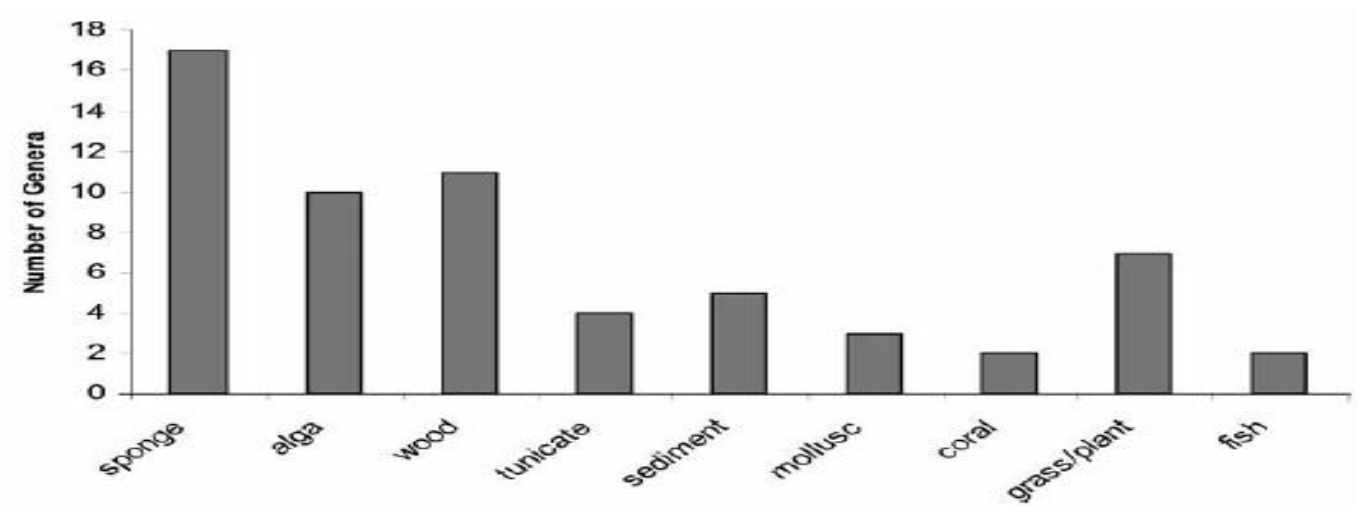

Figura 6. Número de gêneros distintos de fungos derivados de ambiente marinho baseado em diferentes fontes (Fonte: BUGNI e IRELAND, 2004).

Embora existam registros de uma quantidade significativa de novos produtos naturais produzidos pelos fungos derivados de ambiente marinho (BUGNI; IRELAND, 2004), são escassos os estudos relacionados à avaliação da produção de enzimas ligninolíticas e degradação de poluentes ambientais por estes organismos.

No Brasil, tem sido desenvolvidos estudos pioneiros referentes à biodiversidade de fungos derivados de algas e invertebrados marinhos e na busca de enzimas produzidas por estes fungos com potencial aplicação biotecnológica, que reportam a capacidade de fungos derivados de cnidários marinhos, representantes dos filos Ascomycota (Aspergillus sclerotiorum CBMAI 849 e Cladosporium cladosporioides CBMAI 857) e Zygomycota (Mucor racemosus CBMAI 847) para descolorir o corante RBBR (DA SILVA et al., 2008), produzir enzimas ligninolíticas em altas concentrações de sal (12,5 e 23 \%) (BONUGLI-SANTOS; DURRANT; SETTE, 2010a) e degradar HPAs (BONUGLI-SANTOS et al., 2009; PASSARINI et al., 2011a). Em adição, três fungos basidiomicetos isolados das esponjas marinhas Amphimedon viridis e Dragmacidon reticulatum apresentaram capacidade de produção das enzimas ligninolíticas $\mathrm{LiP}, \mathrm{MnP}$ e lacase e de descoloração entre 65 e $100 \%$ do corante RBBR em diferentes condições de 
cultivo, incluindo os meios acrescidos de sal (BONUGLI-SANTOS et al., 2012). fungo basidiomiceto Marasmiellus sp. CBMAl 1062 foi capaz de degradar 80,0 \% e $75,9 \%$ dos HPAs pireno e benzo[a]pireno, respectivamente, quando submetido a ensaios com salinidade a $35 \%$ (MAGRINI, 2012).

\subsection{Delineamento experimental como ferramenta utilizado para a otimização da degradação de HPAs}

A degradação de HPAs depende de vários fatores como fontes de carbono, nitrogênio, pH, temperatura, salinidade entre outros (MAGRINI, 2012). Neste caso, são adotados delineamentos experimentais, para avaliar quais os fatores podem influenciar positivamente ou negativamente na degradação. O planejamento experimental deve ser realizado para determinar a influência das variáveis sobre respostas desejadas, além de quantificar o efeito das variáveis no processo e reduzir o número de experiências ou repetições, melhorando a qualidade da informação obtida através dos resultados, os quais podem ser obtidos com confiabilidade e assim permitem análises estatísticas consistentes (RODRIGUES; IEMMA, 2009).

$O$ delineamento experimental Plackett-Burman (PB) é um método bem consistente, e que estabelece se o resultado de um procedimento analítico é afetado por mudanças em cada fator relevante. A sua mais importante característica é que todos eles envolvem experimentos $4 n$, onde $n=1,2,3 \ldots$. Em cada caso, o número máximo de elementos que podem ser estudados é $4^{n-1}$, portanto um delineamento experimental PB8 pode estudar não mais que 7 fatores; um PB12, não pode estudar mais que 11 fatores e assim por diante (ANALYTICAL METHODS COMMITTEE, 2013).

O delineamento PB é ideal para a seleção de efeitos em sistemas em que se pretende identificar alguns principais fatores que afetam o resultado. Assim, os principais fatores em PB não são confundidos, não gerando resultados enganosos, no entanto, valores altos de efeito dos fatores podem evidenciar interações entre estes. Assim, um bom delineamento experimental é importante em muitos estudos de análise e outros processos químicos. Muitas vezes é necessário mais de um delineamento experimental para se atingir o objetivo desejado (RODRIGUES; IEMMA, 2009).

Fatoriais completos, que estudam todos os fatores (variáveis experimentais) que afetam a resposta do sistema, utilizando pelo menos dois níveis (valores) para 
cada um dos fatores, podem dar origem a um grande número de ensaios. Isto acontece porque até mesmo processos simples podem ser afetados por um grande número de fatores. Além disso, estes fatores podem afetar a resposta do sistema interativamente, ou seja, o efeito de um fator pode depender dos níveis de outros. Quaisquer interações também devem ser diferenciadas aleatoriamente de erros de medição (ANALYTICAL METHODS COMMITTEE, 2013). 


\section{OBJETIVOS}

O presente projeto tem como objetivo geral utilizar fungos recuperados de esponjas marinhas do acervo da coleção de pesquisa da DRM (CPQBA/UNICAMP) visando avaliação do potencial biotecnológico relacionado à degradação/descoloração de poluentes ambientais.

\subsection{Objetivos específicos}

* Triagem de fungos de origem marinha produtores de enzimas ligninolíticas em meio sólido (análise qualitativa);

- Avaliação do potencial de descoloração de corantes sintéticos pertencentes a diferentes classes (reativo black 5, índigo blue 1 e preto sulfuroso) e da produção de enzimas ligninolíticas (LiP, MnP e lacase) pelos fungos que apresentarem resultados satisfatórios na triagem em meio sólido e/ou na degradação dos corantes sintéticos;

- Avaliação da degradação dos HPAs pireno e benzo[a]pireno pelos fungos que apresentarem produção significativa das enzimas ligninolíticas:

- $\quad$ análises quantitativas (GC-EM);

- avaliação de diferentes parâmetros na degradação dos HPAs (desenho experimental);

* Identificação dos metabólitos formados por CG-EM na degradação de HPAs. 


\section{MATERIAIS E MÉTODOS}

\subsection{Reativação de fungos filamentosos isolados a partir de amostras de esponjas}

Foram utilizados no presente projeto 185 fungos filamentosos selecionados como representantes de grupos taxonômicos distintos pelo método de fingerprinting genético (ARDRA, Amplified Ribosomal DNA Restriction Analysis) por Menezes et al. (2010), os quais foram recuperados de amostras de esponjas marinhas Amphimedon viridis, Axinella corrugata, Chelonaplysilla erecta, Dragmacidon reticulatum, Mycale laxissima e Petronica citrina coletadas no litoral norte do estado de São Paulo (Figura 7) no âmbito do projeto Temático Fapesp 05/60175-2.

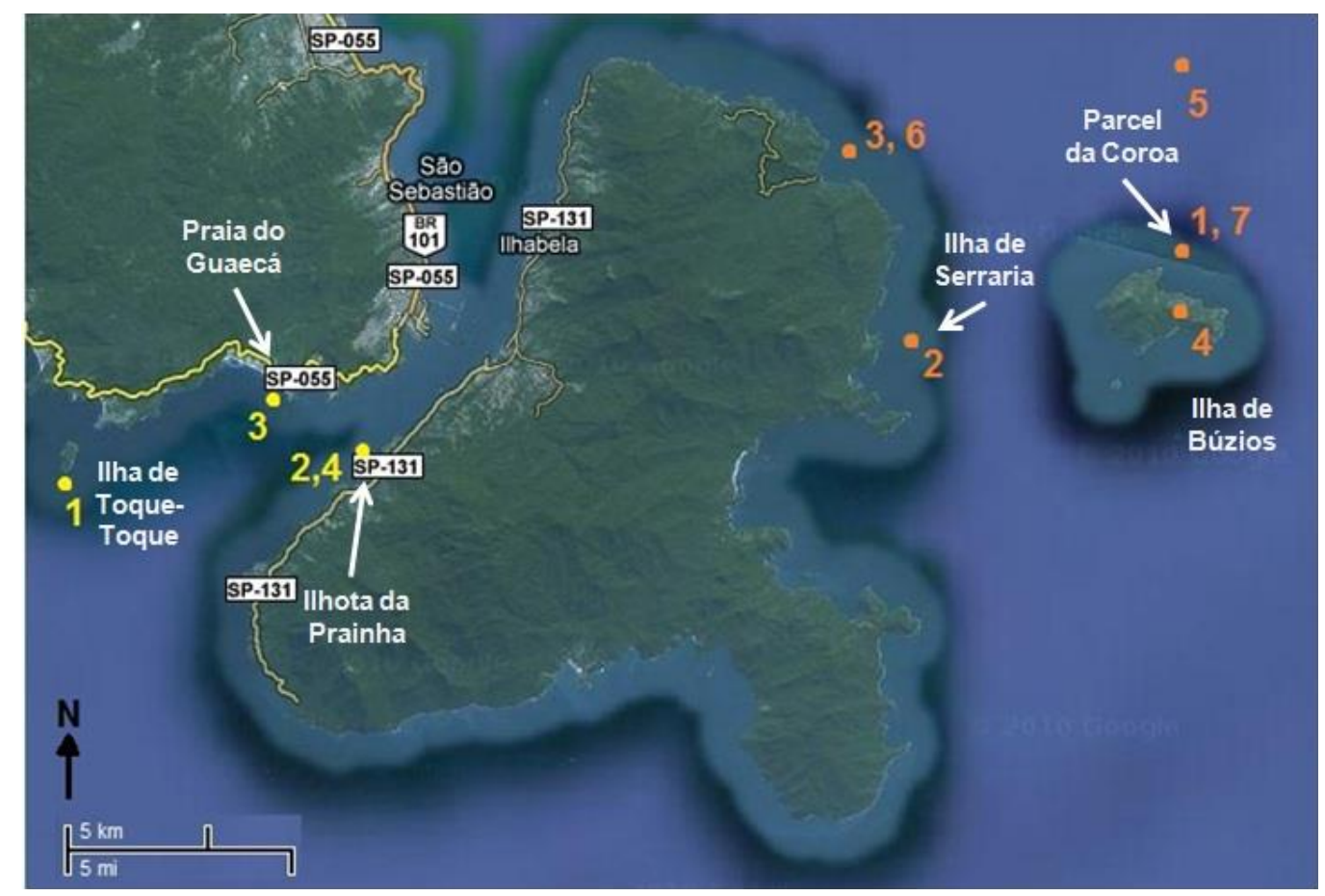

Figura 7. Mapa com a localização dos pontos de coleta (em amarelo) em São Sebastião e Ilhabela (SP).

Os isolados encontram-se preservados nas coleções de pesquisa associadas à Coleção Brasileira de Micro-organismos de Ambiente e Indústria (CBMAI) da Divisão de Recursos Microbianos do CPQBA/UNICAMP e à Central de Recursos Microbianos da UNESP do Instituto de Biociências de Rio Claro (CRM-UNESP) por 
meio de dois métodos distintos: ultracongelamento a $-80{ }^{\circ} \mathrm{C}$ e Castellani (preservação em água esterilizada a $4{ }^{\circ} \mathrm{C}$ ). Os fungos foram reativados em meio MA2 (extrato de malte $2 \%+2 \%$ de ágar) acrescidos de $3 \%$ de $\mathrm{NaCl}$.

\subsection{Seleção de fungos produtores de enzimas ligninolíticas}

Os fungos filamentosos derivados de esponjas representantes de grupos taxonômicos distintos foram selecionados por meio da avaliação da capacidade de produção de enzimas ligninolíticas utilizando o protocolo descrito por D' Souza et al. (2006). Para tanto, os isolados foram cultivados em placas de Petri contendo o meio B\&K (10g. $\mathrm{L}^{-1}$ de glicose, $2 \mathrm{~g}$. $\mathrm{L}^{-1}$ de peptona, $1 \mathrm{~g}$. $\mathrm{L}^{-1}$ de extrato de levedura e $20 \mathrm{~g} . \mathrm{L}^{-1}$ de ágar) suplementado com $4 \mathrm{mM}$ o substrato enzimático guaiacol (3-metoxi-4hidroxifenil), a $28{ }^{\circ} \mathrm{C}$ por 7 dias. Após 0 tempo de incubação, os isolados que apresentaram a produção da cor marrom sob ou ao redor do micélio fúngico em meio contendo guaiacol, foram consideradas positivas para a atividade de lacase (D'SOUZA et al., 2006).

\subsection{Descoloração de corantes sintéticos}

\subsubsection{Avaliação do potencial de descoloração}

Os fungos filamentosos derivados marinhos selecionados na seção 4.2 foram utilizados nos experimentos de avaliação da descoloração dos corantes sintéticos índigo blue (atina), reativo preto 5 (sulfuroso) e preto sulfuroso (reativo), os quais foram selecionados por serem de difícil degradação e amplamente utilizados pelas indústria têxteis, incluindo o pólo industrial da região de Americana (SP). Amostras dos corantes foram cedidas pela empresa Texpal Química Ltda.

Após a reativação dos fungos filamentosos em meio sólido, MA2 (2\% de extrato de malte $+2 \%$ de ágar) $+3 \% \mathrm{NaCl}$, três cilindros de $5 \mathrm{~mm}$ de diâmetro da margem das colônias foram inoculados em Erlenmeyer de $150 \mathrm{~mL}$ contendo $50 \mathrm{~mL}$ de caldo $\mathrm{MB} 2 \%+3 \% \mathrm{NaCl}$ e foram incubados por 72 horas a $28 \stackrel{\circ}{\circ} \mathrm{C}$ sob agitação de $140 \mathrm{rpm}$. Após o período de 72 horas de incubação cada corante foi adicionado na concentração de $500 \mathrm{mg}$. L $\mathrm{L}^{-1}$. Após 7 dias a contar do tempo zero, as amostras foram centrifugadas por 10 minutos a $10.000 \mathrm{rpm}$ para obtenção do extrato 
enzimático. A atividade de descoloração foi avaliada por espectrofotometria UV/VIS. No tempo zero foi realizada a leitura da absorbância no comprimento de onda dos corantes preto sulfuroso, índigo blue e reativo black $5(640 \mathrm{~nm}, 640 \mathrm{~nm}$ e $660 \mathrm{~nm}$, respectivamente) e após 7 dias de cultivo. As absorbâncias do tempo final e do tempo zero foram calculadas a partir da absorbância final e inicial e os valores de descoloração foram expressos em porcentagem (\%). Em adição, experimentos controle foram conduzidos por meio da incubação do meio adicionado de corante $e$ sem a inoculação do fungo e também por meio da incubação do fungo em meio sem a adição do corante. Todos os experimentos foram conduzidos em triplicata.

\subsection{Avaliação da produção das enzimas ligninolíticas}

A avaliação da produção das enzimas lignina peroxidase (LiP), manganês peroxidase (MnP) e lacase foi realizada a partir do extrato enzimático obtido (4.3.1) de acordo com a metodologia descrita abaixo:

\subsubsection{Lignina Peroxidase (LiP)}

A atividade da lignina peroxidase foi avaliada por espectrofotometria UV/VIS a partir do aldeído veratrílico produzido $\left(\varepsilon 310 \mathrm{~nm}=9.300 \mathrm{M}^{-1} \mathrm{~cm}^{-1}\right)$ na oxidação do álcool veratrílico que foi usado como substrato. A mistura foi composta de $1 \mathrm{~mL}$ de

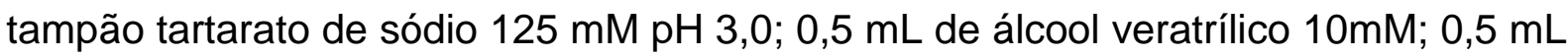
de peróxido de hidrogênio $2 \mathrm{mM}$ e $0,5 \mathrm{~mL}$ do extrato enzimático. A reação foi iniciada adicionando o peróxido de hidrogênio e o aparecimento do aldeído veratrílico foi determinado lendo-se a absorbância a 310 nm (ARORA e GILL, 2001).

\subsubsection{Manganês Peroxidase (MnP)}

Esta atividade foi quantificada por meio da oxidação do vermelho de fenol a $610 \mathrm{~nm}$. A mistura da reação foi composta de $0,5 \mathrm{~mL}$ de solução de extrato enzimático, $0,1 \mathrm{~mL}$ de vermelho de fenol $(0,01 \%), 0,1 \mathrm{~mL}$ de lactato de sódio $(0,25$ M), 0,2 $\mathrm{mL}$ de albumina bovina (0,5\%), $50 \mu \mathrm{l} \mathrm{MnSO} 4(2 \mathrm{mM}), 50 \mu \mathrm{l}$ de peróxido de hidrogênio em tampão succinato de sódio $(20 \mathrm{mM} ; \mathrm{pH} 4,5)$. A mistura foi incubada a 
temperatura ambiente por 5 minutos e a reação foi interrompida pela adição de $40 \mu l$ de $\mathrm{NaOH}(2 \mathrm{~N})\left(\varepsilon 610 \mathrm{~nm}=4.460 \mathrm{M}^{-1} \mathrm{~cm}^{-1}\right)$ (KUWAHARA et al., 1984).

\subsubsection{Lacase}

A atividade enzimática de lacase foi determinada espectrofotometricamente pela oxidação da siringaldazina $\left(\varepsilon 525 \mathrm{~nm}=65.000 \mathrm{M}^{-1} \mathrm{~cm}^{-1}\right)$. A mistura foi composta de 0,2 $\mathrm{mL}$ de tampão citrato-fosfato $0,05 \mathrm{M}(\mathrm{pH} 5,0), 0,1 \mathrm{~mL}$ de água deionizada, 0,6 $\mathrm{mL}$ da solução enzimática e $0,1 \mathrm{~mL}$ de siringaldazina $1,0 \mathrm{mM}$ preparada em etanol (P.A.). O monitoramento do aumento da absorbância foi verificado a $525 \mathrm{~nm}$. (SZKLARZ et al., 1989).

Para a obtenção dos extratos enzimáticos, o meio líquido de cultivo foi centrifugado a 10.000 rpm por $30 \mathrm{~min}$ a $4 \stackrel{\circ}{\circ}$, após o período de incubação. Uma unidade enzimática $(U)$ foi definida como a quantidade de enzima necessária para oxidar $1 \mu \mathrm{mol}$ de substrato por minuto. A atividade enzimática foi expressa em $U^{-1}$ do caldo enzimático e os cálculos realizados a partir da Equação 1, derivada da Lei de Beer-Lambert.

$U^{-1}=\Delta A \times V \times 10^{6} / \varepsilon \times R \times t$

(Equação 1),

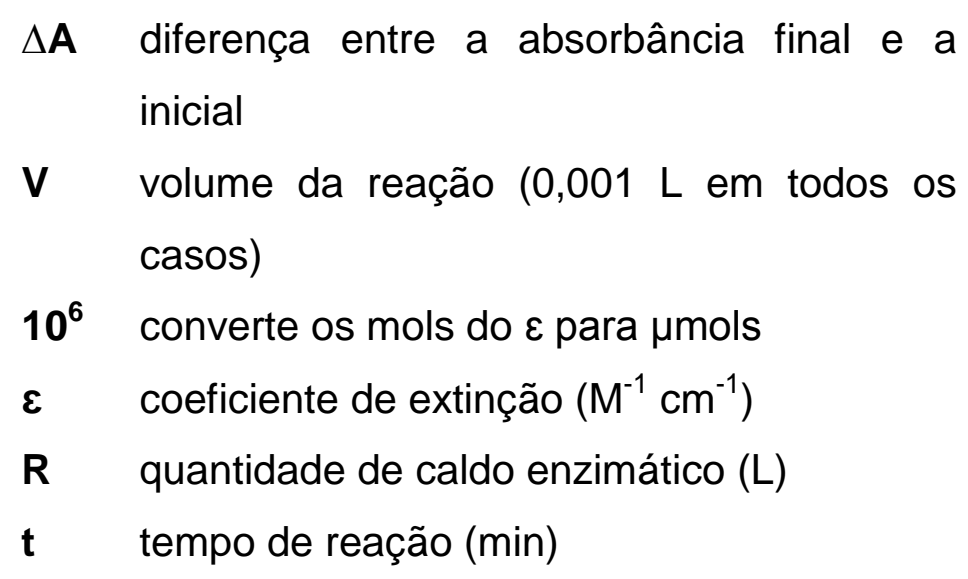




\subsection{Avaliação da degradação in vitro dos HPAs pireno e benzo[a]pireno}

\subsubsection{Condições de cultivo}

Os isolados que apresentarem maiores produções das enzimas ligninolíticas foram cultivados em meio MA2 \% acrescidos de $3 \%$ de $\mathrm{NaCl}$ e após o crescimento três cilindros de $5 \mathrm{~mm}$ de diâmetro da margem das colônias foram transferidos para frascos Erlenmeyer de $125 \mathrm{~mL}$ contendo $50 \mathrm{~mL}$ de caldo $\mathrm{MB} 2 \%$ e MB2 \%+3 \% NaCl. Os frascos foram incubados por $72 \mathrm{~h}$ a $28{ }^{\circ} \mathrm{C}$ e a $140 \mathrm{rpm}$ e após este período, 1,0 $\mathrm{mL}$ das soluções $2 \mathrm{mg} \cdot \mathrm{mL}^{-1}$ de pireno e $2 \mathrm{mg} \cdot \mathrm{mL}^{-1}$ de benzo[a]pireno (ambas preparadas separadamente com reagente dimetilsulfóxido) foram adicionadas aos frascos Erlenmeyer, em quatro réplicas para cada solução. Os frascos foram incubados no escuro por mais 7 dias. Como controles, o pireno e o benzo[a]pireno foram incubados em meio de cultura (MB2 \% e MB2 \%+3 \% NaCl) em adição do fungo. Ainda, este mesmo meio de cultivo sem a adição de HPAs e sem o inóculo microbiano foi utilizado como branco (PASSARINI; SETTE; RODRIGUES, 2011).

\subsubsection{Degradação in vitro dos HPAs pireno e benzo[a]pireno}

Esta etapa do trabalho foi desenvolvida em colaboração com a Dra. Marili Rodrigues da Divisão de Química Orgânica e Farmacêutica (DQOF) do CPQBA/UNICAMP. Cabe ressaltar, que o processo de extração e quantificação dos HPAs presentes no meio fermentativo e adsorvido no micélio utilizado no presente projeto foi otimizado e validado pela Dra. Marili Rodrigues (PASSARINI; SETTE; RODRIGUES, 2011).

\subsubsection{Extração dos HPAs para análise por Cromatografia Gasosa e Espectrometria de Massa (GC-EM)}

A cada Erlenmeyer da amostra contendo o fungo em meio fermentativo descrito na seção 4.5 .1 foi adicionado $50 \mathrm{~mL}$ de acetato de etila com subsequente desintegração celular no dispersor (Polytron) 14.000 rpm durante 1 min. Em seguida, a haste do dispersor foi lavada com acetato de etila (aproximadamente $10 \mathrm{~mL}$ ) e o material foi filtrado sob algodão embebido com acetato de etila diretamente acoplado 
no funil de separação de $250 \mathrm{~mL}$. As fases contidas no funil de separação foram submetidas à agitação vigorosa durante 1 min e a fase orgânica filtrada sob algodão com sulfato de sódio anidro saturado com acetato de etila diretamente no balão de fundo redondo de $250 \mathrm{~mL}$. A fase aquosa recolhida separadamente foi re-extraída com mais $50 \mathrm{~mL}$ de acetato de etila durante $1 \mathrm{~min}$. As fases orgânicas foram depositadas no balão de $250 \mathrm{~mL}$ e evaporadas em rota-evaporador com banho entre 40-45 ${ }^{\circ} \mathrm{C}$ até volume reduzido (cerca de $1 \mathrm{~mL}$ ). O conteúdo do balão foi transferido analiticamente para balão volumétrico de $10 \mathrm{~mL}$ contendo $1 \mathrm{~mL}$ da solução de padrão interno (dibutilftalato $619 \mu \mathrm{g} / \mathrm{mL}$ em acetato de etila) e submetido à análise por GC-EM.

\subsubsection{Análise quantitativa da degradação dos HPAs por GC-EM}

As análises por GC-EM foram realizadas em um cromatógrafo a gás HP 6890N (Hewlett Packard) acoplado ao detector seletivo de massas HP 5975 e injetor automático HP 7683B operando no modo splitless com liner HP 5062-3587. A separação cromatográfica foi realizada em coluna capilar HP-5MS (30 m x 0,25 mm, $0,25 \mu \mathrm{m})$. As injeções foram realizadas automaticamente $(1 \mu \mathrm{L})$ no modo "splitless" com a válvula aberta após 0,6 min e com o injetor operando a $180 \stackrel{\circ}{\circ}$. A vazão do gás de arraste (hélio) foi de $1 \mathrm{~mL} / \mathrm{min}$. Para a quantificação dos HPAs foi utilizado o método de padronização interna utilizando como padrão interno o dibutilftalato na concentração de $619 \mu \mathrm{g} / \mathrm{mL}$ em acetato de etila, com 13 pontos de concentração. $O$ detector seletivo de massas foi utilizado no modo SIM (Single ĺon Monitoring) indicado para a quantificação. Dessa forma, para o pireno e benzo[a]pireno foram atribuídos os fragmentos mais abundantes para serem utilizados como íons de quantificação (IQ) e outros dois íons para identificação (II), considerando o tempo de eluição de cada analito. Os tempos de retenção e as abundâncias relativas de IQ e II foram utilizados como critérios de confirmação. Os padrões analíticos utilizados para análise de HPAs foram: pireno e benzo[a]pireno adquiridos junto a Sigma, com pureza de $98 \%$ e $100 \%$, respectivamente, além do padrão interno dibutilftalato da Mallinckrodt. A construção da curva analítica para quantificação dos HPAs foi preparada conforme Passarini (2008). A programação utilizada foi $60^{\circ} \mathrm{C}, 60-280^{\circ} \mathrm{C}$ (a $5{ }^{\circ} \mathrm{C}$ por min), $280^{\circ} \mathrm{C}$ por $26 \mathrm{~min}, 280-310^{\circ} \mathrm{C}$ (a $5^{\circ} \mathrm{C}$ por min), $310^{\circ} \mathrm{C}$ por $5 \mathrm{~min}$, intencionando-se monitorar os íons 176, 189, 218, 234 e 236 (MAGRINI, 2012). 


\subsubsection{Avaliação da adsorção dos HPAs ao micélio}

Após o crescimento da biomassa inicial conforme descrito na seção 4.3.1, os frascos foram esterilizados em autoclave por $30 \mathrm{~min}$ a $121{ }^{\circ} \mathrm{C}$ e pressão de $1 \mathrm{~atm}$. Em seguida, os HPAs pireno e BaP dissolvidos em dimetilsulfóxido foram adicionados separadamente aos frascos na concentração de $2 \mathrm{mg} \cdot \mathrm{mL}^{-1}$ e incubados por 7 dias nas mesmas condições. A análise quantitativa da adsorção dos HPAs por CG-EM foi realizada de acordo com a seção 4.5.2.1 e análise quantitativa conforme a seção 4.5.2.2. Os experimentos foram realizados em triplicata.

\subsubsection{Otimização da degradação de HPAs através do delineamento experimental}

O planejamento de experimento e a otimização de processos através do delineamento experimental foram realizados para os isolados que apresentaram os melhores resultados nos experimentos de degradação, visando otimização da taxa de degradação e avaliação da influência de diferentes fatores na atividade enzimática e degradação do pireno.

\subsection{Delineamentos experimentais de Plackett-Burman (PB)}

Os fungos selecionados foram submetidos ao delineamento experimental de PB para avaliação das variáveis quantidade de inóculo, $\mathrm{pH}$, salinidade, concentrações de extrato de malte, glicose, peptona, extrato de levedura, sulfato de cobre $\left(\mathrm{CuSO}_{4}\right)$ e sulfato de manganês $\left(\mathrm{MnSO}_{4}\right)$ como indutores das enzimas lacase e manganês peroxidase, respectivamente. Outras variáveis, como a concentração do pireno $\left(2 \mathrm{mg} \cdot \mathrm{mL}^{-1}\right)$, a agitação (140 rpm) e a temperatura $(28 \stackrel{\circ}{\circ})$ foram fixadas. Para a salinidade foi utilizada água do mar artificial que continha (em g L ${ }^{-1}$ de água destilada): $\mathrm{NaCl}(23,93), \mathrm{Na}_{2} \mathrm{SO}_{4}(4), \mathrm{KCl}(0,68), \mathrm{NaHCO}_{3}(0,19), \mathrm{KBr}(0,098), \mathrm{H}_{3} \mathrm{BO}_{3}$ $(0,026), \mathrm{NaF}(0,003), \mathrm{MgCl}_{2} \cdot 6 \mathrm{H}_{2} \mathrm{O}(10,83), \mathrm{CaCl} \cdot 2 \mathrm{H}_{2} \mathrm{O}(1,51)$ e $\mathrm{SrCl}_{2} \cdot 6 \mathrm{H}_{2} \mathrm{O}(0,02)$ (KESTER et al., 1967). Todas as diferentes variáveis foram preparadas em dois níveis, designados como -1 para o inferior e +1 para o superior (Tabela 1). Três ensaios no ponto central foram acrescentados à matriz para a determinação do erro padrão durante a análise dos resultados, totalizando 20 ensaios (PB20) e permitindo 
a avaliação do efeito das 9 variáveis sobre a degradação de pireno. A matriz de planejamento foi analisada estatisticamente utilizando o software STATISTICA 7.0 (STAT SOFT, INC. 1995).

Tabela 1. Níveis das variáveis estudadas no delineamento de Plackett-Burman com 9 variáveis (PB20), aplicado à degradação de pireno.

\begin{tabular}{|c|c|c|c|}
\hline Variável & $\begin{array}{c}\text { Nível } \\
\text { inferior }\end{array}$ & $\begin{array}{l}\text { Ponto } \\
\text { central }\end{array}$ & $\begin{array}{c}\text { Nível } \\
\text { superior }\end{array}$ \\
\hline & -1 & 0 & 1 \\
\hline 1. $\mathrm{pH}$ & 7 & 8 & 9 \\
\hline 2. Salinidade $(\% 0)$ & 0 & 17,5 & 35 \\
\hline 3. Glicose $\left(g \cdot \mathrm{L}^{-1}\right)$ & 0 & 2,5 & 5 \\
\hline 4. Extrato de Malte (g. $\left.\mathrm{L}^{-1}\right)$ & 0 & 2 & 4 \\
\hline 5. Peptona (g. $\left.\mathrm{L}^{-1}\right)$ & 0 & 1 & 2 \\
\hline 6. Extrato de Levedura (g. $\left.\mathrm{L}^{-1}\right)$ & 0 & 1 & 2 \\
\hline 7. $\mathrm{MnSO}_{4}$ (indutor $\mathrm{MnP}$ ) & 0 & $2 \mathrm{mM}$ & $4 \mathrm{mM}$ \\
\hline 8. $\mathrm{CuSO}_{4}$ (indutor lacase) & 0 & $2 \mathrm{mM}$ & $4 \mathrm{mM}$ \\
\hline 9. Inóculo (cilindros $5 \mathrm{~mm}$ ) & 2 & 3 & 4 \\
\hline
\end{tabular}

Um segundo planejamento experimental de PB foi realizado para o fungo que apresentou maior degradação de pireno. Neste planejamento foram fixadas algumas variáveis do planejamento anterior (PB20) como a quantidade de inóculo (3 cilindros), a salinidade (35\%), $\mathrm{pH}(7.0)$ e o indutor de manganês peroxidase, $\mathrm{MnSO}_{4}$ (4 mM). As variáveis glicose e indutor de lacase $\left(\mathrm{CuSO}_{4}\right)$ foram descartadas. A riboflavina e o fosfato de potássio bibásico $\left(\mathrm{KH}_{2} \mathrm{PO}_{4}\right)$ foram duas novas variáveis introduzidas aos ensaios. Todas as diferentes variáveis foram preparadas em dois níveis, designados como -1 para o inferior e +1 para o superior (Tabela 2). Três ensaios no ponto central foram acrescentados à matriz para a determinação do erro padrão durante a análise dos resultados, totalizando 16 ensaios (PB16) e permitindo a avaliação do efeito das 5 variáveis sobre a degradação de pireno. A matriz de planejamento foi analisada estatisticamente utilizando o software STATISTICA 7.0 (STAT SOFT, INC. 1995). 
Tabela 2. Níveis das variáveis estudadas no delineamento de Plackett-Burman com 5 variáveis (PB16), aplicado à degradação de pireno.

\begin{tabular}{lccc}
\hline \multicolumn{1}{c}{ Variável } & $\begin{array}{c}\text { Nível } \\
\text { inferior }\end{array}$ & Ponto central & $\begin{array}{c}\text { Nível } \\
\text { superior }\end{array}$ \\
& -1 & 0 & 1 \\
1. Extrato de Malte $\left(\mathrm{g} \cdot \mathrm{L}^{-1}\right)$ & 4 & 5 & 6 \\
\hline 2. Peptona $\left(\mathrm{g} \cdot \mathrm{L}^{-1}\right)$ & 2 & 3 & 4 \\
3. Extrato de levedura $\left(\mathrm{g} \cdot \mathrm{L}^{-1}\right)$ & 2 & 3 & 4 \\
$\begin{array}{l}\text { 4. Fosfato de potássio bibásico } \\
\left(\mathrm{KH}_{2} \mathrm{PO}\right.\end{array}$ & 0 & 0,1 & 0,2 \\
5. Riboflavina $(\%)$ & & & 0,02 \\
\hline
\end{tabular}

\subsection{Delineamento experimental Fatorial Fracionado $2^{4-1}$}

Após a análise estatística das variáveis significativas e seus efeitos, um novo delineamento foi proposto. Com a intenção de avaliar novas concentrações do extrato de malte, peptona e extrato de levedura e uma nova faixa de $\mathrm{pH}(7,0,8,0$ e $9,0)$, um delineamento fatorial fracionado $2^{4-1}$ foi realizado e todas as diferentes variáveis foram preparadas em dois níveis, designados como -1 para o inferior $e+1$ para o superior (Tabela 3). Três ensaios no ponto central foram acrescentados à matriz para a determinação do erro padrão durante a análise dos resultados, totalizando 12 ensaios (FF12) e permitindo a avaliação do efeito das 4 variáveis sobre a degradação de pireno. A matriz de planejamento foi analisada estatisticamente utilizando o software STATISTICA 7.0 (STAT SOFT, INC. 1995). 
Tabela 3. Níveis das variáveis estudadas no delineamento fatorial fracionado $2^{4-1}$ (FF12), aplicado à degradação de pireno.

\begin{tabular}{|c|c|c|c|}
\hline Variável & Nível inferior & $\begin{array}{l}\text { Ponto } \\
\text { central }\end{array}$ & Nível superior \\
\hline & -1 & 0 & 1 \\
\hline 1. Extrato de Malte $\left(\mathrm{g} \mathrm{L}^{-1}\right)$ & 6 & 6,5 & 7 \\
\hline 2. Peptona $\left(\mathrm{g} \mathrm{L}^{-1}\right)$ & 3 & 4 & 5 \\
\hline 3. Extrato de levedura $\left(\mathrm{g} \mathrm{L}^{-1}\right)$ & 4 & 5 & 6 \\
\hline 4. $\mathrm{pH}$ & 7 & 8 & 9 \\
\hline
\end{tabular}

\subsection{Delineamento Composto Central Rotacional (DCCR)}

Com base nos resultados dos efeitos das variáveis avaliadas no delineamento Fatorial Fracionado 24-1, um Delineamento Composto Central Rotacional foi realizado para a as variáveis concentrações de extrato de malte e peptona. Todas as diferentes variáveis foram preparadas em 4 níveis, designados como -1,41 e -1 para os inferiores $e+1,41 e+1$ para os superiores (Tabela 4). Três ensaios no ponto central foram acrescentados à matriz para a determinação do erro padrão durante a análise dos resultados, totalizando 12 ensaios (DCCR12) e permitindo a avaliação do efeito das 2 variáveis sobre a degradação de pireno. A matriz de planejamento foi analisada estatisticamente utilizando o software STATISTICA 7.0 (STAT SOFT, INC. 1995).

Tabela 4. Níveis das variáveis estudadas no Delineamento Composto Central Rotacional (DCCR12)

\begin{tabular}{cccccc}
\hline Variáveis & $\mathbf{- 1 , 4 1}$ & $\mathbf{- 1}$ & $\mathbf{0}$ & $\mathbf{1}$ & $\mathbf{1 , 4 1}$ \\
\hline 1. Extrato de malte $\left(\mathrm{g} \cdot \mathrm{L}^{-1}\right)$ & 6,5 & 6,65 & 7 & 7,35 & 7,5 \\
& & & & & 3,35 \\
2. Peptona $\left(\mathrm{g} \cdot \mathrm{L}^{-1}\right)$ & 2,5 & 2,65 & 3 & 3,5 \\
\hline
\end{tabular}




\subsection{Análise qualitativa dos metabólitos formados durante a degradação dos HPAs por Cromatografia Gasosa e Espectrometria de Massa (GC-EM)}

A avaliação dos metabólitos formados no processo de degradação do pireno foi realizada utilizando metodologia validada pela equipe da Divisão de Química Orgânica e Farmacêutica (CPQBA/UNICAMP) como descrito por Passarini et al. (2011). A análise qualitativa da degradação dos HPAs é de suma importância, visto que, as vias de degradação destes compostos por fungos são pouco conhecidas e os fungos derivados marinhos podem utilizar rotas de degradação diferentes dos seus parceiros terrestres.

Para detecção dos metabólitos formados durante a degradação dos HPAs, o fungo selecionado foi incubado em meio líquido durante 7 dias em presença de pireno e BaP, sob as mesmas condições de cultivo da seção 4.5.1. A extração dos HPAs foi realizada em homogeneizador Ultra-Turrax com $50 \mathrm{~mL}$ de acetato de etila.

Após duas extrações, as fases orgânicas foram agrupadas e secas em evaporador rotativo a vácuo em banho-maria a $30 \stackrel{\circ}{\circ}$. Para cada tempo de cultivo foram feitas 5 réplicas, agrupadas afim de se obter maior concentração de produtos formados. $\mathrm{O}$ resíduo final foi então dissolvido em $2 \mathrm{~mL}$ de acetato de etila e $1 \mu \mathrm{L}$ injetado no cromatógrafo gasoso CG-EM. Os componentes das amostras foram separados numa coluna capilar HP-5 MS (30 m x 0,25 mm x 0,25 $\mu \mathrm{m})$ na seguinte programação de temperatura: $60^{\circ} \mathrm{C}\left(5^{\circ} \mathrm{C} / \mathrm{min}\right) 280^{\circ} \mathrm{C} / 26 \mathrm{~min}\left(5{ }^{\circ} \mathrm{C} / \mathrm{min}\right) 310^{\circ} \mathrm{C} / 5$ min. A temperatura do injetor foi de $250{ }^{\circ} \mathrm{C}$ (injeção splitless) e a temperatura da interface foi de $300{ }^{\circ} \mathrm{C}$. As amostras foram analisadas no modo varredura completa (SCAN) e a faixa de massas monitorada foi de 40 a 600 u.m.a. A identificação dos picos foi feita pela comparação do espectro de massas com os dados disponíveis na biblioteca NIST 98 e independentemente pela interpretação dos padrões de fragmentação. As amostras também foram analisadas no modo monitoramento seletivo de íons (SIM). A identificação dos metabólitos foi alcançada medindo-se um íon de identificação e pelo menos um íon adicional de confirmação por composto, conforme espectros de massas descritos na literatura. Os experimentos foram analisados juntamente com um controle sem o HPA pireno. 


\subsection{Extração do DNA genômico e amplificação dos genes marcadores taxonômicos para a identificação do isolado CeAC2}

A identificação do isolado CeAC2 que apresentou potencial biotecnológico foi realizada por meio de taxonomia molecular. Após cultivo do fungo em meio PDB, o DNA genômico foi obtido de acordo com Da Silva et al. (2008). As regiões ITS-5.8SITS2 rRNA foram amplificadas com os primers ITS1 (5'-CCG TAG GTG AACCTG CGG-3') e ITS4 (5'-TCC TCC GCT TAT TGA TAT GC-3'). A reação da polimerase em cadeia (PCR) foi realizada em $25 \mu \mathrm{L}$ de volume final contendo: DNA genômico (5-25 ng), cada primer (0.4 mM), dNTPs (0.2 mM, GEHealthcare), MgCl2 (1.5 mM, Invitrogen), Taq polimerase (2.0 U, Invitrogen) e tampão de reação (10 $\mu \mathrm{L}$, Invitrogen). A amplificação foi realizada conforme descrito por Bonugli-Santos et al. (2010), com inicial desnaturação por 5 min a $94 \stackrel{\circ}{\circ}$, 30 ciclos de $30 \mathrm{~s}$ a $94 \stackrel{\circ}{\circ}, 30 \mathrm{~s} \mathrm{a}$ $55^{\circ} \mathrm{C}$ e 1 min a $72{ }^{\circ} \mathrm{C}, 10 \mathrm{~min}$ a $72^{\circ} \mathrm{C}$, e finalmente resfriado a $4{ }^{\circ} \mathrm{C}$. Os amplicons foram purificados, quantificados e sequenciados de acordo com Sette, Oliveria e Manfio (2005) em sequenciador automático MegaBace (Healthcare, GE) com os primers ITS1 and ITS4 para as regiões ITS1-5.8S-ITS2. As sequências obtidas das regiões ITS-5.8S-ITS2 do DNA ribossomal do isolado CeAC2 foram reunidas em um contig utilizando o software Phred/Phrap/Consed (EWING et al. 1998). As sequências foram comparadas com sequências ITS-rDNA do banco de dados GenBank (http://www.ncbi.nlm.nih.gov) utilizando BLASTn.

\subsection{Análises filogenéticas para identificação do isolado CeAC 2}

O alinhamento das seqüências nucleotídicas foi realizado utilizando os programas Clustal W e Clustal X (THOMPSON et al. 1994), sendo utilizadas para as comparações sequências confiáveis depositadas nas bases de dados provenientes de coleções de cultura internacionalmente reconhecidas como CBS, NRRL e CBMAI. O método de Neighbour-joining, utilizando o modelo de substituição Kimura 2-parâmetros (KIMURA, 1980), foi usado para estimar a distância evolutiva e a árvore filogenética foi construída usando o software MEGA $5.0 \mathrm{com}$ o algoritmo Maximum Likelihood e os valores de bootstrap foram calculados com 1.000 replicatas. 


\section{RESULTADOS E DISCUSSÃo}

\subsection{Seleção de fungos ligninolíticos}

Dos 185 ribotipos distintos de fungos filamentosos isolados de esponjas marinhas 174 foram reativados e submetidos a um screening em meio sólido (MA2 $\%+3 \% \mathrm{NaCl}$ ) suplementado com o corante RBBR $\left(500 \mathrm{mg} . \mathrm{L}^{-1}\right)$. Os resultados foram negativos para esse screening, uma vez que nenhum isolado descoloriu 0 corante. Entretanto, todos apresentaram crescimento micelial similar ao crescimento do experimento controle (cultivos sem adição do corante RBBR), indicando a tolerância ao corante utilizado para a seleção. Um novo método de screening foi utilizado, onde os 174 fungos foram submetidos ao crescimento em meio sólido B\&K suplementado com $4 \mathrm{mM}$ de guaiacol (Figura 8). A coloração marrom indica a presença da enzima lacase (D'SOUZA et al. 2006). A triagem inicial resultou em 61 isolados positivos $(35,05 \%)$.
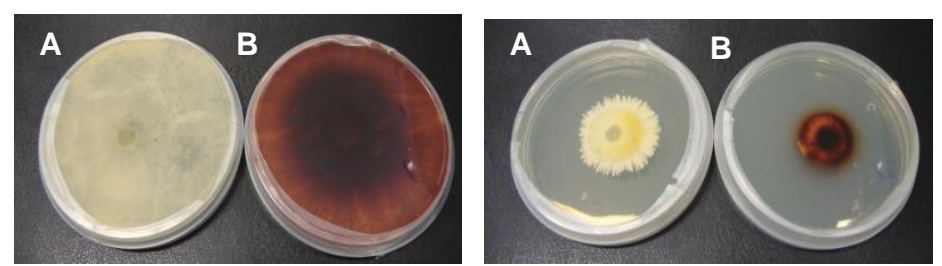

Figura 8. Screening de produção de lacase em meio B\&K acrescido de guaiacol: (A) experimento controle - crescimento dos fungos em B\&K sem guaiacol. (B) Formação do composto marrom escuro na presença de guaiacol.

\subsection{Avaliação da produção das enzimas ligninolíticas em meio líquido e suplementado com corantes}

As enzimas ligninolíticas de fungos filamentosos agem sinergisticamente e eficientemente na degradação de polímeros de lignina. As lacases são proteínas multi-cobre que catalisa a oxidação de substratos fenólicos com concomitante redução de oxigênio molecular à água. $\mathrm{A} \mathrm{MnP}$ oxida $\mathrm{Mn}$ (II) a $\mathrm{Mn}$ (III) que por sua vez oxida uma variedade de fenóis monoméricos incluindo corantes tanto quanto compostos de lignina. A LiP possui a habilidade para catalisar a oxidação de compostos de alto potencial redox. Por essa habilidade, a LiP é considerada um oxidante mais forte que o $\mathrm{MnP}$, que por sua vez é mais forte que a lacase e não 
requer a participação de mediadores na oxidação de substratos não fenólicos (WONG, 2009).

Dentre os 61 isolados positivos, 10 foram avaliados quanto à produção de lacase, lignina peroxidase (LiP), manganês peroxidase (MnP) em ensaios com e sem a suplementação dos corantes têxteis preto sulfuroso (PS), índigo blue (IB) e reativo black 5 (RB5). Os isolados foram selecionados mediante a intensidade de cor marrom no screening em placa com o substrato enzimático guaiacol e foram cultivados em caldo extrato de malte $\mathrm{MB} 2 \%+3 \% \mathrm{NaCl}$ e após $72 \mathrm{~h}$ de cultivo a 28 oC e $140 \mathrm{rpm}$, o meio foi suplementado com $500 \mathrm{mg} . \mathrm{L}^{-1}$ dos corantes PS, IB e RB5 (separadamente). Nenhum dos isolados avaliados apresentou descoloração dos corantes índigo blue, preto sulfuroso e reativo Black 5, em meio líquido, após 7 dias de cultivo. A quantificação das enzimas lacase, LiP e MnP foi realizada no $3^{\circ}$ e no $7^{\circ}$ dia de cultivo (após a suplementação dos corantes têxteis) utilizando como substratos enzimáticos a siringaldazina, o álcool veratrílico e o vermelho de fenol, respectivamente. Os três isolados que apresentaram as maiores atividades das enzimas estudadas (Figura 9, 10 e 11) foram previamente identificados com base em taxonomia molecular por Passarini et al. (2013) como Pleospora sp. CBMAI 1358, Trichoderma harzianum CBMAl 1359 e Arthopyrenia salicis CBMAI 1330 (Tabela 5).

Tabela 5 . Identificação dos fungos derivados marinhos ligninolíticos, número do depósito, código de origem e fonte de isolamento.

\begin{tabular}{ccc}
\hline Número de depósito/lsolado & Fonte (esponja) & Identificação molecular \\
\hline CBMAI 1358 (DRAC3-6) & Dragmacidon reticulatum & Pleospora sp. \\
CBMAI 1359 (DRG4.3.1-9) & Dragmacidon reticulatum & Trichoderma harzianum \\
CBMAI 1330 (DRRBBR7.2-9) & Dragmacidon reticulatum & Arthopyrenia salicis \\
& & \\
\hline
\end{tabular}

Os três fungos estudados, não apresentaram produção enzimática na presença do corante reativo Black 5. Portanto, as figuras abaixo apresentadas incluem os resultados da produção de lacase (Figura 9), MnP (Figura 10) e LiP (Figura 11) na condição sem corante e na presença dos corantes índigo blue e preto sulfuroso. 


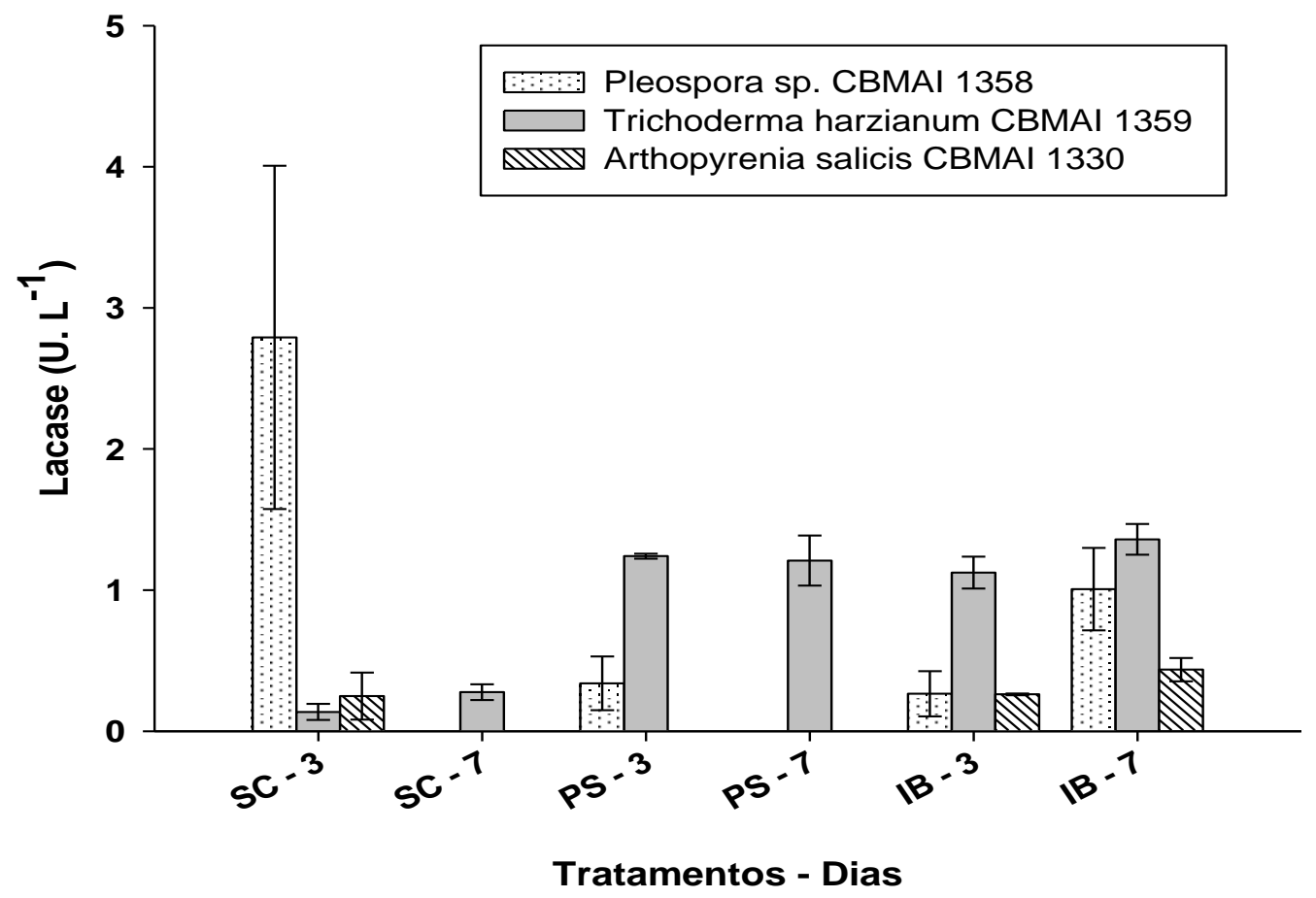

Figura 9. Atividade enzimática de lacase $\left(U \mathrm{~L}^{-1}\right)$ pelos fungos Pleospora sp. CBMAI 1358, Trichoderma harzianum CBMAI 1359 e Arthopyrenia salicis CBMAI 1330, no $3^{\circ}$ e $7^{\circ}$ dia de cultivo em meio líquido $\mathrm{MA} 2 \%+3 \% \mathrm{NaCl}$. Tratamentos: Meio sem corante (SC), suplementados com corante preto sulfuroso (PS) e com o corante índigo blue (IB).

Trichoderma harzianum CBMAI 1359 foi o fungo que produziu a enzima lacase em todas as condições estudadas, com destaque para a produção de lacase na presença do corante índigo blue (IB) de 1,356 U. $\mathrm{L}^{-1}$, no $7^{\circ}$ dia de cultivo. Para o fungo Pleospora sp. CBMAI 1358 obteve-se 2,802 U.L ${ }^{-1}$ de lacase em meio líquido sem corante, sendo essa a maior produção apresentada entre os fungos e as condições estudadas. A produção de lacase por esse fungo foi bem mais baixa $\left(0,340\right.$ e 0,272 U. $L^{-1}$, no $3^{\circ}$ dia de cultivo) do que a produção na condição sem corante (SC), sugerindo que os corantes PS e IB utilizados atuaram como inibidores da produção da enzima. Arthopirenia salicis CBMAI 1330 não produziu lacase na presença do corante preto sulfuroso (PS) e apresentou aumento crescente entre os tempos estudados $\left(0,264\right.$ e 0,437 U. $L^{-1}$, no $3^{\circ}$ e $7^{\circ}$ dia, respectivamente) na presença do corante índigo blue (IB). Para este fungo, a produção na condição sem corante (SC) foi mais baixa do que a obtida com o corante IB, demonstrando que o corante não inibiu a produção da enzima. 


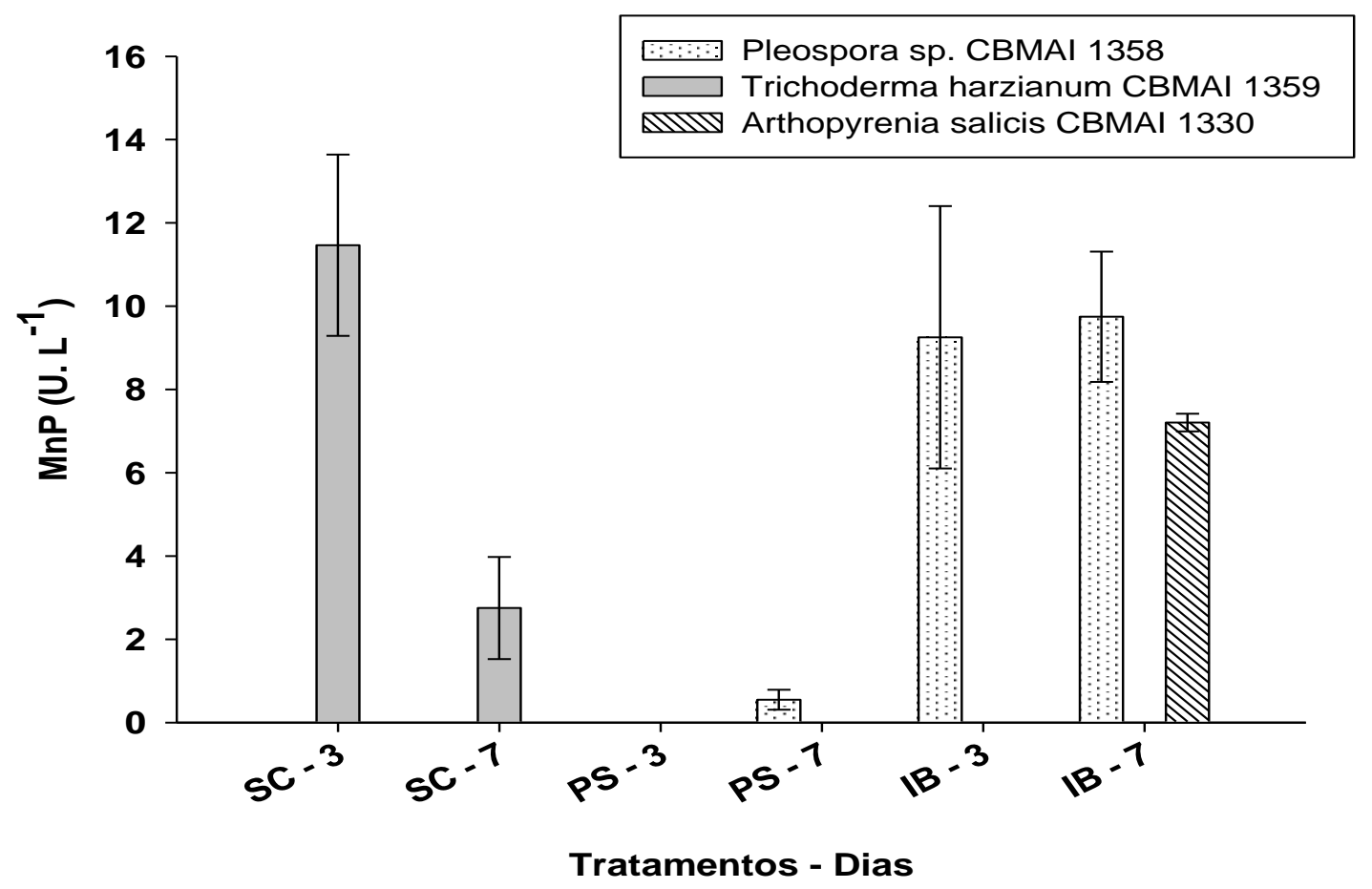

Figura 10. Atividade enzimática de $\mathrm{MnP}\left(\mathrm{U} . \mathrm{L}^{-1}\right)$ pelos fungos Pleospora sp. CBMAl 1358, Trichoderma harzianum CBMAI 1359 e Arthopyrenia salicis CBMAI 1330, no 3으 e 7을 de cultivo em meio líquido $\mathrm{MA}+3 \% \mathrm{NaCl}$. Tratamentos: Meio sem corante (SC), suplementados com corante preto sulfuroso (PS) e com o corante índigo blue (IB).

De maneira geral a enzima MnP foi produzida em maiores quantidades do que a lacase pelos fungos estudados (Figura 10). O fungo Trichoderma harzianum CBMAI 1359 foi o único que produziu MnP em meio líquido sem corante (SC), com produção de 11,45 U. $\mathrm{L}^{-1}$ no $3^{\circ}$ dia de cultivo e diminuição da mesma para 2,64 U.L ${ }^{1}$ após 7 dias de cultivo. Este fungo não foi capaz de produzir a enzima nos meios contendo corante. Pleospora sp. CBMAl 1330 se destacou na produção de MnP na presenca do corante índigo blue (IB) $\left(9,29\right.$ e 9,75 U. $\mathrm{L}^{-1}$, no $3^{\circ}$ e $7^{\circ}$ dia de cultivo, respectivamente). O fungo Arthopyrenia salicis CBMAI 1330 produziu MnP (7,18 U. ${ }^{1}$ ) apenas na presença do corante índigo blue (IB) após 7 dias de cultivo. 


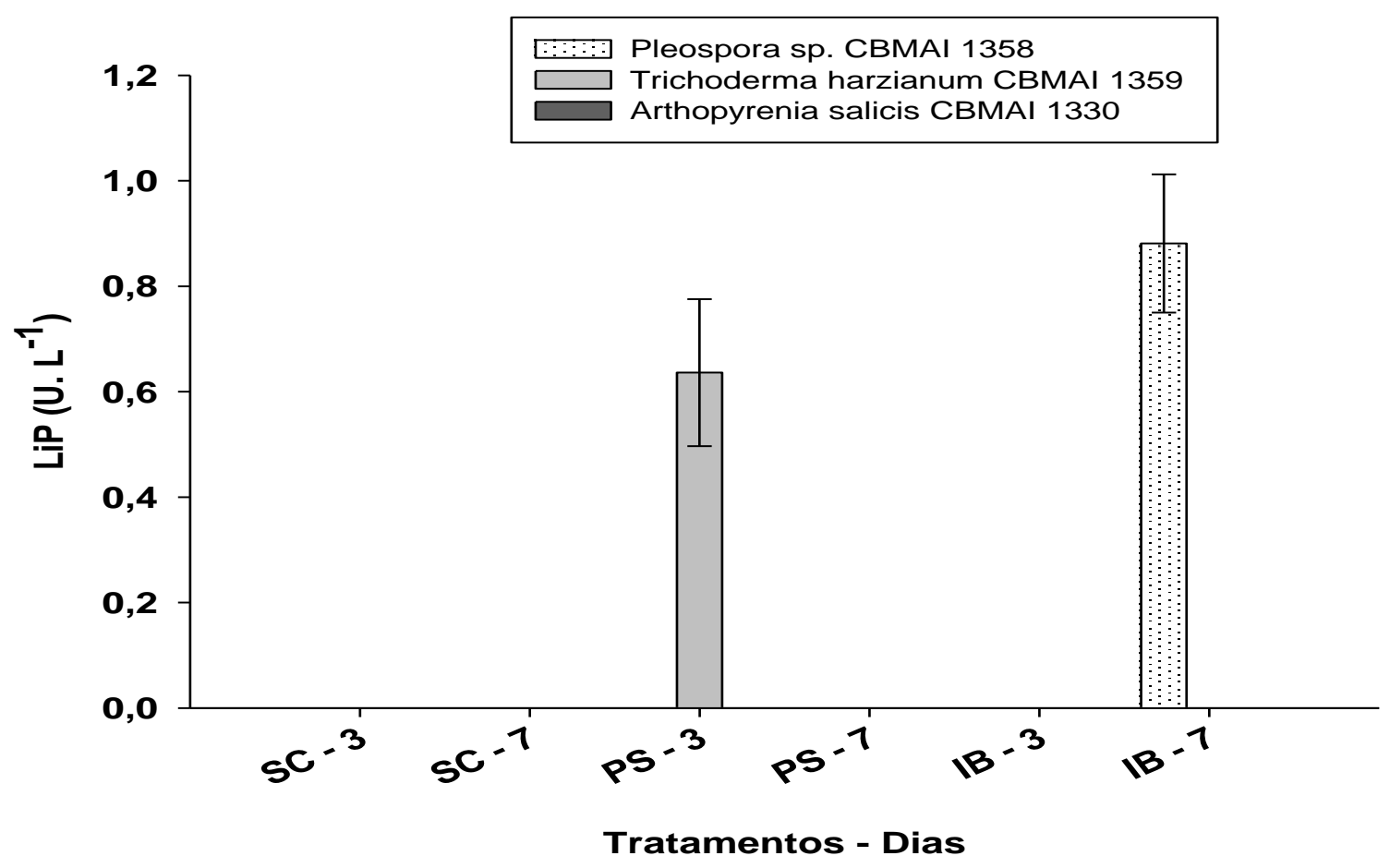

Figura 11. Atividade enzimática de LiP $\left(U \mathrm{~L}^{-1}\right)$ pelos fungos Pleospora sp. CBMAI 1358, Trichoderma harzianum CBMAI 1359 e Arthopyrenia salicis CBMAI 1330, no 3ํㅜ e 7ำ dia de cultivo em meio líquido $\mathrm{MA}+3 \% \mathrm{NaCl}$. Tratamentos: Meio sem corante (SC), suplementados com corante preto sulfuroso (PS) e com o corante índigo blue (IB).

A produção de LiP foi baixa e somente observada para o fungo Trichoderma harzianum CBMAl 1359, no $3^{\circ}$ dia $\left(0,64\right.$ U. $\left.\mathrm{L}^{-1}\right)$, e Pleospora sp. CBMAl 1358, no $7^{\circ}$ dia $\left(0,88 \mathrm{U} . \mathrm{L}^{-1}\right)$, na presença dos corantes preto sulfuroso (PS) e índigo blue (IB), respectivamente. A produção de LiP não foi detectada no meio sem corante (SC).

Os fungos filamentosos de origem marinha têm sido foco de estudos de produção de enzimas ligninolíticas e degradação de poluentes ambientais. Segundo Bonugli-Santos et al., (2010b) os fungos isolados de ambiente marinho Tinctoporellus sp. CBMAI 1061, Marasmiellus sp. CBMAI 1062 e Peniophora sp. CBMAI 1063, foram capazes de produzir maiores quantidades de lacase em condição salina $\mathrm{MB} 2 \%+3 \% \mathrm{NaCl}$ após 7 dias de cultivo. Em outros estudos realizados com as espécies Aspergillus sclerotiorum CBMAI 849, Cladosporium cladosporioides CBMAI 857 e Mucor racemosus CBMAI 847 foi verificada a atividade enzimática de lacase e MnP também em condições salinas (MB2 \%+3 \% $\mathrm{NaCl}$ e MB2 \%+12,5\% $\mathrm{NaCl}$ ) para todos os fungos estudados. M. racemosus CBMAI 847 e $C$. cladosporioides CBMAl 857 também foram capazes de produzir lacase e MnP em condição altamente salina (MB2 \%+ $23 \% \mathrm{NaCl}$ ) (BONUGLISANTOS et al., 2010a). Os resultados obtidos por Bonugli-Santos et al. (2010a), 
evidenciam o potencial de fungos derivados marinhos para aplicações industriais e biorremediação de áreas contaminadas com concentrações elevadas de sal.

A produção das enzimas ligninolíticas, principalmente lacase e MnP é fortemente influenciada pela composição do meio de cultivo e pela estrutura química do corante (EICHLEROVÁ; HOMOLKA; NERUD et al., 2006). Dentre as diferentes fontes de nutrientes que podem influenciar a atividade ligninolítica (GAO et al., 2011), destaque é dado à concentração e o tipo de fontes de nitrogênio. Em um estudo realizado com o fungo Pleurotus calyptratus CCBAS 461 o mesmo produziu 4 vezes mais lacase em meio $M B$ do que em meio Kirk e teve a atividade desta enzima aumentada na presença do corante Orange G (EICHLEROVÁ; HOMOLKA; NERUD, 2006). Culturas de Irpex lacteus em meio líquido, na presença dos corantes reativos Orange 16 e Remazol Brilliant Blue (RBBR) produziram 76,2 U. $\mathrm{L}^{-1}$ de MnP, 2,0 U. $L^{-1}$ de lacase e 1,1 U. $L^{-1}$ de LiP em experimentos conduzidos por 7 dias (NOVOTNÝ et al., 2004). Em adição, altos níveis de atividade de enzimas ligninolíticas em biorreatores foram detectadas após adição do corante Poly R-478 na concentração final de $0,02 \%(\mathrm{p} / \mathrm{v})$.

Embora, as enzimas ligninolíticas possuam potencial aplicação na remediação de poluentes em água e solo, a degradação de compostos recalcitrantes em meio líquido requer altos níveis destas enzimas (COUTO et al., 2000).

\subsection{Degradação dos HPAs pireno e benzo[a]pireno pelos fungos produtores de enzimas ligninolíticas}

Os três isolados selecionados com base na produção das enzimas ligninolítcas em meio líquido foram submetidos aos experimentos de degradação dos poluentes ambientais pireno e benzo[a]pireno. Os fungos foram cultivados por 7 dias a $28^{\circ} \mathrm{C}$ e $140 \mathrm{rpm}$ em meio $\mathrm{MB} 2 \%+3 \% \mathrm{NaCl}$ (condição salina, CS) e MB2\% (condição sem sal, SS) contendo, ambos, pireno e benzo[a]pireno, a concentração de $2 \mathrm{mg} \cdot \mathrm{mL}^{-1}$.

Os resultados demonstraram que os fungos Pleospora sp. CBMAI 1358, Trichoderma harzianum CBMAl 1359 e Arthopyrenia salicis CBMAl 1330 foram capazes de degradar o pireno em 12,50 \% (CS) e 44,01\% (SS), $18,85 \%$ (CS) e $32,50 \%$ (SS) e $17,90 \%$ (CS) e $23,55 \%$ (SS), respectivamente, (Figura 12). Para 
todos os fungos a condição sem sal apresentou melhores resultados de degradação de pireno quando comparado à condição salina.

Quanto à degradação de benzo[a]pireno, os resultados foram menores do que os obtidos para pireno, tanto na condição salina (CS) quanto na não salina (SS). Pleospora sp. CBMAI 1358 apresentou 9,68 \% (CS) 30,38 \% (SS) de degradação do BaP. Trichoderma harzianum CBMAI 1359 e Arthopyrenia salicis CBMAl 1330 foram capazes de degradar este composto em 13,67 \% (CS) e 32,02 \% (SS) e 8,70 \% e $26,37 \%$, respectivamente.

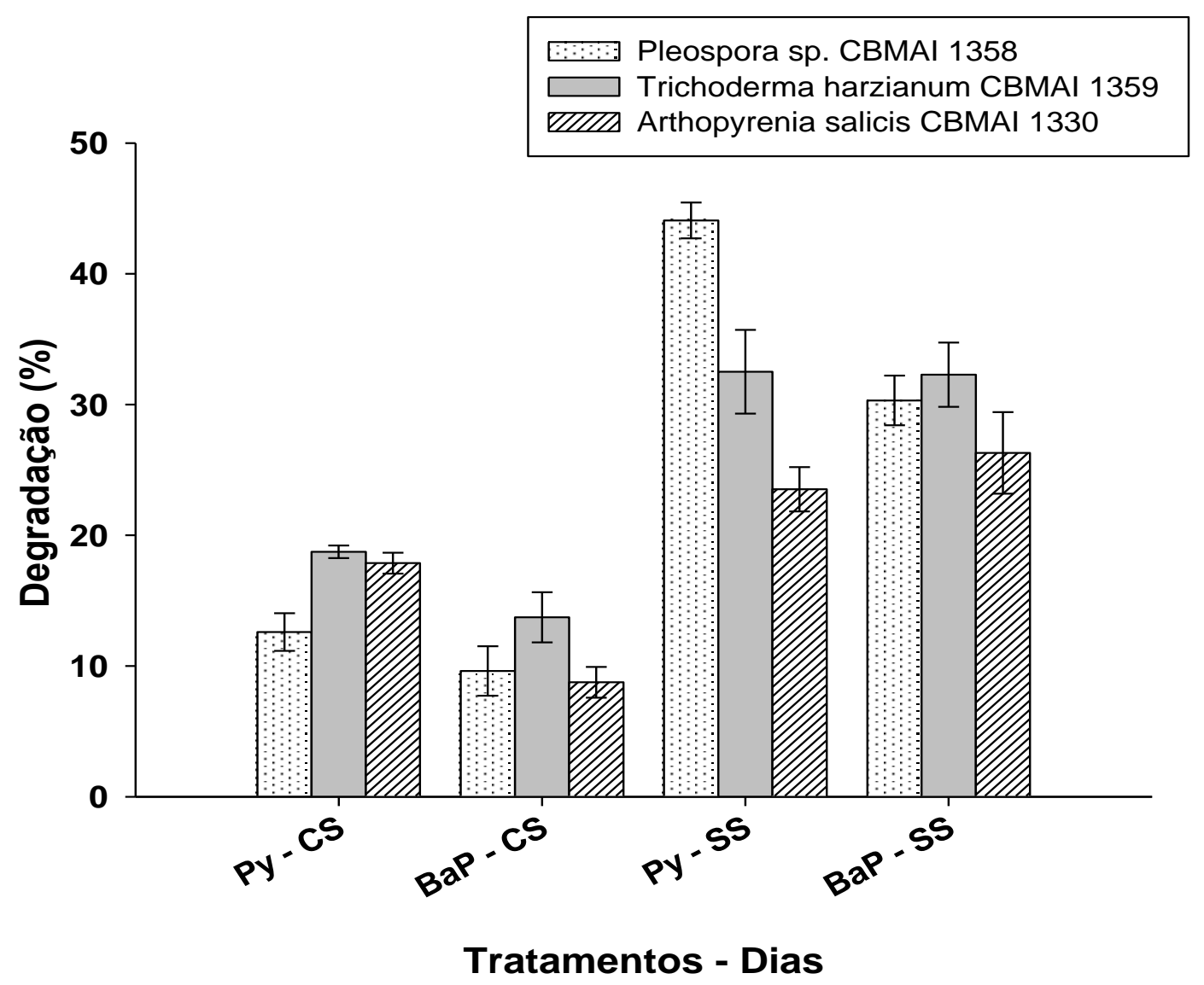

Figura 12. Degradação de pireno e benzo[a]pireno $\left(2 \mathrm{mg} \mathrm{mL}^{-1}\right)$ pelos fungos Pleospora sp. CBMAI 1358, Trichoderma harzianum CBMAl 1359 e Arthopyrenia salicis CBMAl 1330 em meio $\mathrm{MA} 2 \%+3 \% \mathrm{NaCl}$ (condição salina) e MA2\% (condição sem sal), após 7 dias de cultivo a $28^{\circ} \mathrm{C}$ e $140 \mathrm{rpm}$.

Considerando que nenhum dos três fungos selecionados foram capazes de degradar mais do que $50 \%$ dos HPAs estudados, quatro novos isolados foram selecionados (DRR 7-9, CeAC 2, DRR 4.1-6 e DRAC 1-9), com base nos resultados de screening em placa (intensidade da coloração marrom). Os novos isolados 
foram submetidos aos experimentos de degradação de pireno (Figura 13) nas mesmas condições dos ensaios anteriores.

Com exceção do isolado CeAC 2 todos os outros isolados selecionados (DRAC 1-9, DRR7-9 e DRR4.1-9) foram previamente identificados por Passarini et al. (2013) (Tabela 6).

Tabela 6. Identificação dos fungos derivados marinhos, número de depósito, código de origem e fonte de isolamento.

Número de Fonte (esponja) Identificação molecular
depósito/lsolado

\begin{tabular}{ccc}
\hline CBMAI 1464 (CeAC2) & Chelonaplysilla erecta & Xylaria sp. \\
CBMAI 1346 (DRR7-9) & Dragmacidon reticulatum & Chaunopycnis alba \\
CBMAI 1333 (DRAC1-9) & Dragmacidon reticulatum & Biatriospora sp. \\
CBMAI 1351 (DRR 4.1-6) & Dragmacidon reticulatum & Trichoderma viride \\
\hline
\end{tabular}

Os resultados de degradação do pireno revelaram que dois dos quatro isolados selecionados foram capazes de degradar mais do que $50 \%$ de pireno (2 mg.mL ${ }^{-1}$ ): DRR7 (9) e o CeAC 2, os quais apresentaram 66,28 \% e 55,74\% de degradação, respectivamente. Desta forma, estes isolados foram selecionados para os estudos subsequentes de degradação de HPAs, bem como avaliação da descoloração dos corantes PS e IB e da produção de enzimas ligninolíticas.

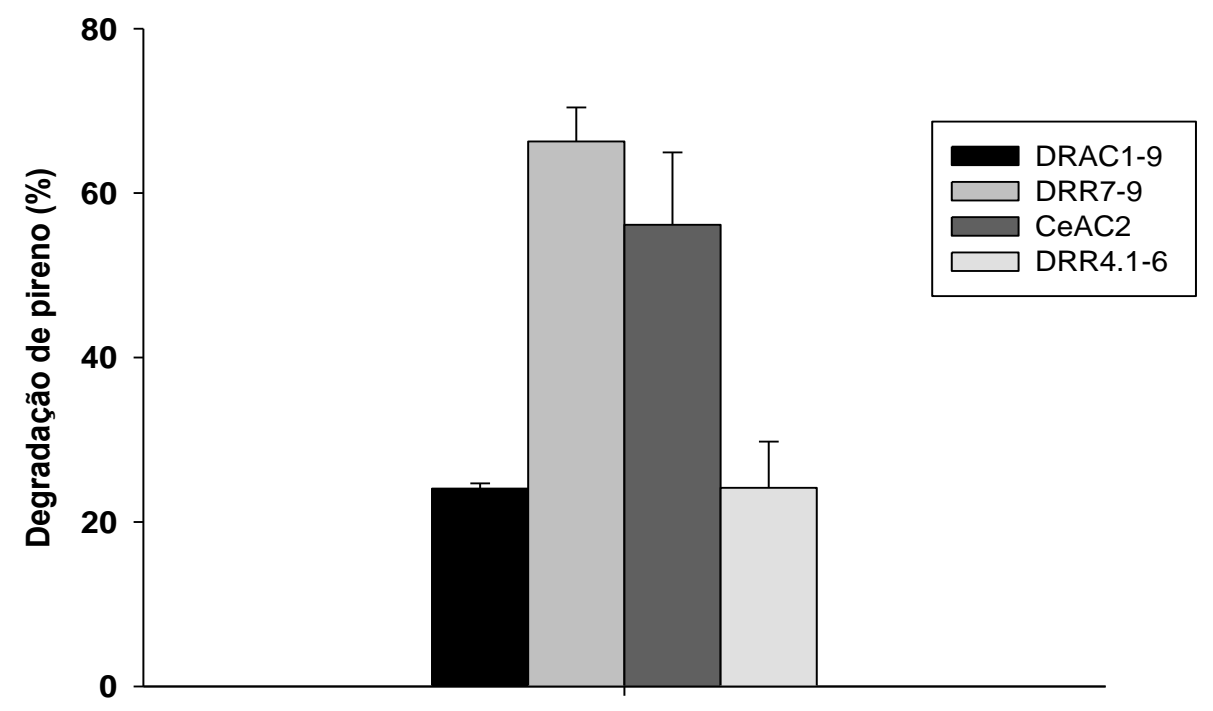

Figura 13. Degradação de pireno $\left(2 \mathrm{mg} \cdot \mathrm{mL}^{-1}\right)$ pelos isolados DRAC1-9, DRR7-9, CeAC 2 e DRR4.1-6 em meio MB2\% após 7 dias de cultivo a $28^{\circ} \mathrm{C}$ e $140 \mathrm{rpm}$. 


\subsection{Identificação molecular do isolado CeAC 2}

$\mathrm{O}$ isolado que ainda não havia sido identificado CeAC 2 e que apresentou $55,74 \%$ de degradação de pireno (Figura 13), foi submetido aos experimentos de taxonomia molecular. Os resultados permitiram a afiliação do mesmo ao gênero Xylaria, conforme apresentado na Figura 14. Para as análises filogenéticas foram utilizadas sequências de maior similaridade com as sequências obtidas do sequenciamento deste fungo e as recuperadas no banco de dados Genbank (www.ncbi.nlm.nih.gov) das coleções de culturas CBS, NRRL e CBMAI. Este fungo foi depositado como Xylaria sp. na Coleção Brasileira de Micro-organismos de Ambiente e Indústria (CBMAI) sob o número CBMAI 1464.

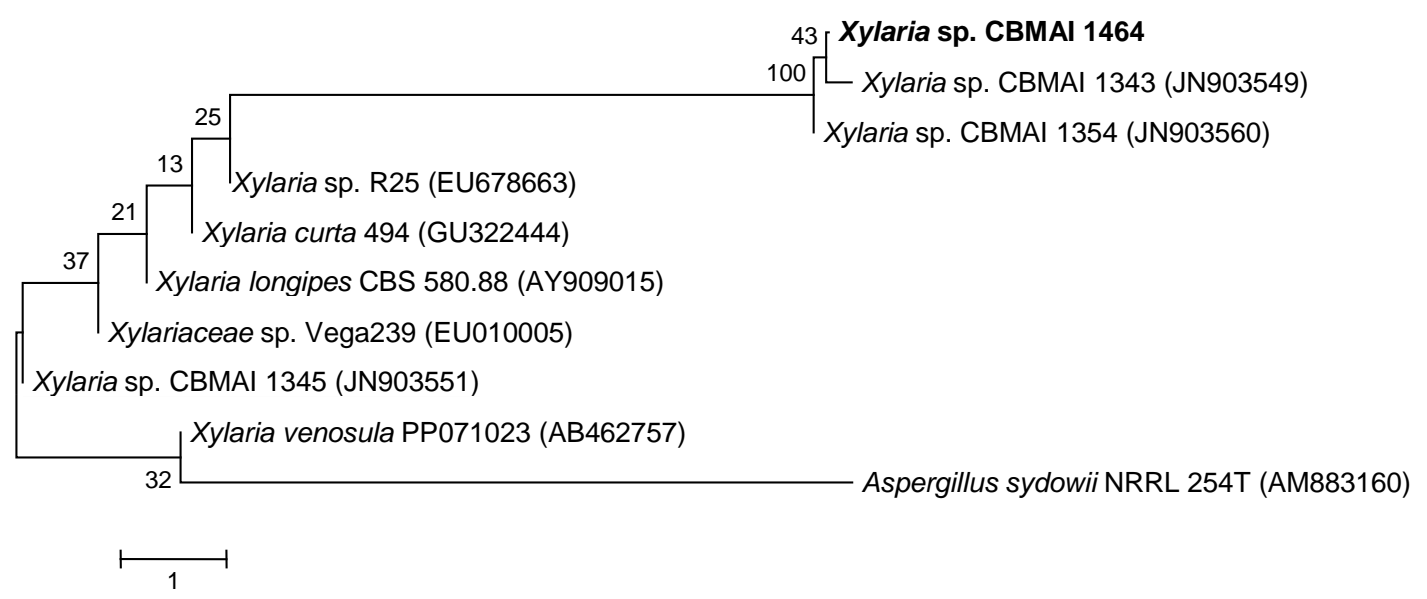

Figura 14. Análise filogenética de ITS-rDNA de Xylaria sp. CBMAI 1464 e de sequências de ITS-rDNA de fungos que apresentaram alta similaridade de sequência do marcador taxonômico utilizado. As distâncias evolutivas e a construção da árvore foram realiazadas pelo método Maximum Likelihood. Valores de bootstrap (1000 replicatas) estão mostrados na forma de \%.

\subsection{Degradação do HPA benzo[a]pireno pelos fungos Chaunopycnis alba CBMAI 1346 e Xylaria sp. CBMAI 1464}

Os fungos que apresentaram os melhores resultados na degradação de pireno (Figura 13), Chaunopycnis alba CBMAI 1346 (DRR 7-9) e Xylaria sp. CBMAI 1464 (CeAC 2), que apresentaram degradação de $66,28 \%$ e 55,74\% foram submetidos a ensaios de degradação de benzo[a]pireno nas mesmas condições dos ensaios de degradação de pireno. Segundo os dados apresentados (Figura 15), C. alba CBMAI 
1346 e Xylaria sp. CBMAI 1464 foram capazes de degradar 61,06\% e 88,16\% de $\mathrm{BaP}$, respectivamente.

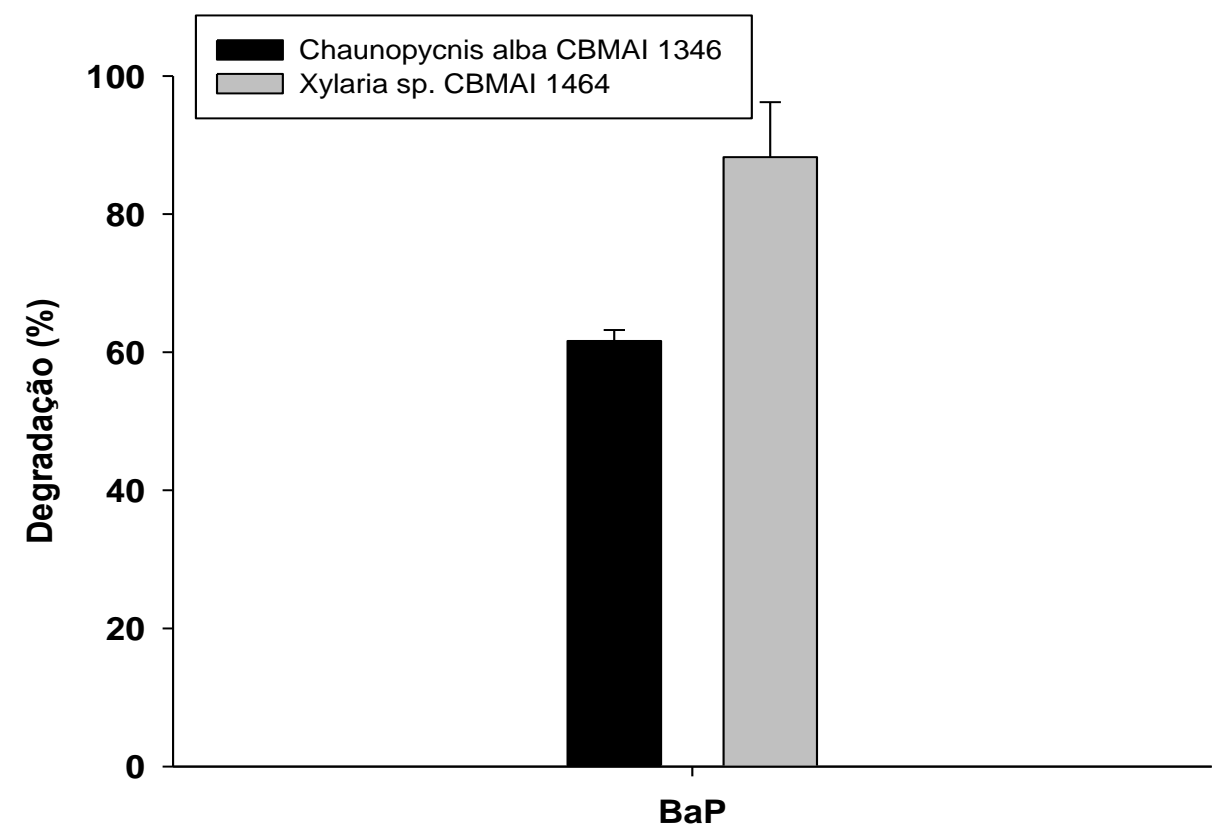

Figura 15. Degradação de benzo[a]pireno $\left(2 \mathrm{mg} \cdot \mathrm{mL}^{-1}\right)$ pelos fungos Chaunopycnis alba CBMAI 1346 e Xylaria sp. CBMAI 1330 em meio MB2\%, após 7 dias de cultivo a $28^{\circ} \mathrm{C}$ e 140 rpm.

Em estudos de degradação de HPAs conduzidos por Passarini et al. (2011b) o fungo Aspergillus sclerotiorum CBMAl 849, demonstrou degradação de pireno de $99,7 \%$ e benzo[a]pireno de $76,6 \%$ após 8 e 16 dias de cultivo, respectivamente. Em um estudo realizado por Chang et al. (2007) com 21 fungos, sete apresentaram capacidade para metabolizar HPAs e entre eles, Xylaria regalis foi o que exibiu a melhor performance degradando $99 \%$ de pireno $(10,2 \mu \mathrm{mol})$ e $90 \%$ de benzo[a]pireno $(4,84 \mu \mathrm{mol})$ em $48 \mathrm{~h}$. No presente estudo, ensaios de degradação de benzo[a]pireno $(\mathrm{BaP})$ também foram realizados com os isolados que evidenciaram um maior potencial de degradação de pireno. Os fungos DRR 7(9) e CeAC2 foram capaz de degradar 66,28 \% e 55,74 \% de BaP após 7 dias de cultivo, respectivamente.

\subsection{Avaliação da adsorção dos HPAs pireno e benzo[a]pireno pelos fungos Chaunopycnis alba CBMAl 1346 e Xylaria sp. CBMAl 1464}

Ensaios adicionais visando observar a ocorrência de adsorção micelial do pireno e benzo[a]pireno pelos fungos estudados foram realizados. Adsorção é a 
fixação de moléculas, geralmente de um fluxo líquido ou gasoso, na superfície de um sólido sem que as moléculas passem a fazer parte deste sólido, no caso dos fungos, esse processo é realizado pela biomassa morta.

Os fungos selecionados C. alba CBMAI 1346 e Xylaria sp. CBMAI 1464, não apresentaram adsorção micelial do pireno, enquanto que para o benzo[a]pireno apresentaram adsorção micelial de 68,96 \% e 83,06 \%, respectivamente (Figura 16). Com base nos resultados de adsorção, podemos sugerir que os fungos degradaram muito pouco do $\mathrm{BaP}$, pois a capacidade degradativa foi de $61,06 \%$ para Chaunopycnis alba CBMAI 1464 (sendo 68,96 \% adsorvido no micélio) e de 88,16\% para Xylaria sp. CBMAI 1464 (sendo 83,06 \% adsorvido no micélio).

Desta forma, os ensaios seguintes de atividade enzimática na presença dos corantes e dos HPAs pireno e benzo[a]pireno (seções 5.7 e 5.8), delineamentos experimentais (seção 5.10) e identificação de metabólitos (seção 5.9 e 5.12) foram realizados somente para o HPA pireno.

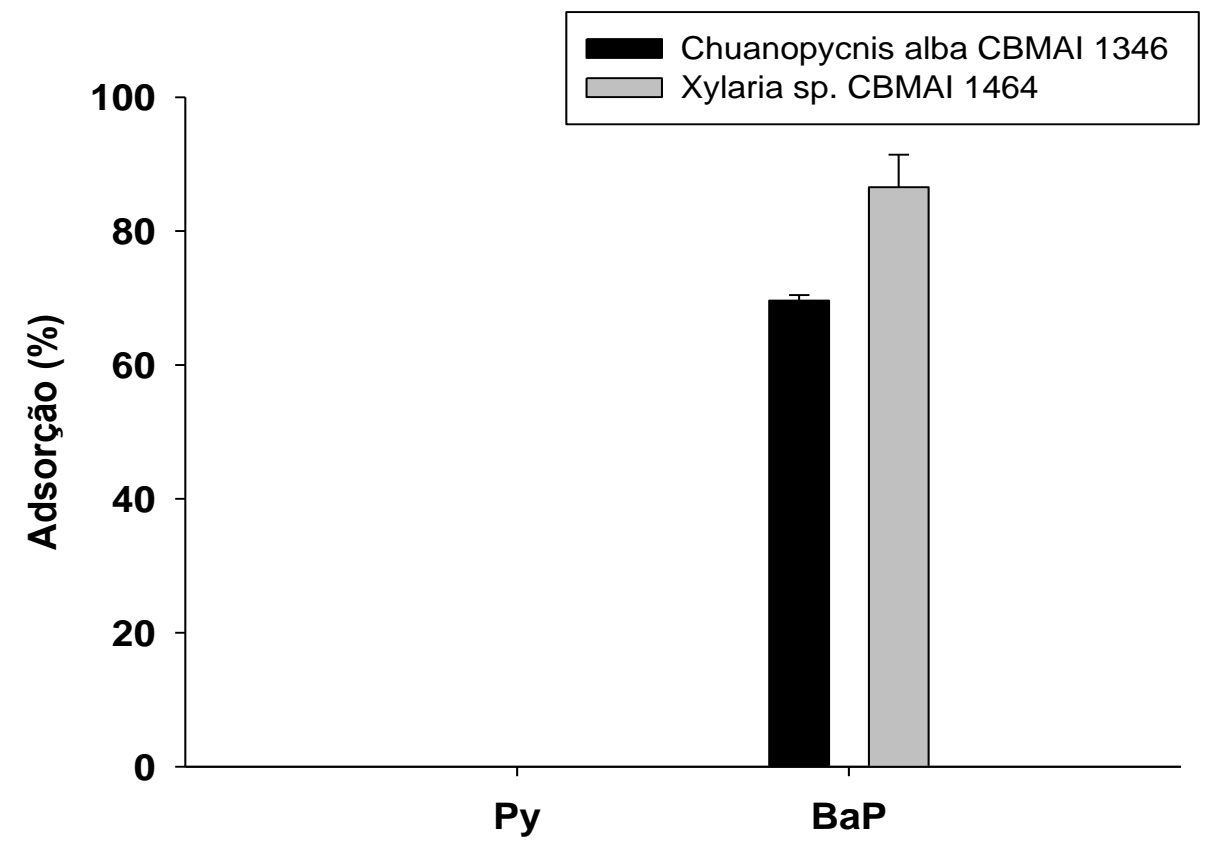

Figura 16. Adsorção (\%) dos HPAs pireno e benzo[a]pireno pelos micélios dos fungos Chaunopycnis alba CBMAl 1346 e Xylaria sp. CBMAl 1464. 
5.7 Avaliação da produção das enzimas ligninolíticas pelos fungos Chaunopycnis alba CBMAl 1346 e Xylaria sp. CBMAl 1464 em meio líquido suplementado com corantes

$\mathrm{Na}$ Figura 17, estão apresentados os valores de atividade enzimática de lacase (17A), MnP (17B) e LiP (17C) para os fungos Chaunoycnis alba CBMAl 1346 e Xylaria sp. CBMAI 1464, sem a presença de corante (SC), na presença dos corantes preto sulfuroso (PS) e índigo blue (IB).
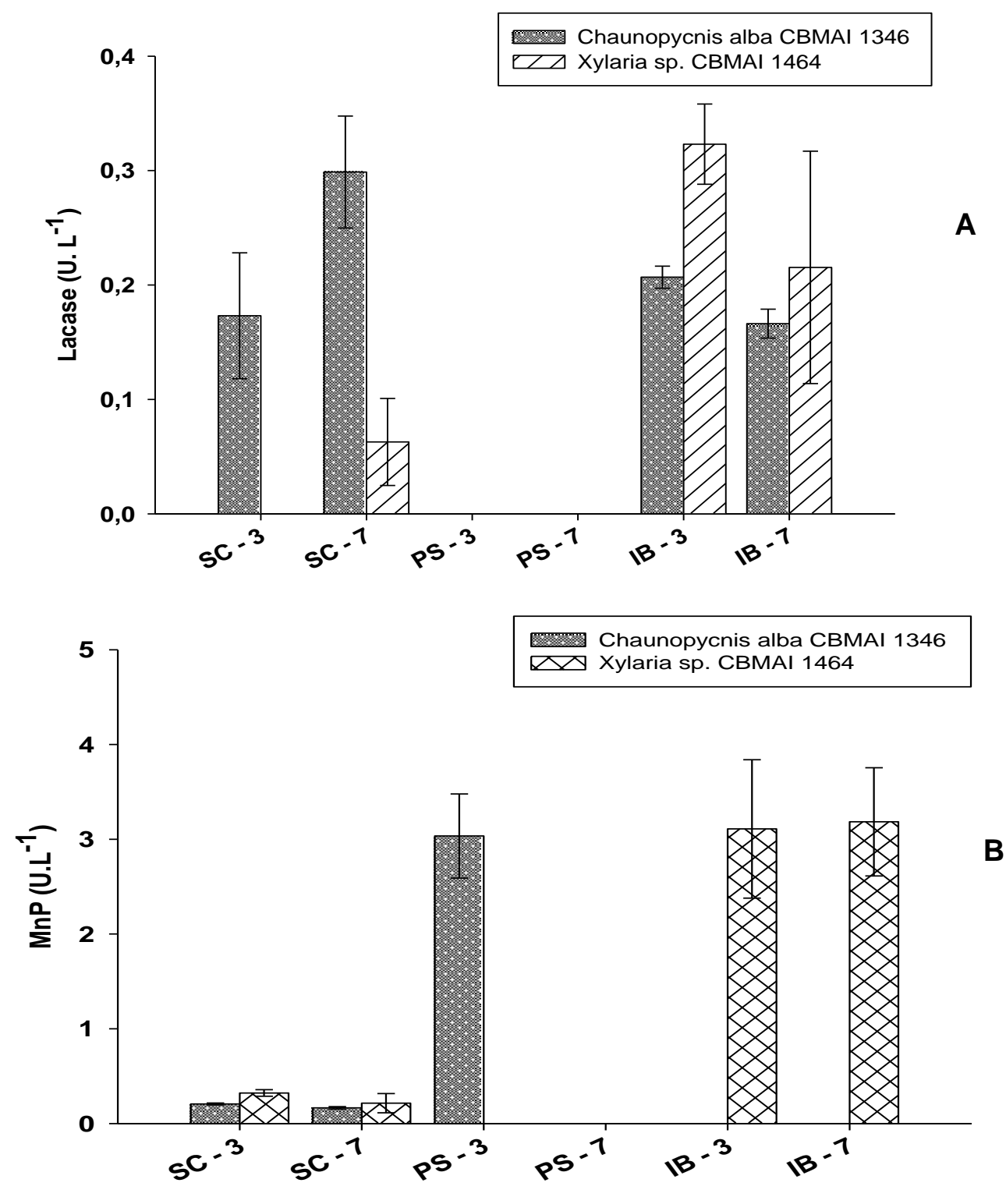


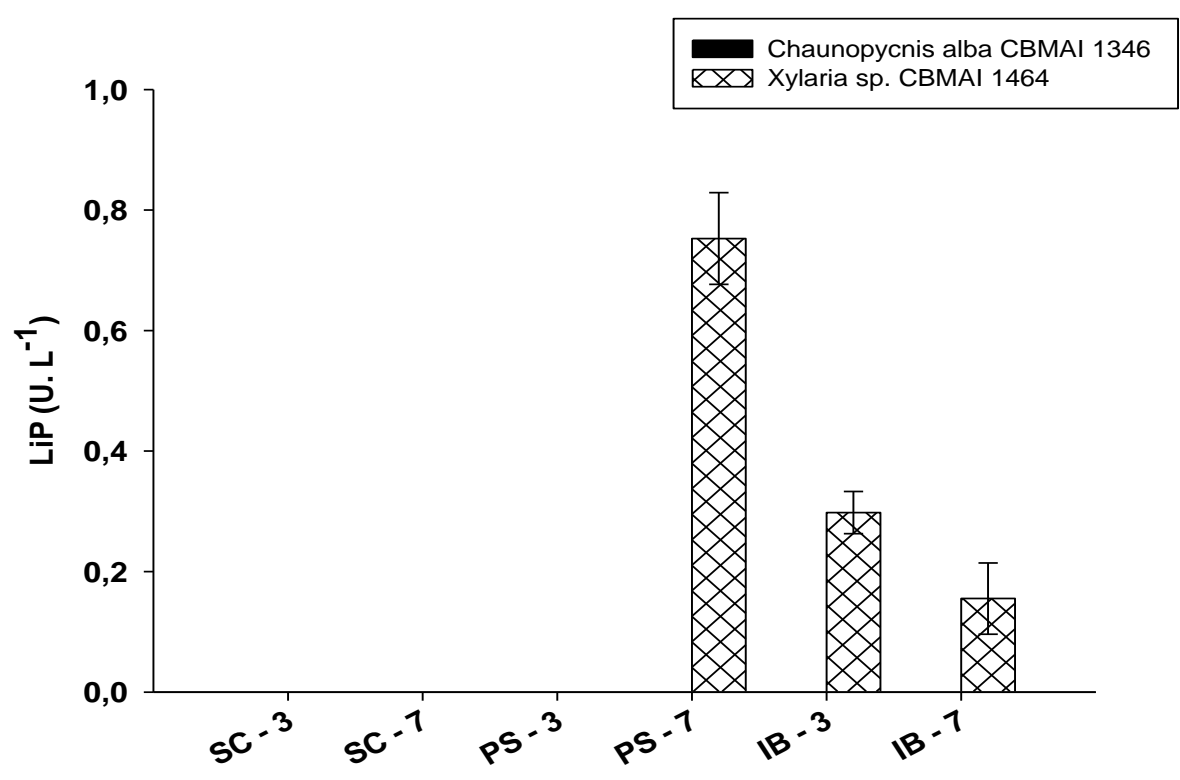

C

Figura 17. Atividade enzimática de lacase, MnP e LiP dos fungos Chaunopycnis alba CBMAI 1346 e Xylaria sp. CBMAI 1464, no meio líquido sem corante (SC), na presença dos corantes preto sulfuroso (PS) e índigo blue (IB), no $3^{\circ}$ e $7^{\circ}$ dia de cultivo em meio MB2\% $\left(28^{\circ} \mathrm{C}\right.$ e $\left.140 \mathrm{rpm}\right)$. A) Lacase, B) MnP, C) LiP.

O fungo C. alba CBMAI 1346 apresentou atividade enzimática em meio líquido sem corante $(\mathrm{SC})$, no $3^{\circ}\left(0,171 \mathrm{U} . \mathrm{L}^{-1}\right)$ e no $7^{\circ}$ dia $\left(0,312 \mathrm{U} . \mathrm{L}^{-1}\right)$, enquanto o fungo Xylaria sp. CBMAI 1464 nestas mesmas condições produziu menor quantidade de lacase e somente no $7^{\circ}$ dia de cultivo $\left(0,072 \mathrm{U} . \mathrm{L}^{-1}\right)$. Na presença do corante índigo blue (IB), C. alba CBMAI 1346 apresentou 0,212 e 0,174 U. L ${ }^{-1}$ no 3o e $7^{\circ}$ dia de cultivo, respectivamente e Xylaria sp. CBMAI 1464 alcançou maiores valores de atividade dessa enzima $\left(0,332\right.$ e 0,219 U. $L^{-1}$, no $3^{\circ}$ e $7^{\circ}$ dia de cultivo, respectivamente), sugerindo a indução da produção da mesma pelo corante índigo blue (IB). Em relação à enzima LiP, a mesma foi apenas produzida na presença dos corantes PS e IB e somente pelo fungo Xylaria sp. CBMAI 1464.

\subsection{Atividade enzimática dos fungos Chaunopycnis alba CBMAl 1346 e Xylaria sp. CBMAl 1464 na presença de pireno e benzo[a]pireno}

A produção enzimática de lacase, MnP e LiP dos fungos $C$. alba CBMAl 1346 e Xylaria sp CBMAI 1464 foi determinada em meio MB2\% com adição de pireno $\left(2 \mathrm{mg} \cdot \mathrm{mL}^{-1}\right)$ e benzo[a]pireno $\left(2 \mathrm{mg} \cdot \mathrm{mL}^{-1}\right)$ após 7 dias de cultivo, a $28{ }^{\circ} \mathrm{C} \mathrm{e}$ 140 rpm. Na Figura 17 estão apresentados os valores para a atividade das enzimas ligninolíticas produzidas por esses dois fungos em meio líquido adicionados de 
pireno (Figura 18A) e de benzo[a]pireno (Figura 18B) e sem adição dos HPAs (Figura 18C).

Nos ensaios de avaliação da atividade enzimática na presença de pireno, o fungo Chaunopycnis alba CBMAI 1346 apresentou 1,07 U.L-1 de lacase, 0,836 U.L-1 de MnP e 0,347 $\mathrm{U}^{-1}$ de LiP. Para o fungo Xylaria sp. CBMAI 1464 foram observados valores mais baixos de produção enzimática, sendo $0,136 \mathrm{U}$. $\mathrm{L}^{-1}$ de lacase, 0,783 U. $\mathrm{L}^{-1}$ de $\mathrm{MnP}$ e $0,159 \mathrm{U}$. $\mathrm{L}^{-1}$ de LiP. Na presença de $\mathrm{BaP}$, a produção enzimática para as enzimas estudadas foi mais alta para ambos os fungos, com destaque para a produção de 16,94 U. $L^{-1}$ de MnP pelo fungo Chaunopycnis alba CBMAl 1346 e 8,05 U. $\mathrm{L}^{-1}$ de MnP pelo Xylaria sp. CBMAl 1464. Lacase e LiP apresentaram valores próximos para ambos os fungos, sendo que para lacase os valores foram superiores aos obtidos em meio suplementado com pireno. Na ausência dos HPAS (Figura 17C), os fungos C. alba CBMAI 1346 e Xylaria sp. CBMAI 1464 não foram capazes de produzir LiP e apresentaram 0,299 U.L $L^{-1}$ e 0,062 U. $L^{-1}$ de atividade enzimática de lacase e $0,165 \mathrm{U} . \mathrm{L}^{-1}$ e $0,214 \mathrm{U} . \mathrm{L}^{-1}$ de atividade de $\mathrm{MnP}$, respectivamente. Assim, os resultados obtidos no presente estudo sugerem que as enzimas lacase, MnP e LiP, produzidas pelos fungos Chaunopycnis alba CBMAI 1346 e Xylaria sp. CBMAI 1464 foram estimuladas na presença dos HPAs e que possivelmente estejam envolvidas no processo de degradação dos HPAs estudados.

Hadibarata e Kristanti (2012) reportaram a produção de lacase, MnP e LiP durante a degradação de benzo[a]pireno. Os autores sugerem que estas enzimas possuem um papel importante na transformação deste composto, pois o processo de degradação foi observado após a produção das mesmas. 

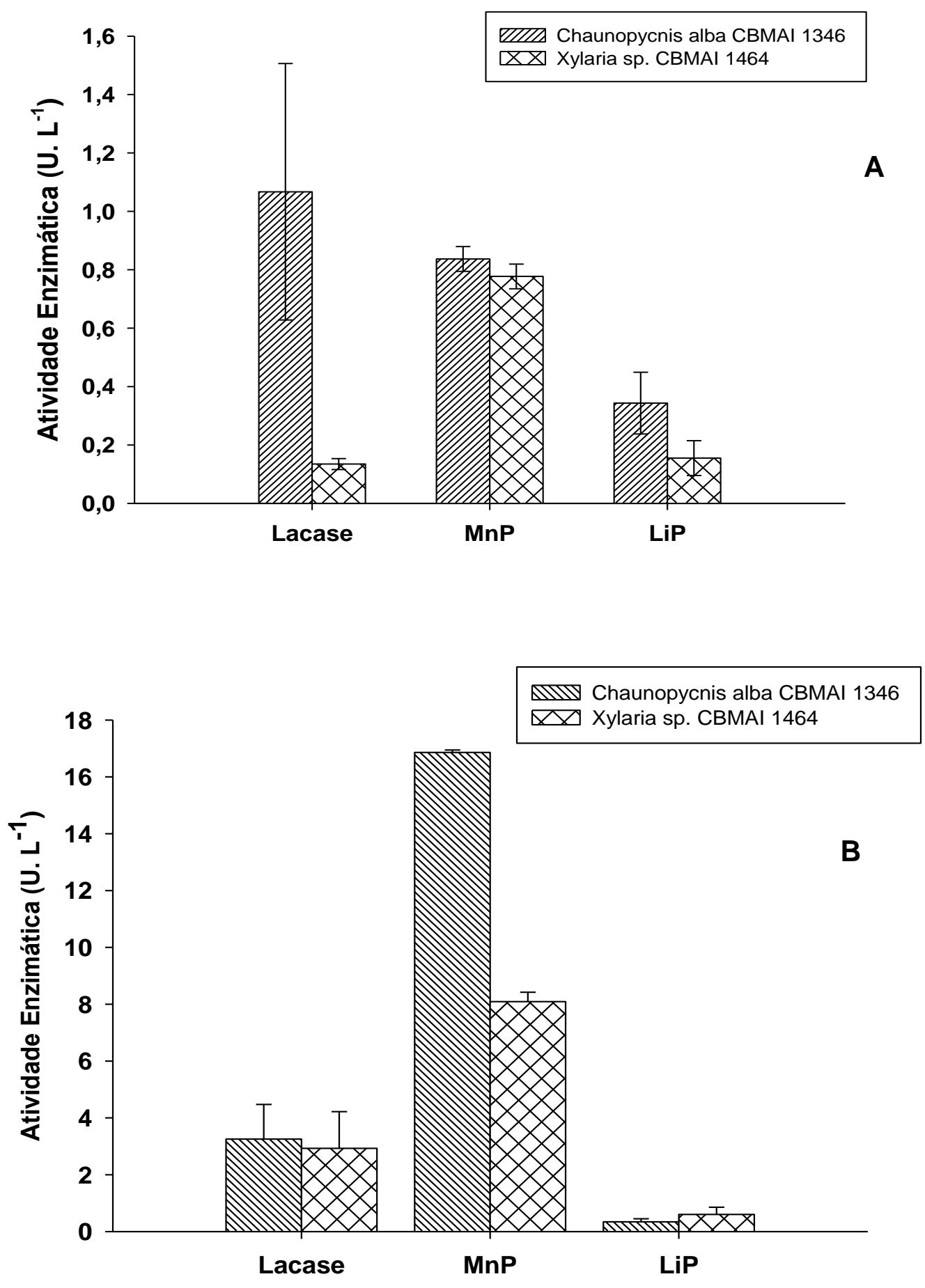


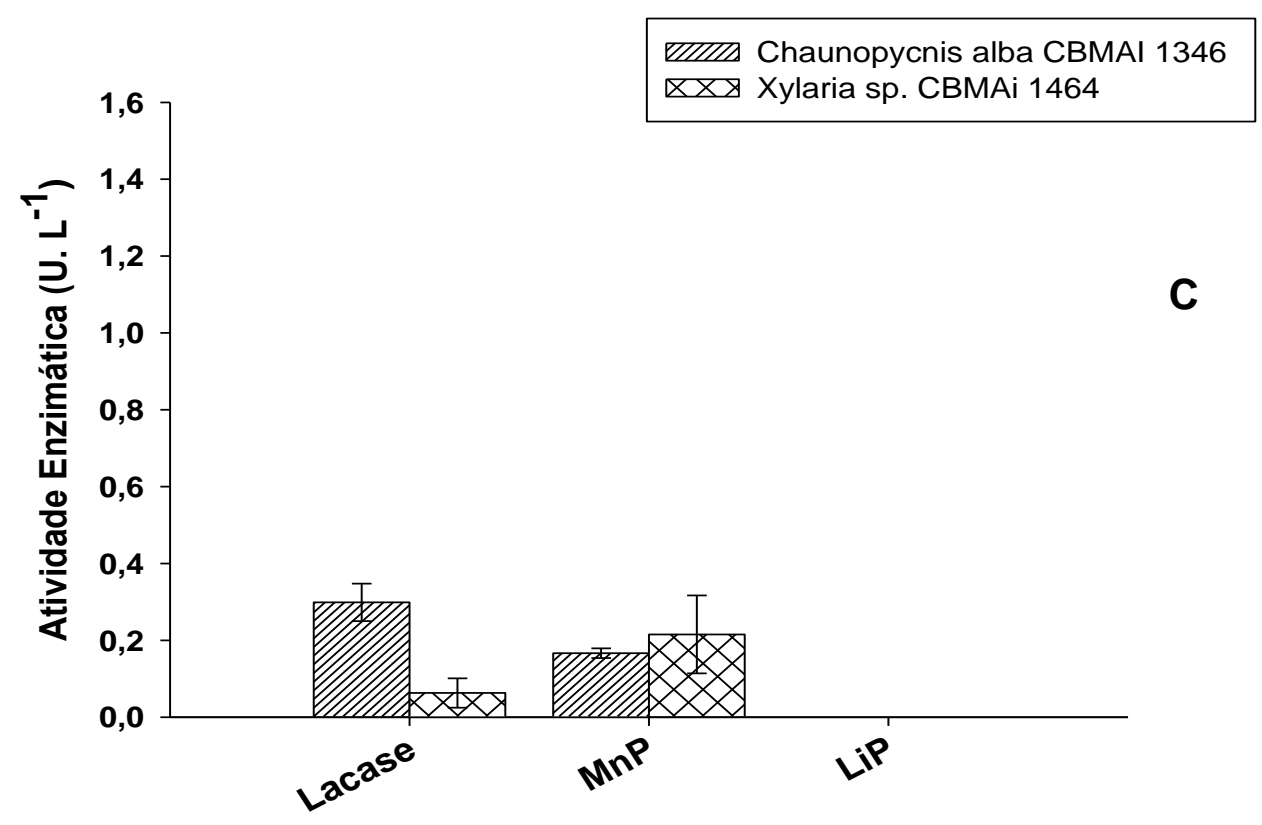

Figura 18. Atividade enzimática de lacase, MnP e LiP $\left(\mathrm{U}^{-1}\right)$ de Xylaria sp.CBMAl 1464 e Chaunopycnis alba CBMAI 1346 em meio MB2\%, A) adicionado com Py $\left(2 \mathrm{mg} \cdot \mathrm{mL}^{-1}\right)$, B) adicionado de BaP (2 mg. $\left.\mathrm{mL}^{-1}\right)$ e C) sem a presença dos HPAs, após 7 dias de cultivo a $28^{\circ} \mathrm{C}$ e $140 \mathrm{rpm}$.

De acordo com Wang et al. (2009) LiP e MnP devem ser as primeiras enzimas responsáveis pela degradação de HPAs em solo. No entanto, em estudos conduzidos com consórcio de basidiomicetos, que são os fungos capazes de degradar eficientemente a lignina, Anastasi et al. (2009) detectaram atividades baixas de MnP e LiP e nenhuma relação entre elas e a degradação de pireno foi encontrada. De acordo com Anastasi et al. (2009) não pode ser excluída a hipótese de que estas enzimas devem estar envolvidas na degradação de pireno, seja no início da reação de oxidação ou nos seguintes passos intermediários resultantes do primeiro ataque. Um estudo realizado com Crinipellis stipitaria revelou que a lacase foi produzida em meio líquido YMG após 3 dias de cultivo e esta enzima foi apontada como a responsável pela formação do metabólito pirenoquinona no meio de cultvo (LAMBERT et al., 1994).

\subsection{Identificação de metabólitos formados durante a degradação de pireno pelo fungo Chaunopycnis alba CBMAI 1346}

No presente estudo, análises preliminares de identificação dos metabólitos formados pelo fungo $C$. alba CBMAl 1346 durante a degradação do pireno foram realizadas por cromatografia gasosa e espectrometria de massas (GC-EM), visando 
a caracterização dos compostos formados, e verificação do potencial de toxicidade. Estas análises foram realizadas apenas para Chuanopycnis alba CBMAI 1346, pois ambos os fungos selecionados para o estudo fazem parte do mesmo grupo (Filo Ascomycota) e teoricamente envolveriam os mesmos mecanismos de degradação. Em adição, o fungo C. alba CBMAI 1346 apresentou 66,28\% de degradação, enquanto o fungo Xylaria sp. CBMAl 1464 apresentou 55,74\% (Figura 13).

Os picos obtidos no GC-EM foram identificados por comparação dos espectros de massas com os dados disponíveis na biblioteca do programa computacional NIST MS SEARCH versão 2.0 e pela interpretação dos padrões de fragmentação de cada composto comparativamente com dados descritos na literatura (LUAN et al., 2006; MAGRINI, 2012). Na Tabela 7 estão apresentados os íons monitorados nas análises realizadas no modo SIM na degradação de pireno pelo fungo $C$. alba CBMAl 1346, durante 7 dias de cultivo em meio MA2\%.

Tabela 7. Íons monitorados na detecção dos metabólitos formados na degradação de pireno pelo fungo $C$. alba CBMAl 1346: tempo de retenção e características da espectrometria de massas (MAGRINI, 2012).

\begin{tabular}{ccccc}
\hline $\mathbf{t}_{\mathbf{R}}(\mathbf{m i n})$ & İon molecular & $\begin{array}{c}\text { Íons de } \\
\text { confirmação } \\
(\mathbf{m} / \mathbf{z})\end{array}$ & $\begin{array}{c}\text { Composto } \\
\text { sugerido }\end{array}$ & $\begin{array}{c}\text { Composto } \\
\text { parental }\end{array}$ \\
\hline 38,521 & 218 & 189 & 1-hidroxipireno & pireno \\
40,987 & 236 & $218,189,176$ & pireno dihidrodiol & pireno \\
42,117 & 236 & $218,189,176$ & pireno dihidrodiol & pireno \\
44,019 & 234 & $176,218,189$ & dihidroxipireno & pireno \\
\hline
\end{tabular}

O cromatograma expandido no intervalo de $t_{R} 10$ min a 24 min no modo Scan, na degradação do pireno pelo fungo $C$. alba CBMAl 1346 após 7 dias de cultivo está apresentado da Figura 19. 


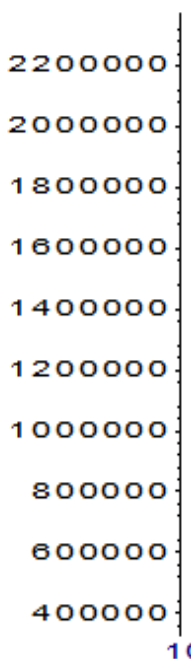

20000010.465

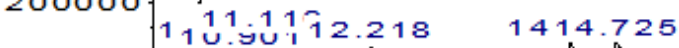

TIC: A.D d data.ms

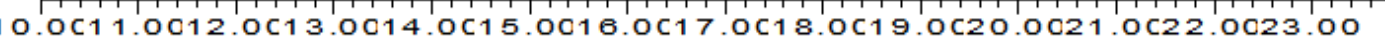

Time -->

Figura 19. Cromatograma expandido no intervalo de $t_{R} 10$ min a 24 min no modo Scan, na degradação do pireno pelo fungo $C$. alba CBMAI 1346 após 7 dias de cultivo a $28^{\circ} \mathrm{C}$ e 140 rpm.

Na Tabela 8 são apresentados os metabólitos resultantes (íons moleculares detectados) da degradação de pireno em meio $\mathrm{MB} 2 \%$ pelo fungo $C$. alba CBMAI 1346 após 7 dias de cultivo.

Tabela 8. Identificação dos metabólitos da degradação de pireno pelo fungo $C$. alba CBMAI 1346: tempo de retenção $\left(t_{R}\right)$ e características da espectrometria de massas.

\begin{tabular}{ccccc}
\hline Picos & $\mathbf{t}_{\mathbf{R}}(\mathbf{m i n})$ & $\begin{array}{c}\text { Íons moleculares } \\
(\mathbf{m} / \mathbf{z})\end{array}$ & Compostos sugeridos & $\begin{array}{c}\text { Abundância } \\
\text { relativa (\%) }\end{array}$ \\
\hline $\mathbf{1}$ & 10,46 & 192 & Mono-hidroxifenantreno & 6,70 \\
$\mathbf{2}$ & 10,68 & 192 & Mono-hidroxifenantreno & 2,23 \\
$\mathbf{3}$ & 10,90 & $220,192,172$ & Lactona & 0,77 \\
$\mathbf{4}$ & 11,11 & $192,182,129$ & Mono-hidroxifenantreno & 2,65 \\
$\mathbf{5}$ & 11,82 & 206,191 & $\mathrm{NI}^{*}$ & 1,38 \\
$\mathbf{6}$ & 12,21 & 198 & $\mathrm{NI}^{*}$ & 2,16 \\
$\mathbf{7}$ & 14,25 & 256,213 & $\mathrm{NI}^{*}$ & 1,69 \\
$\mathbf{8}$ & 17,25 & 280,256 & $\mathrm{NI}^{*}$ & 1,51 \\
$\mathbf{9}$ & 17,54 & 202,101 & $\mathrm{Pireno}^{*}$ & 77,73 \\
$\mathbf{1 0}$ & 18,85 & 280,256 & $\mathrm{NI}^{*}$ & 0,75 \\
$\mathbf{1 1}$ & 23,57 & 218,189 & Dihidroxipireno & 2,39 \\
\hline
\end{tabular}

${ }^{\star} \mathrm{NI}$ - Não Identificado 
Os resultados das análises por CG-EM possibilitaram a verificação da presença de pireno e de diversos metabólitos, dentre os quais foram identificados o mono-hidroxifenantreno $(\mathrm{MM}=192)$ com $11,58 \%$ de abundância relativa, dihidroxipireno $(\mathrm{MM}=218) \mathrm{com} 2,39 \%$ e lactona ( $\mathrm{MM}=220$ ) com $0,77 \%$. Estes compostos também foram encontrados por Luan et al. (2006) na degradação de pireno utilizando consórcio bacteriano, após 7, 14 e 21 dias de cultivo. Em estudos anteriores do nosso grupo de pesquisa o composto dihidroxipireno foi detectado em resíduo resultante da degradação de pireno pelo basidiomiceto de origem marinha Marasmiellus sp. CBMAI 1062, após 5 e 15 dias de cultivo (MAGRINI, 2012). Passarini et al. (2011) demonstraram que Aspergillus sclerotium CBMAl 849, um ascomiceto, e Mucor racemosus CBMAI 847, um zigomiceto, foram capazes de metabolizar pireno em pirenilsulfato e metabolizar benzo[a]pireno a benzo[a]pirenilsulfato, sugerindo que o mecanismo utilizado por estes fungos é mediado pelo sistema citocromo P-450 monooxigenase, seguido pela conjugação íons sulfato. Os metabólitos 5, 6, 7, 8 e 10 não puderam ser identificados de acordo com os íons moleculares encontrados.

$\mathrm{Na}$ Figura 20 estão apresentadas as estruturas químicas dos compostos encontrados no modo de varredura (Scan) resultantes do processo de degradação de pireno pelo fungo $C$. alba CBMAl 1346 em ensaios conduzidos por 7 dias.<smiles>c1cc2ccc3cccc4ccc(c1)c2c34</smiles>

Pireno $(M M=202)$<smiles>OC1c2cccc3ccc4cccc(c4c23)C1O</smiles>

Dihidroxipireno $(\mathrm{MM}=236)$<smiles>O=c1oc2cccc3ccc4cccc1c4c32</smiles>

Lactona $(\mathrm{MM}=220)$<smiles>Oc1cccc2ccc3ccccc3c12</smiles>

Hidroxifenantreno $(\mathrm{MM}=192)$ 
Figura 20. Estruturas químicas de compostos resultantes da degradação de pireno pelo fungo $C$. alba CBMAI 1346, após 7 dias de cultivo a $28 \stackrel{\circ}{\mathrm{C}}$ e $140 \mathrm{rpm}$.

A Figura 21 apresenta o cromatograma modo SIM expandido ( $t_{R} 37$ a 42,5 min) dos metabólitos formados na degradação de pireno pelo fungo $C$. alba CBMAI 1346. A análise da amostra no modo SIM evidenciou a presença de dois compostos com tempo de retenção 38,322 e 38,535 min. Estes compostos foram identificados como hidroxipirenos $(\mathrm{MM}=218)$, no entanto, a posição da hidroxila não foi determinada. O hidroxipireno, principal metabólito do pireno, é carcinogênico e pouco solúvel em água (HWANG et al., 2001). Estudos com os fungos Crinipellis stipitaria e Cunninghamella elegans apontaram 1-hidroxipireno e pirenoquinonas como produtos metabólicos do pireno (CERNIGLIA et al., 1986; LAMBERT et al., 1994), no entanto, este último também pode produzir metabólitos não tóxicos (conjugados glicosídicos) (CERNIGLIA et al., 1986). Os espectros de massas desses compostos estão apresentados nas Figuras 22 e 23.

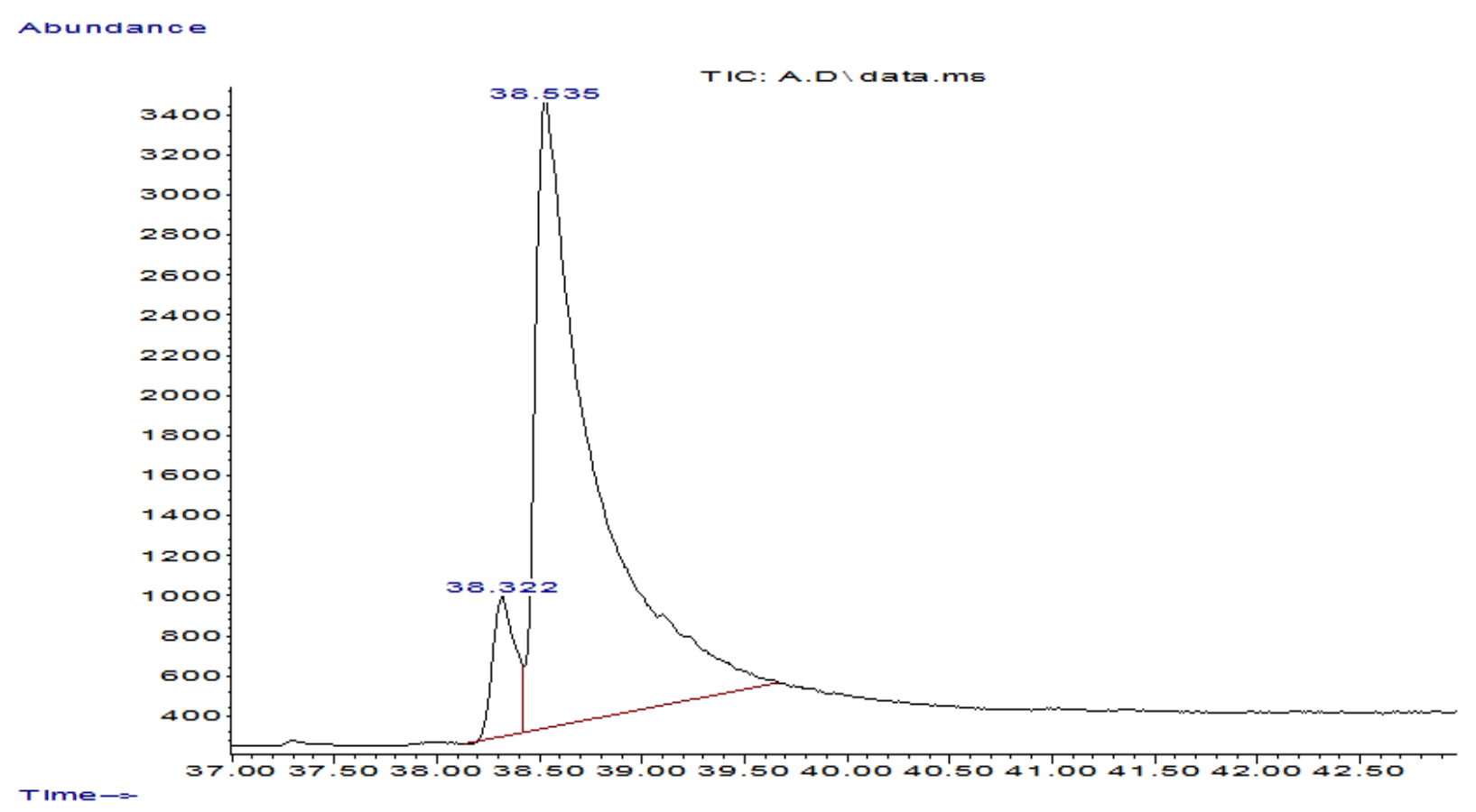

Figura 21. Cromatograma modo SIM dos metabólitos formados na degradação de pireno pelo fungo C.alba CBMAI 1346, após 7 dias de cultivo a $28^{\circ} \mathrm{C}$ e $140 \mathrm{rpm}$. 


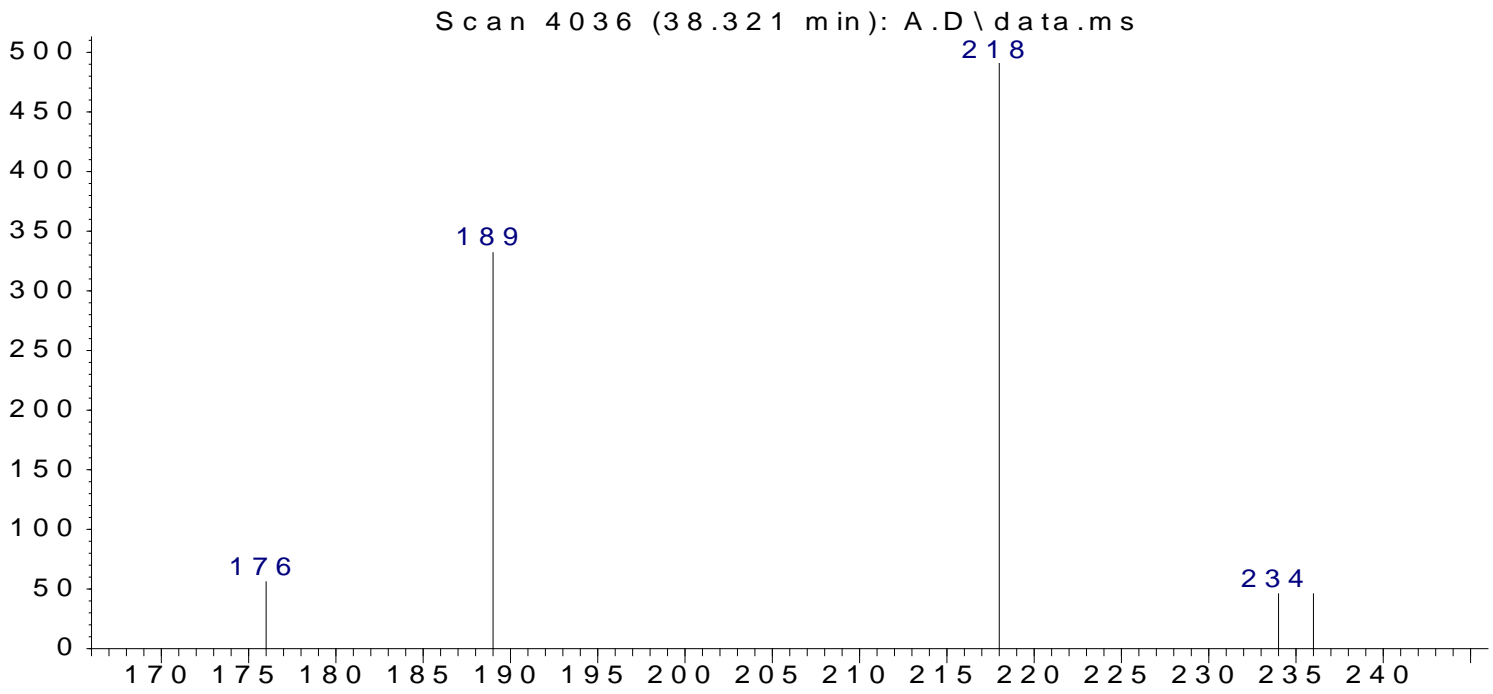
$\mathrm{m} / \mathrm{z}-\mathrm{s}$

Figura 22. Perfil cromatográfico dos metabólitos formados pela degradação do pireno por $\mathrm{C}$. alba CBMAI 1346 após 7 dias de cultivo ( $t_{R} 38,321 \mathrm{~min}$ ).

A bundance

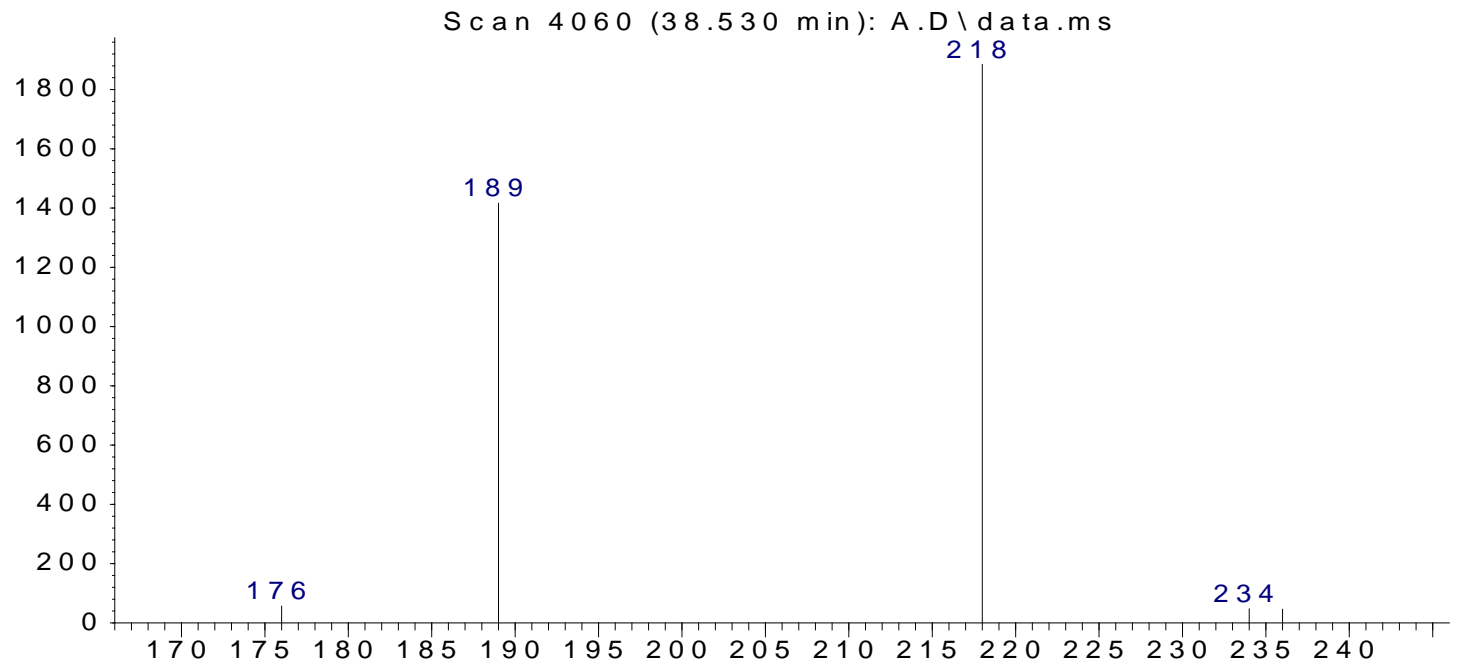
$\mathrm{m} / \mathrm{z}-\mathrm{s}$

Figura 23. Perfil cromatográfico dos metabólitos formados pela degradação do pireno por $C$. alba CBMAI 1346, após 7 dias de cultivo ( $\left.\mathrm{t}_{\mathrm{R}} 38,530 \mathrm{~min}\right)$.

$\mathrm{Na}$ análise dos perfis cromatográficos da amostra no modo SIM, o metabólito mais abundantemente identificado e seu padrão de espectro de massas é característico do composto hidroxipireno (Tabela 7, Figuras 22 e 23). Este metabólito também foi encontrado abundantemente na degradação de pireno pelo fungo de origem marinha Marasmiellus sp. CBMAl 1062 após 5 e 15 dias de cultivo (MAGRINI, 2012). 
Os compostos gerados pela degradação de pireno pelo fungo $C$. alba CBMAI 1346, detectados no presente estudo por GC-EM no modo Scan, podem apresentar toxicidade ou não (lactona). Os íons detectados no modo SIM sugerem hidroxipirenos, que são os principais metabólitos da degradação de pireno, evidenciando $\mathrm{o}$ ataque às moléculas deste composto pelo fungo estudado. Os metabólitos formados a partir do metabolismo de pireno pelas enzimas ligninolíticas (como as pirenoquinonas) não foram detectados. A identificação de metabólitos é frequentemente dificultada pela baixa concentração dos mesmos, por esta razão, nos ensaios conduzidos, outros metabólitos provavelmente presentes podem não ter sido identificados. Ensaios com maior tempo de degradação de HPAs podem permitir a identificação de outros compostos (LUAN et al., 2006).

\section{10 Delineamento experimental de Plackett-Burman para a otimização da degradação de pireno pelos fungos Chaunopycnis alba CBMAl 1346 e Xylaria sp. CBMAl 1464}

Visando a otimização da degradação de pireno pelo fungos selecionados Chaunopycnis alba CBMAl 1346 e Xylaria sp. CBMAI 1464, um planejamento experimental foi estabelecido. Primeiramente foi utilizado o delineamento de Plackett-Burman (PB) objetivando avaliar a influência de 9 variáveis (Tabela 9) na degradação de pireno após 7 dias de cultivo a $28{ }^{\circ} \mathrm{C}$ e $140 \mathrm{rpm}$, totalizando 20 ensaios (PB20).

Os resultados do PB (Tabela 9) demonstraram que os ensaios 5 e 7 apresentaram as melhores valores de degradação $(74,78 \%$ e $79,39 \%$, respectivamente) de pireno pelo fungo C. alba CBMAI 1346. 
Tabela 9. Degradação de pireno (\%), valores reais e codificados da matriz do delineamento de Plackett-Burman com 9 variáveis, no total de 20 ensaios (PB20) para o fungo Chaunopycnis alba CBMAI 1346.

1. pH 2. Salinidade 3. Glicose 4. Extrato de 5. Peptona

Ensaios $(\%)$ $\left(\mathrm{g} \mathrm{L}^{-1}\right) \quad$ Malte $\left(\mathrm{g} \mathrm{L}^{-1}\right)$ (g L-1)

6. Extrato de

7. Indutor

8. Indutor $\mathrm{MnSO}_{4}$ ) (Lacase -

9. Inóculo (cilindros

Degradação Levedura $L^{-1}$ )

\begin{tabular}{|c|c|c|c|c|c|c|c|c|c|c|}
\hline 1 & $7(1)$ & $0(-1)$ & $0(-1)$ & $0(-1)$ & $0,1 \mathrm{~g}(1)$ & $0(-1)$ & $0(-1)$ & $\begin{array}{c}4 \mathrm{mM}(2 \mathrm{~mL}) \\
-\mathrm{H}(1)\end{array}$ & $4(1)$ & 6,67 \\
\hline 2 & $7(1)$ & $35 \%$ \% (-1) & $0(-1)$ & $0(-1)$ & $0(-1)$ & $0,1 \mathrm{~g}(1)$ & $0(-1)$ & $0(-1)$ & $4(1)$ & 11,83 \\
\hline 3 & $7(1)$ & $35 \%$ (1) & $0,25 \mathrm{~g}(1)$ & $0(-1)$ & $0(-1)$ & $0(-1)$ & $\begin{array}{c}4 \mathrm{mM}(2 \mathrm{ml})- \\
\mathrm{ASW}(1)\end{array}$ & $0(-1)$ & $2(-1)$ & 15,78 \\
\hline 4 & $7(1)$ & $35 \%$ (1) & $0,25 \mathrm{~g}(1)$ & $0,2 \mathrm{~g}(1)$ & $0(-1)$ & $0(-1)$ & $0(-1)$ & $\begin{array}{c}4 \mathrm{mM}(2 \mathrm{~mL}) \\
-\mathrm{ASW}(1)\end{array}$ & $2(-1)$ & 8,19 \\
\hline 5 & $9(-1)$ & $35 \%$ (1) & $0,25 \mathrm{~g}(1)$ & $0,2 \mathrm{~g}(1)$ & $0,1 \mathrm{~g}(1)$ & $0(-1)$ & $0(-1)$ & $0(-1)$ & $4(1)$ & 74,78 \\
\hline 6 & $7(1)$ & $0(-1)$ & $0,25 g(1)$ & $0,2 \mathrm{~g}(1)$ & $0,1 \mathrm{~g}(1)$ & $0,1 \mathrm{~g}(1)$ & $0(-1)$ & $0(-1)$ & $2(-1)$ & 68,45 \\
\hline 7 & $9(-1)$ & $35 \%$ (1) & $0(-1)$ & $0,2 \mathrm{~g}(1)$ & $0,1 \mathrm{~g}(1)$ & $0,1 \mathrm{~g}(1)$ & $\begin{array}{c}4 \mathrm{mM}(2 \mathrm{ml}) \\
-\mathrm{ASW}(1)\end{array}$ & $0(-1)$ & $2(-1)$ & 79,39 \\
\hline 8 & $7(1)$ & $0(-1)$ & $0,25 \mathrm{~g}(1)$ & $0(-1)$ & $0,1 \mathrm{~g}(1)$ & $0,1 \mathrm{~g}(1)$ & $\begin{array}{c}4 \mathrm{mM}(2 \mathrm{ml}) \\
-\mathrm{H}(1)\end{array}$ & $\begin{array}{c}4 \mathrm{mM}(2 \mathrm{~mL}) \\
-\mathrm{H}(1)\end{array}$ & $2(-1)$ & 11,69 \\
\hline 9 & $7(1)$ & $35 \%$ (1) & $0(-1)$ & $0,2 \mathrm{~g}(1)$ & $0(-1)$ & $0,1 \mathrm{~g}(1)$ & $\begin{array}{c}4 \mathrm{mM}(2 \mathrm{ml}) \\
\operatorname{ASW}(1)\end{array}$ & $\begin{array}{c}4 \mathrm{mM}(2 \mathrm{~mL}) \\
\mathrm{ASW}(1)\end{array}$ & $4(1)$ & 39,39 \\
\hline 10 & $9(-1)$ & $35 \%$ (1) & $0,25 \mathrm{~g}(1)$ & $0(-1)$ & $0,1 \mathrm{~g}(1)$ & $0(-1)$ & $\begin{array}{c}4 \mathrm{mM}(2 \mathrm{ml}) \\
\mathrm{ASW}(1)\end{array}$ & $\begin{array}{c}4 \mathrm{mM}(2 \mathrm{~mL}) \\
\mathrm{ASW}(1)\end{array}$ & $4(1)$ & 8,04 \\
\hline 11 & $9(-1)$ & $0(-1)$ & $0,25 \mathrm{~g}(1)$ & $0,2 \mathrm{~g}(1)$ & $0(-1)$ & $0,1 \mathrm{~g}(1)$ & $0(-1)$ & $\begin{array}{c}4 \\
\mathrm{mM}(2 \mathrm{~mL})- \\
\mathrm{H}(1)\end{array}$ & $4(1)$ & 5,82 \\
\hline 12 & $7(1)$ & $0(-1)$ & $0(-1)$ & $0,2 \mathrm{~g}(1)$ & $0,1 \mathrm{~g}(1)$ & $0(-1)$ & $\begin{array}{c}4 \mathrm{mM}(2 \mathrm{ml})- \\
\mathrm{H}(1)\end{array}$ & $0(-1)$ & $4(1)$ & 52,85 \\
\hline 13 & $9(-1)$ & $35 \%$ (1) & $0(-1)$ & $0(-1)$ & $0,1 \mathrm{~g}(1)$ & $0,1 \mathrm{~g}(1)$ & $0(-1)$ & $\begin{array}{c}4 \mathrm{mM}(2 \mathrm{~mL}) \\
\mathrm{ASW}(1)\end{array}$ & $2(-1)$ & 36,36 \\
\hline 14 & $9(-1)$ & $0(-1)$ & $0,25 g(1)$ & $0(-1)$ & $0(-1)$ & $0,1 \mathrm{~g}(1)$ & $\begin{array}{c}4 \mathrm{mM}(2 \mathrm{ml})- \\
\mathrm{H}(1)\end{array}$ & $0(-1)$ & $4(1)$ & 23,98 \\
\hline
\end{tabular}




\begin{tabular}{|c|c|c|c|c|c|c|c|c|c|c|}
\hline 15 & $9(-1)$ & $0(-1)$ & $0(-1)$ & $0,2 \mathrm{~g}(1)$ & $0(-1)$ & $0(-1)$ & $\begin{array}{c}4 \mathrm{mM}(2 \mathrm{ml}) \\
\mathrm{H}(1)\end{array}$ & $\begin{array}{c}4 \mathrm{mM}(2 \mathrm{~mL}) \\
\mathrm{H}(1)\end{array}$ & $2(-1)$ & 16,29 \\
\hline 16 & $9(-1)$ & $0(-1)$ & $0(-1)$ & $0(-1)$ & $0(-1)$ & $0(-1)$ & $0(-1)$ & $0(-1)$ & $2(-1)$ & 15,61 \\
\hline 17 & $8(0)$ & $17,5 \%$ \% (0) & $0,125 \mathrm{~g}(0)$ & $0,1 \mathrm{~g}(0)$ & $0,05 g(0)$ & $0,05 \mathrm{~g}(0)$ & $\begin{array}{c}2 \mathrm{mM}(1 \mathrm{ml}) \\
\mathrm{H}(0)\end{array}$ & $\begin{array}{c}2 \mathrm{mM}(1 \mathrm{ml}) \\
\mathrm{H}(0)\end{array}$ & $3(0)$ & 28,53 \\
\hline 18 & $8(0)$ & $17,5 \%$ \% (0) & $0,125 \mathrm{~g}(0)$ & $0,1 \mathrm{~g}(0)$ & $0,05 g(0)$ & $0,05 \mathrm{~g}(0)$ & $\begin{array}{c}2 \mathrm{mM}(1 \mathrm{ml})- \\
\mathrm{H}(0)\end{array}$ & $\begin{array}{c}2 \mathrm{mM}(1 \mathrm{ml}) \\
\mathrm{H}(0)\end{array}$ & $3(0)$ & 27,71 \\
\hline 19 & $8(0)$ & $17,5 \%$ \% (0) & $0,125 \mathrm{~g}(0)$ & $0,1 \mathrm{~g}(0)$ & $0,05 g(0)$ & $0,05 g(0)$ & $\begin{array}{c}2 \mathrm{mM}(1 \mathrm{ml})- \\
\mathrm{H}(0)\end{array}$ & $\begin{array}{c}2 \mathrm{mM}(1 \mathrm{ml}) \\
\mathrm{H}(0)\end{array}$ & $3(0)$ & 20,68 \\
\hline $\begin{array}{c}\text { Control } \\
\text { e } \\
\text { negativ } \\
0\end{array}$ & $8(0)$ & $17,5 \%$ \% (0) & $0,125 \mathrm{~g}(0)$ & $0,1 \mathrm{~g}(0)$ & $0,05 g(0)$ & $0,05 g(0)$ & $\begin{array}{c}2 \mathrm{mM}(1 \mathrm{ml})- \\
\mathrm{H}(0)\end{array}$ & $\begin{array}{c}2 \mathrm{mM}(1 \mathrm{ml}) \\
\mathrm{H}(0)\end{array}$ & - & 0 \\
\hline
\end{tabular}


Os efeitos das variáveis utilizadas no delineamento experimental de PlackettBurman (PB20) estão apresentados na Figura 24.

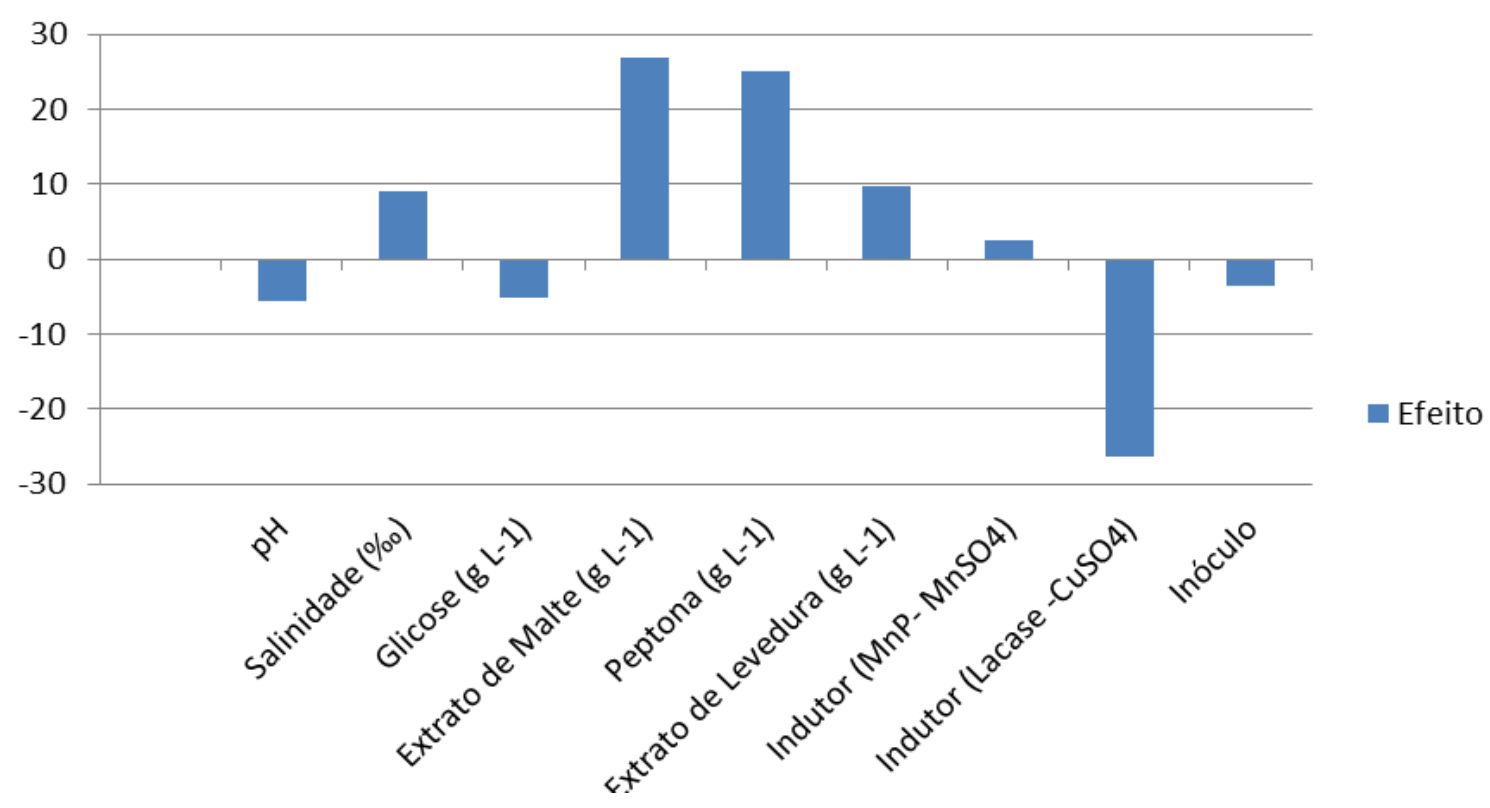

Figura 24. Efeito das variáveis estudadas no delineamento de Plackett-Burman (PB20) sobre o processo de degradação do fungo C. alba CBMAI 1346.

Para o fungo C. alba CBMAI 1464, as variáveis salinidade, concentrações de extrato de malte , peptona, extrato de levedura e indutor $\left(\mathrm{MnP}^{-} \mathrm{MnSO}_{4}\right)$ tiveram efeito positivo no processo de degradação de pireno (Figura 24), sendo significativas $(p<0,1)$ as variáveis salinidade, concentrações de extrato de malte, peptona e extrato de levedura (Tabela 10). A variável indutor de lacase $\left(\mathrm{CuSO}_{4}\right)$ foi significativa, no entanto teve efeito negativo no processo de degradação (Tabela 10, Figura 24). O efeito positivo das fontes de nitrogênio aponta que a degradação é fortemente influenciada por essas fontes. A salinidade foi uma das 4 variáveis de destaque dos efeitos positivos, sugerindo a halotolerância do fungo estudado. 
Tabela 10. Erro padrão e significância $(p<0,1)$ das variáveis estudadas no PB20 de $C$. alba CBMAI 1346.

\begin{tabular}{|c|c|c|}
\hline Variáveis & Erro padrão & $\mathrm{p}(<0,1)$ \\
\hline $\mathrm{pH}$ & 4,771361 & 0,264505 \\
\hline Salinidade (\%o) & 4,771361 & 0,090378 \\
\hline Glicose $\left(\mathrm{g} \mathrm{L}^{-1}\right)$ & 4,771361 & 0,303257 \\
\hline Extrato de Malte $\left(\mathrm{g} \mathrm{L}^{-1}\right)$ & 4,771361 & 0,000319 \\
\hline Peptona $\left(\mathrm{g} \mathrm{L}^{-1}\right)$ & 4,771361 & 0,000511 \\
\hline Extrato de Levedura $\left(\mathrm{g} \mathrm{L}^{-1}\right)$ & 4,771361 & 0,069310 \\
\hline Indutor $\left(\mathrm{MnP}-\mathrm{MnSO}_{4}\right)$ & 4,771361 & 0,618530 \\
\hline Indutor (Lacase -CuSO $\left.{ }_{4}\right)$ & 4,771361 & 0,000377 \\
\hline Inóculo & 4,771361 & 0,476133 \\
\hline
\end{tabular}

Os resultados do PB20 aplicado para o fungo Xylaria sp. CBMAI 1464 estão apresentados na Tabela 11. Os ensaios 5 e 6 foram os que apresentaram melhores valores de degradação (46 \% e 35,02 \%, respectivamente). 
Tabela 11. Degradação de pireno (\%), valores reais e codificados da matriz do delineamento de Plackett-Burman com 9 variáveis, no total de 20 ensaios (PB20) para o fungo Xylaria sp. CBMAI 1464.

\begin{tabular}{|c|c|c|c|c|c|c|c|c|c|c|}
\hline Ensaios & 1. $\mathrm{pH}$ & $\begin{array}{l}\text { 2. Salinidade } \\
(\%)\end{array}$ & $\begin{array}{l}\text { 3. Glicose } \\
\left(\mathrm{g} \mathrm{L}^{-1}\right)\end{array}$ & $\begin{array}{l}\text { 4. Extrato } \\
\text { de Malte } \\
\left(g^{-1}\right)\end{array}$ & $\begin{array}{l}5 . \\
\text { Peptona } \\
\text { (g L-1) }\end{array}$ & $\begin{array}{l}\text { 6. Extrato de } \\
\text { Levedura ( } g \\
\left.\mathrm{~L}^{-1}\right)\end{array}$ & $\begin{array}{l}\text { 7. Indutor } \\
\left(\mathrm{MnP}^{-}\right. \\
\left.\mathrm{MnSO}_{4}\right)\end{array}$ & $\begin{array}{l}\text { 8. Indutor } \\
\text { (Lacase - } \\
\text { CuSO }_{4} \text { ) }\end{array}$ & $\begin{array}{l}\text { 9. Inóculo } \\
\text { (cilindros } \\
5 \mathrm{~mm} \text { ) }\end{array}$ & Degradação (\%) \\
\hline 1 & $7(1)$ & $0(-1)$ & $0(-1)$ & $0(-1)$ & $0,1 \mathrm{~g}(1)$ & $0(-1)$ & $0(-1)$ & $\begin{array}{c}4 \\
\mathrm{mM}(2 \mathrm{~m} \\
\mathrm{L})(1)\end{array}$ & $4(1)$ & 18,65 \\
\hline 2 & $7(1)$ & $35 \%$ \% (-1) & $0(-1)$ & $0(-1)$ & $0(-1)$ & $0,1 \mathrm{~g}(1)$ & $0(-1)$ & $0(-1)$ & $4(1)$ & 21,18 \\
\hline 3 & $7(1)$ & $35 \%$ (1) & $0,25 \mathrm{~g}(1)$ & $0(-1)$ & $0(-1)$ & $0(-1)$ & $\begin{array}{c}4 \mathrm{mM}(2 \mathrm{ml}) \\
\mathrm{ASW}(1)\end{array}$ & $0(-1)$ & $2(-1)$ & 15,26 \\
\hline 4 & $7(1)$ & $35 \%$ (1) & $0,25 g(1)$ & $0,2 \mathrm{~g}(1)$ & $0(-1)$ & $0(-1)$ & $0(-1)$ & $\begin{array}{c}4 \\
\mathrm{mM}(2 \mathrm{~m} \\
\mathrm{L}) \\
\mathrm{ASW}(1)\end{array}$ & $2(-1)$ & 25,14 \\
\hline 5 & $9(-1)$ & $35 \%$ (1) & $0,25 \mathrm{~g}(1)$ & $0,2 \mathrm{~g}(1)$ & $0,1 \mathrm{~g}(1)$ & $0(-1)$ & $0(-1)$ & $0(-1)$ & $4(1)$ & 46,00 \\
\hline 6 & $7(1)$ & $0(-1)$ & $0,25 g(1)$ & $0,2 \mathrm{~g}(1)$ & $0,1 \mathrm{~g}(1)$ & $0,1 \mathrm{~g}(1)$ & $0(-1)$ & $0(-1)$ & $2(-1)$ & 35,02 \\
\hline 7 & $9(-1)$ & $35 \%$ (1) & $0(-1)$ & $0,2 \mathrm{~g}(1)$ & $0,1 \mathrm{~g}(1)$ & $0,1 \mathrm{~g}(1)$ & $\begin{array}{c}4 \mathrm{mM}(2 \mathrm{ml}) \\
\mathrm{ASW}(1)\end{array}$ & $0(-1)$ & $2(-1)$ & 24,00 \\
\hline 8 & $7(1)$ & $0(-1)$ & $0,25 \mathrm{~g}(1)$ & $0(-1)$ & $0,1 \mathrm{~g}(1)$ & $0,1 \mathrm{~g}(1)$ & $\begin{array}{c}4 \mathrm{mM}(2 \mathrm{ml}) \\
(1)\end{array}$ & $\begin{array}{c}4 \\
\mathrm{mM}(2 \mathrm{~m} \\
\mathrm{L})(1)\end{array}$ & $2(-1)$ & 19,22 \\
\hline 9 & $7(1)$ & $35 \%$ (1) & $0(-1)$ & $0,2 \mathrm{~g}(1)$ & $0(-1)$ & $0,1 \mathrm{~g}(1)$ & $\begin{array}{c}4 \mathrm{mM}(2 \mathrm{ml}) \\
\mathrm{ASW}(1)\end{array}$ & $\begin{array}{c}4 \\
\mathrm{mM}(2 \mathrm{~m} \\
\mathrm{L}) \\
\mathrm{ASW}(1)\end{array}$ & $4(1)$ & 25,57 \\
\hline 10 & $9(-1)$ & $35 \%$ (1) & $0,25 g(1)$ & $0(-1)$ & $0,1 \mathrm{~g}(1)$ & $0(-1)$ & $\begin{array}{c}4 \mathrm{mM}(2 \mathrm{ml}) \\
\mathrm{ASW}(1)\end{array}$ & $\begin{array}{c}4 \\
\mathrm{mM}(2 \mathrm{~m} \\
\mathrm{L}) \\
\mathrm{ASW}(1)\end{array}$ & $4(1)$ & 20,17 \\
\hline 11 & $9(-1)$ & $0(-1)$ & $0,25 \mathrm{~g}(1)$ & $0,2 \mathrm{~g}(1)$ & $0(-1)$ & $0,1 \mathrm{~g}(1)$ & $0(-1)$ & $\begin{array}{c}4 \\
\mathrm{mM}(2 \mathrm{~m}\end{array}$ & $4(1)$ & 10,11 \\
\hline
\end{tabular}




\begin{tabular}{|c|c|c|c|c|c|c|c|c|c|c|}
\hline & & & & & & & & L)(1) & & \\
\hline 12 & $7(1)$ & $0(-1)$ & $0(-1)$ & $0,2 \mathrm{~g}(1)$ & $0,1 \mathrm{~g}(1)$ & $0(-1)$ & $\begin{array}{c}4 \mathrm{mM}(2 \mathrm{~mL}) \\
\text { (1) }\end{array}$ & $0(-1)$ & $4(1)$ & 25,94 \\
\hline 13 & $9(-1)$ & $35 \%$ (1) & $0(-1)$ & $0(-1)$ & $0,1 \mathrm{~g}(1)$ & $0,1 \mathrm{~g}(1)$ & $0(-1)$ & $\begin{array}{c}4 \\
\mathrm{mM}(2 \mathrm{~m} \\
\mathrm{L}) \\
\mathrm{ASW}(1)\end{array}$ & $2(-1)$ & 15,04 \\
\hline 14 & $9(-1)$ & $0(-1)$ & $0,25 \mathrm{~g}(1)$ & $0(-1)$ & $0(-1)$ & $0,1 \mathrm{~g}(1)$ & $\begin{array}{c}4 \mathrm{mM}(2 \mathrm{ml}) \\
(1)\end{array}$ & $0(-1)$ & $4(1)$ & 24,38 \\
\hline 15 & $9(-1)$ & $0(-1)$ & $0(-1)$ & $0,2 \mathrm{~g}(1)$ & $0(-1)$ & $0(-1)$ & $\begin{array}{c}4 \mathrm{mM}(2 \mathrm{ml}) \\
(1)\end{array}$ & $\begin{array}{c}4 \\
\mathrm{mM}(2 \mathrm{~m} \\
\mathrm{L})(1)\end{array}$ & $2(-1)$ & 10,65 \\
\hline 16 & $9(-1)$ & $0(-1)$ & $0(-1)$ & $0(-1)$ & $0(-1)$ & $0(-1)$ & $0(-1)$ & $0(-1)$ & $2(-1)$ & 9,26 \\
\hline 17 & $8(0)$ & $17,5 \%$ (0) & $\begin{array}{c}0,125 \\
g(0)\end{array}$ & $0,1 \mathrm{~g}(0)$ & $0,05 \mathrm{~g}(0)$ & $0,05 g(0)$ & $\begin{array}{c}2 \mathrm{mM}(1 \mathrm{ml}) \\
(0)\end{array}$ & $\begin{array}{c}2 \mathrm{mM} \\
(1 \mathrm{ml}) \\
(0)\end{array}$ & $3(0)$ & 34,29 \\
\hline 18 & $8(0)$ & $17,5 \%$ (0) & $\begin{array}{c}0,125 \\
g(0)\end{array}$ & $0,1 \mathrm{~g}(0)$ & $0,05 g(0)$ & $0,05 \mathrm{~g}(0)$ & $\begin{array}{c}2 \mathrm{mM}(1 \mathrm{ml}) \\
(0)\end{array}$ & $\begin{array}{c}2 \\
\mathrm{mM}(1 \mathrm{~m} \\
\text { l) }(0)\end{array}$ & $3(0)$ & 25,22 \\
\hline 19 & $8(0)$ & $17,5 \%$ (0) & $\begin{array}{c}0,125 \\
g(0)\end{array}$ & $0,1 \mathrm{~g}(0)$ & $0,05 g(0)$ & $0,05 \mathrm{~g}(0)$ & $\begin{array}{c}2 \mathrm{mM}(1 \mathrm{ml}) \\
(0)\end{array}$ & $\begin{array}{l}2 \\
\mathrm{mM}(1 \mathrm{~m} \\
\text { l) }(0)\end{array}$ & $3(0)$ & 34,61 \\
\hline $\begin{array}{l}\text { Controle } \\
\text { negativo }\end{array}$ & $8(0)$ & $17,5 \%$ (0) & $\begin{array}{c}0,125 \\
g(0)\end{array}$ & $0,1 \mathrm{~g}(0)$ & $0,05 \mathrm{~g}(0)$ & $0,05 \mathrm{~g}(0)$ & $\begin{array}{c}2 \mathrm{mM}(1 \mathrm{ml}) \\
(0)\end{array}$ & $\begin{array}{l}2 \\
\mathrm{mM}(1 \mathrm{~m} \\
\text { l) }(0)\end{array}$ & - & 0 \\
\hline
\end{tabular}


Os efeitos produzidos pelas variáveis estudadas no processo de degradação do fungo Xylaria sp. CBMAl 1464 estão apresentados na Figura 25.

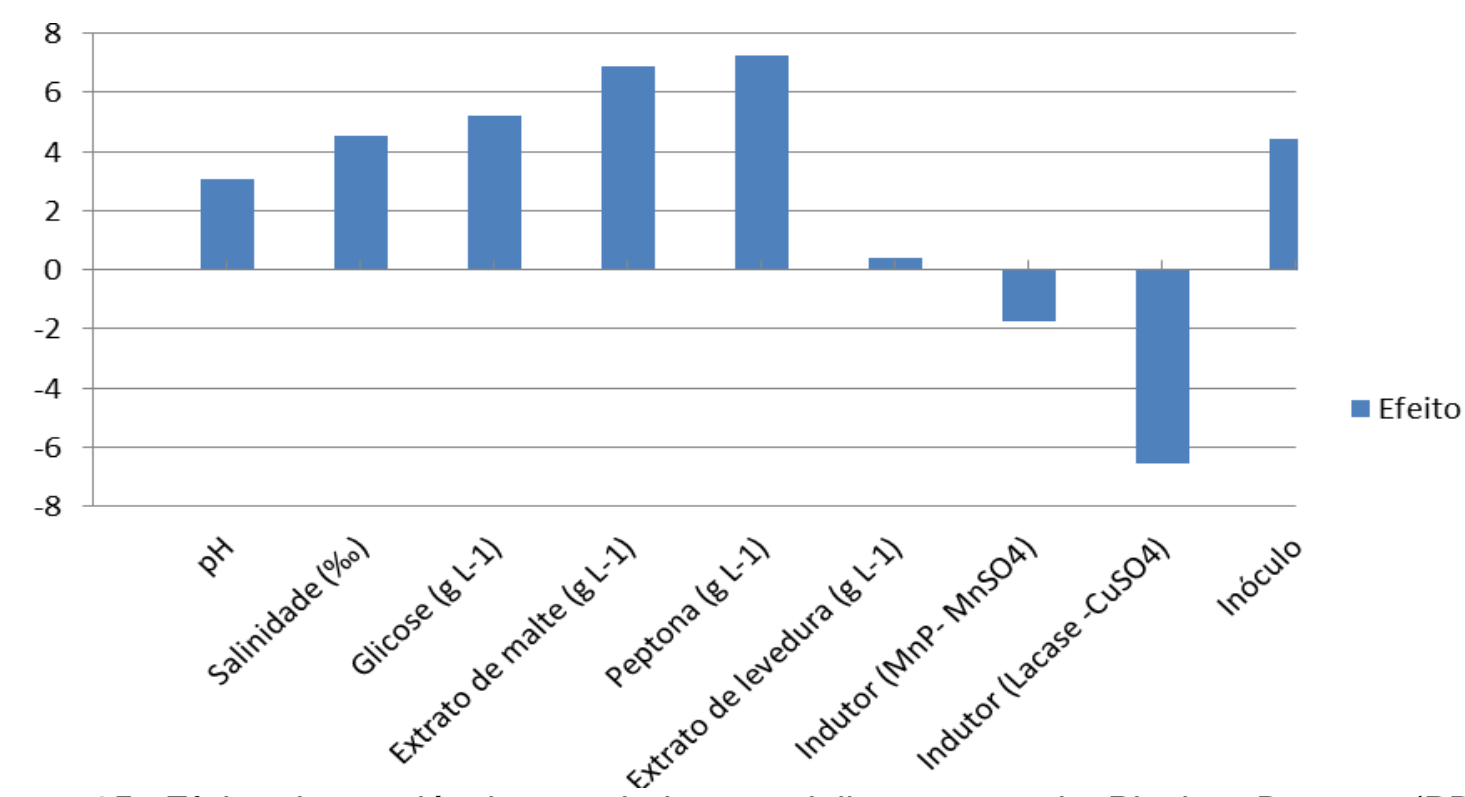

Figura 25. Efeito das variáveis estudadas no delineamento de Plackett-Burman (PB20) sobre o processo de degradação do fungo Xylaria sp. CBMAl 1464.

Para o fungo Xylaria sp. CBMAl 1464, as variáveis $\mathrm{pH}$, salinidade, concentrações de extrato de malte, peptona, extrato de levedura e inóculo tiveram efeito positivo no processo de degradação de pireno, no entanto, nenhuma delas foi significativa ao nível $90 \%(\mathrm{p}<0,1)$ (Tabela 12). Os indutores ( $\mathrm{MnP}-\mathrm{MnSO}_{4}$ e CuSO 4$)$ apresentaram efeito negativo na degradação do pireno (Figura 25). 
Tabela 12. Erro padrão e significância $(p<0,1)$ das variáveis estudadas no PB20 de Xylaria sp. CBMAI 1464.

\begin{tabular}{|c|c|c|}
\hline Variáveis & Erro padrão & $p(0,1 \%)$ \\
\hline $\mathrm{pH}$ & 4,226406 & 0,487562 \\
\hline Salinidade (\%o) & 4,226406 & 0,311110 \\
\hline Glicose $\left(g^{-1}\right)$ & 4,226406 & 0,247988 \\
\hline Extrato de Malte $\left(\mathrm{g} \mathrm{L}^{-1}\right)$ & 4,226406 & 0,138366 \\
\hline Peptona $\left(\mathrm{g} \mathrm{L}^{-1}\right)$ & 4,226406 & 0,120582 \\
\hline Extrato de Levedura $\left(\mathrm{g} \mathrm{L}^{-1}\right)$ & 4,226406 & 0,926807 \\
\hline Indutor (MnP- $\left.\mathrm{MnSO}_{4}\right)$ & 4,226406 & 0,686317 \\
\hline Indutor (Lacase -CuSO ${ }_{4}$ ) & 4,226406 & 0,155646 \\
\hline Inóculo & 4,226406 & 0,319369 \\
\hline
\end{tabular}

Tendo em vista os resultados obtidos no delineamento experimental para os dois fungos estudados, o fungo $C$. alba CBMAI 1346 foi selecionado para dar continuidade aos estudos de degradação e um novo delineamento experimental do tipo PB foi estabelecido com base nos resultados do primeiro PB20 para este fungo (Tabela 9, Figura 24). As variáveis $\mathrm{pH}(7.0)$, salinidade (35\%o), quantidade de inóculo (3 cilindros de $5 \mathrm{~mm}$ ) e o indutor $\mathrm{MnSO}_{4}(4 \mathrm{mM})$ foram fixadas. As variáveis que apresentaram efeito positivo (extrato de malte, extrato de levedura e peptona) foram avaliadas em novas concentrações e dois novos indutores de enzimas ligninolíticas $\left(\mathrm{KH}_{2} \mathrm{PO}_{4}\right.$ e riboflavina) foram introduzidos. Assim o novo PB foi composto por cinco variáveis (Tabela 2), totalizando 16 ensaios (PB16). Os resultados de degradação obtidos no novo planejamento estão apresentados na Tabela 13. 
Tabela 13. Degradação de pireno (\%) pelo fungo C. alba CBMAI 1346, obtidos pelo planejamento de Plackett \& Burman de 16 ensaios (PB16).

\begin{tabular}{|c|c|c|c|c|c|c|}
\hline Ensaios & $\begin{array}{l}\text { 1. Extrato de } \\
\text { malte }\left(g \cdot \mathrm{L}^{-1}\right)\end{array}$ & $\begin{array}{l}\text { 2. Peptona } \\
\left(g . L^{-1}\right)\end{array}$ & $\begin{array}{l}\text { 3. Extrato } \\
\text { de levedura } \\
\left(\mathrm{g} \cdot \mathrm{L}^{-1}\right)\end{array}$ & $\begin{array}{l}\text { 4. } \mathrm{KH}_{2} \mathrm{PO}_{4} \\
\left(\mathrm{~g} \cdot \mathrm{L}^{-1}\right)\end{array}$ & $\begin{array}{c}\text { 5. Riboflavina } \\
(\%)\end{array}$ & $\begin{array}{c}\text { Degradação } \\
(\%)\end{array}$ \\
\hline 1 & $0,3 \mathrm{~g}(1)$ & $0,1 \mathrm{~g}(-1)$ & $0,2 \mathrm{~g}(1)$ & $0(-1)$ & $0(-1)$ & 38,08 \\
\hline 2 & $0,3 g(1)$ & $0,2 \mathrm{~g}(1)$ & $0,1 \mathrm{~g}(-1)$ & $0,1 \mathrm{~g}(1)$ & $0(-1)$ & 44,91 \\
\hline 3 & $0,2 \mathrm{~g}(-1)$ & $0,2 \mathrm{~g}(1)$ & $0,2 \mathrm{~g}(1)$ & $0(-1)$ & $0,02(1)$ & 51,23 \\
\hline 4 & $0,3 \mathrm{~g}(1)$ & $0,1 \mathrm{~g}(-1)$ & $0,2 \mathrm{~g}(1)$ & $0,1 \mathrm{~g}(1)$ & $0(-1)$ & 36,25 \\
\hline 5 & $0,3 \mathrm{~g}(1)$ & $0,2 \mathrm{~g}(1)$ & $0,1 \mathrm{~g}(-1)$ & $0,1 \mathrm{~g}(1)$ & $0,02(1)$ & 35,42 \\
\hline 6 & $0,3 \mathrm{~g}(1)$ & $0,2 \mathrm{~g}(1)$ & $0,2 \mathrm{~g}(1)$ & $0(-1)$ & $0,02(1)$ & 24,22 \\
\hline 7 & $0,2 \mathrm{~g}(-1)$ & $0,2 \mathrm{~g}(1)$ & $0,2 \mathrm{~g}(1)$ & $0,1 \mathrm{~g}(1)$ & $0(-1)$ & 26,27 \\
\hline 8 & $0,2 \mathrm{~g}(-1)$ & $0,1 \mathrm{~g}(-1)$ & $0,2 \mathrm{~g}(1)$ & $0,1 \mathrm{~g}(1)$ & $0,02(1)$ & 58,28 \\
\hline 9 & $0,2 \mathrm{~g}(-1)$ & $0,1 \mathrm{~g}(-1)$ & $0,1 \mathrm{~g}(-1)$ & $0,1 \mathrm{~g}(1)$ & $0,02(1)$ & 0 \\
\hline 10 & $0,3 g(1)$ & $0,1 \mathrm{~g}(-1)$ & $0,1 \mathrm{~g}(-1)$ & $0(-1)$ & $0,02(1)$ & 41,29 \\
\hline 11 & $0,2 \mathrm{~g}(-1)$ & $0,2 \mathrm{~g}(1)$ & $0,1 \mathrm{~g}(-1)$ & $0(-1)$ & $0(-1)$ & 37,71 \\
\hline 12 & $0,2 \mathrm{~g}(-1)$ & $0,1 \mathrm{~g}(-1)$ & $0,1 \mathrm{~g}(-1)$ & $0(-1)$ & $0(-1)$ & 40,99 \\
\hline 13 & $0,25 g(0)$ & $0,15 g(0)$ & $0,15 g(0)$ & $0,05 g(0)$ & $0,01(0)$ & 36,54 \\
\hline 14 & $0,25 \mathrm{~g}(0)$ & $0,15 \mathrm{~g}(0)$ & $0,15 g(0)$ & $0,05 \mathrm{~g}(0)$ & $0,01(0)$ & 49,05 \\
\hline 15 & $0,25 \mathrm{~g}(0)$ & $0,15 \mathrm{~g}(0)$ & $0,15 g(0)$ & $0,05 \mathrm{~g}(0)$ & $0,01(0)$ & 56,72 \\
\hline $\begin{array}{l}\text { Controle } \\
\text { negativo }\end{array}$ & $0,25 \mathrm{~g}(0)$ & $0,15 \mathrm{~g}(0)$ & $0,15 g(0)$ & $0,05 g(0)$ & $0,01(0)$ & 0 \\
\hline
\end{tabular}

A máxima degradação de pireno obtida no PB16 para o fungo C. alba CBMAI 1346 foi no ensaio 8 (58,28 \%). Os efeitos das variáveis estudadas no novo planejamento estão apresentados na Figura 26. 


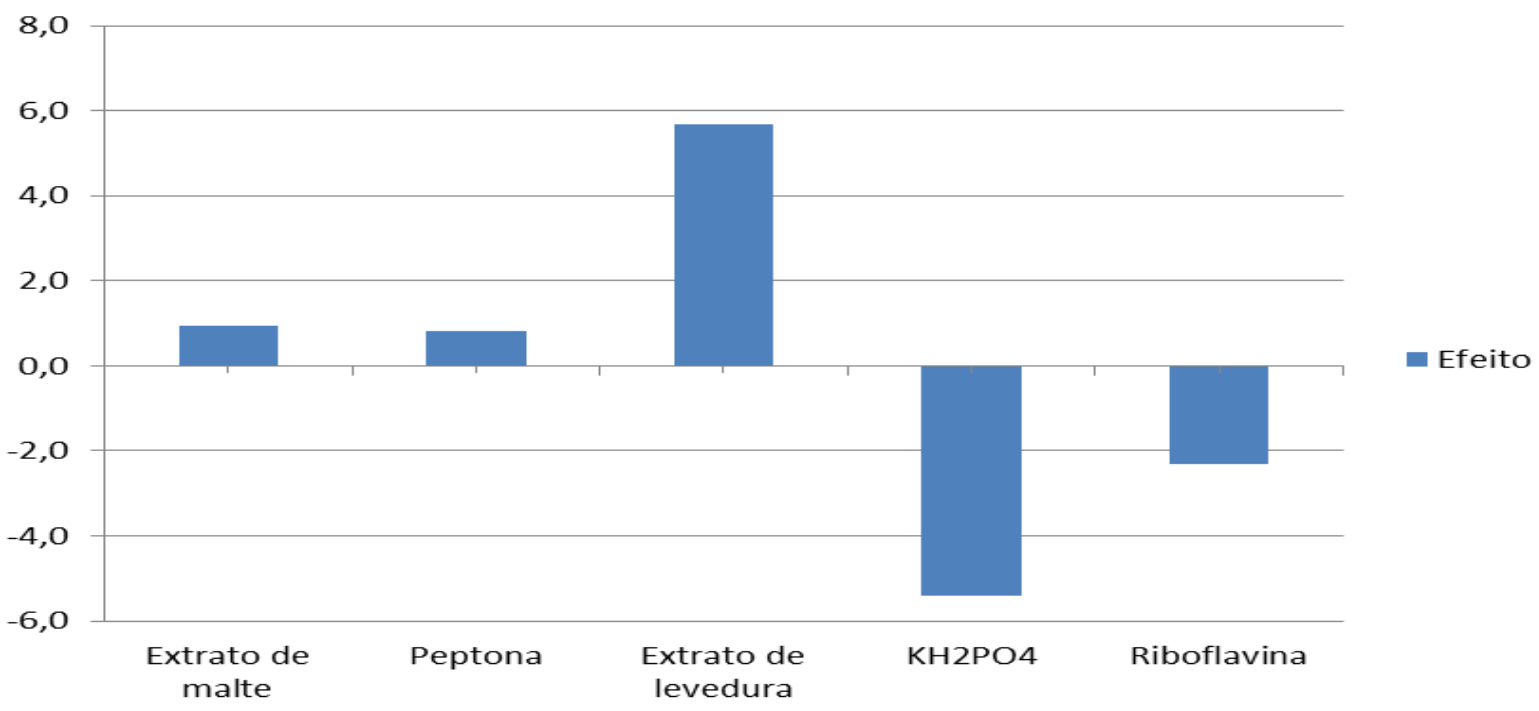

Figura 26. Efeito das variáveis estudadas no delineamento de Plackett-Burman (PB16) sobre o processo de degradação do fungo C.alba CBMAl 1346.

As concentrações de extrato de malte, peptona e extrato de levedura tiveram efeito positivo sobre o processo de degradação de pireno após 7 dias de incubação. As variáveis riboflavina e fosfato de potássio bibásico $\left(\mathrm{KH}_{2} \mathrm{PO}_{4}\right)$ adicionadas ao PB16, como indutores de produção de enzimas ligninolítcas, tiveram efeito negativo sobre o processo, sugerindo que os indutores podem ter atuado como inibidores da degradação e possivelmente influenciando a biomassa fúngica, visto que o crescimento micelial neste ensaio foi reduzido em comparação ao ensaio anterior (análise visual). Nenhuma das variáveis estudadas neste delineamento apresentou significância ao nível de 90 \% (Tabela 14).

Tabela 14. Erro padrão e significância $(p<0,1)$ das variáveis estudadas no PB16 de $C$. alba CBMAI 1346.

\begin{tabular}{lcc}
\hline \multicolumn{1}{c}{ Variáveis } & Erro padrão & $\mathbf{p}(<\mathbf{0 , 1})$ \\
\hline Extrato de Malte $\left(\mathbf{g ~ L}^{-1}\right)$ & 10,00411 & 0,926525 \\
Peptona $\left(\mathbf{g ~ L}^{-1}\right)$ & 10,00411 & 0,936889 \\
Extrato de levedura $\left(\mathbf{g ~ L}^{-1}\right)$ & 10,00411 & 0,584704 \\
Fosfato de potássio bibásico $\left(\mathrm{KH}_{\mathbf{2}} \mathrm{PO}_{4}\right)\left(\mathbf{g ~ L}^{-1}\right)$ & 10,00411 & 0,602354 \\
Riboflavina (\%) & 10,00411 & 0,823443 \\
\hline
\end{tabular}

Devido ao fato dos resultados de degradação obtidos no PB16 terem sido mais baixos do que os apresentados no PB20, um novo planejamento foi proposto para 
dar continuidade à otimização do processo de degradação de pireno pelo fungo $C$. alba CBMAI 1346.

\subsection{Delineamento experimental Fatorial Fracionado $2^{4-1}$ utilizado para a otimização da degradação de pireno pelo fungo Chaunopycnis alba CBMAl 1346}

Diante dos resultados acima citados, um delineamento Fatorial Fracionado $2^{4-}$ 1 foi proposto. Neste novo delineamento foi avaliado o efeito das variáveis significativas do PB20 (extrato de malte, extrato de levedura e peptona) (Figura 23), sem a presença das variáveis que apresentaram efeito negativo (riboflavina e $\mathrm{KH}_{2} \mathrm{PO}_{4}$ ) (Figura 24) no PB16 e com a adição da variável pH (na faixa de 7,0, 8,0 e 9,0 ), visto que o melhor ensaio de degradação $(79,39 \%$ ) ocorreu em pH 9,0 (ensaio 7, Tabela 9). Outras variáveis foram fixadas: salinidade (35\%), sulfato de manganês $\left(\mathrm{MnSO}_{4}\right)$, pireno $\left(2 \mathrm{mg} \cdot \mathrm{mL}^{-1}\right)$, extrato de levedura $\left(6 \mathrm{~g}^{\mathrm{L}} \mathrm{L}^{-1}\right)$, quantidade de inóculo (3 cilindros de $5 \mathrm{~mm}$ ), agitação (140 rpm) e temperatura (28 $\left.{ }^{\circ} \mathrm{C}\right)$. Os valores das variáveis do delineamento Fatorial Fracionado $2^{4-1}$ estão apresentados na (Tabela 3).

Os resultados da degradação de pireno pelo fungo C. alba CBMAI 1346, obtidos pelo delineamento fatorial fracionado $2^{4-1}$ estão apresentados na Tabela 15. Os ensaios 2 e 6 apresentaram os melhores valores de degradação $(61,59 \%$ e $94,17 \%$, respectivamente). 
Tabela 15. Degradação, valores reais e codificados da matriz do delineamento Fatorial Fracionado com 4 variáveis, no total de 12 ensaios (FF12), pelo fungo Chaunopycnis alba CBMAl 1346, obtidos pelo delineamento Fatorial Fracionado $2^{4-1}$.

\begin{tabular}{cccccc}
\hline Ensaios & $\begin{array}{c}\text { 1. Extrato de } \\
\text { malte }\left(\mathbf{g} \cdot \mathbf{L}^{-1}\right)\end{array}$ & $\begin{array}{c}\mathbf{2 . ~ P e p t o n a} \\
\mathbf{( g . \mathbf { L } ^ { - 1 } )}\end{array}$ & $\begin{array}{c}\text { 3. Extrato de } \\
\text { levedura }\left(\mathbf{g} \cdot \mathbf{L}^{-1}\right)\end{array}$ & $\mathbf{4} \mathbf{p H}$ & Degradação (\%) \\
$\mathbf{1}$ & $-1(0,300)$ & $-1(0,150)$ & $-1(0,200)$ & $-1(7,0)$ & 33,29 \\
$\mathbf{2}$ & $1(0,350)$ & $-1(0,150)$ & $-1(0,200)$ & $1(9,0)$ & 61,59 \\
$\mathbf{3}$ & $-1(0,300)$ & $1(0,250)$ & $-1(0,200)$ & $1(9,0)$ & 38,38 \\
$\mathbf{4}$ & $1(0,350)$ & $1(0,250)$ & $-1(0,200)$ & $-1(7,0)$ & 33,71 \\
$\mathbf{5}$ & $-1(0,300)$ & $-1(0,150)$ & $1(0,300)$ & $1(9,0)$ & 35,28 \\
$\mathbf{6}$ & $1(0,350)$ & $-1(0,150)$ & $1(0,300)$ & $-1(7,0)$ & 94,17 \\
$\mathbf{7}$ & $-1(0,300)$ & $1(0,250)$ & $1(0,300)$ & $-1(7,0)$ & 36,69 \\
$\mathbf{9}$ & $1(0,350)$ & $1(0,250)$ & $1(0,300)$ & $1(9,0)$ & 24,97 \\
$\mathbf{1 0}$ & $0(0,325)$ & $0(0,200)$ & $0(0,250)$ & $0(8,0)$ & 31,00 \\
\hline $\mathbf{1 1}$ & $0(0,325)$ & $0(0,200)$ & $0(0,250)$ & $0(8,0)$ & 41,85 \\
\hline $\begin{array}{c}\text { Controle } \\
\text { negativo }\end{array}$ & $0(0,325)$ & $0(0,200)$ & $0(0,250)$ & $0(8,0)$ & 42,37 \\
\hline
\end{tabular}

$\mathrm{Na}$ Figura 27 são apresentados os efeitos das variáveis utilizadas no delineamento experimental fatorial fracionado $2^{4-1}$.

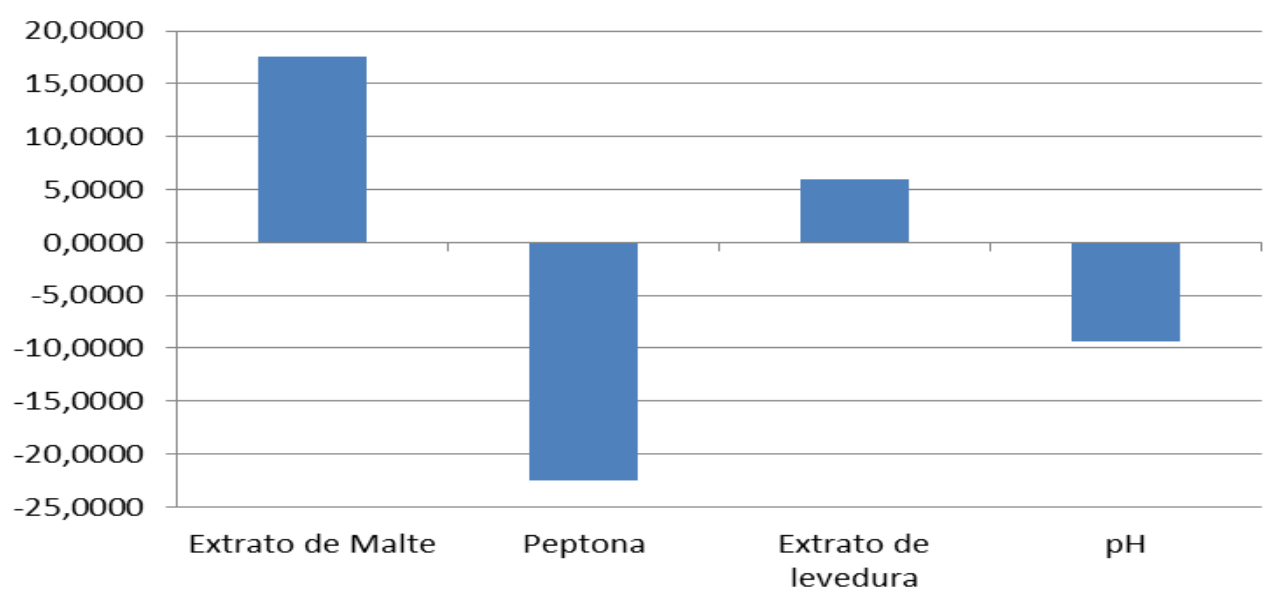

Figura 27. Efeito das variáveis estudadas no delineamento fatorial fracionado $2^{4-1}$ sobre 0 processo de degradação do fungo C. alba CBMAI 1346.

As variáveis extrato de malte e extrato de levedura tiveram efeito positivo $(17,57$ e 5,99, respectivamente) no processo de degradação de pireno, no entanto, 
nenhuma das variáveis estudadas no delineamento fatorial fracionado $2^{4-1}$ foi significativa ao nível de $90 \%(p<0,1)$, como mostra a Tabela 16 .

Tabela 16. Erro padrão e significância $(p<0,1)$ das variáveis estudadas no delineamento fatorial fracionado $2^{4-1}$ de C. alba CBMAl 1346.

\begin{tabular}{lcc}
\hline Variáveis & $\begin{array}{c}\text { Erro } \\
\text { padrão }\end{array}$ & $\mathbf{p}(<\mathbf{0 , 1})$ \\
\hline Extrato de Malte $\left(\mathbf{g ~ L}^{-1}\right)$ & 12,27788 & 0,202172 \\
Peptona $\left(\mathbf{g ~ L}^{-1}\right)$ & 12,27788 & 0,116650 \\
Extrato de Levedura $\left(\mathrm{g} \mathrm{L}^{-1}\right)$ & 12,27788 & 0,642717 \\
$\mathbf{p H}$ & 12,27788 & 0,475376 \\
\hline
\end{tabular}

Após a análise dos resultados obtidos no delineamento fatorial fracionado $2^{4-1}$, um Delineamento Composto Central Rotacional (DCCR) foi realizado utilizando as variáveis extrato de malte e extrato de levedura (nas concentrações apresentadas na Tabela 4), as quais apresentaram efeito positivo sobre o processo de degradação de pireno do experimento anterior (Figura 26). Neste novo planejamento experimental permaneceram fixadas todas as variáveis do delineamento anterior (fatorial fracionado $2^{4-1}$ ) e foi fixado $0 \mathrm{pH}$ (7.0). Os resultados obtidos estão apresentados na Tabela 17. 
Tabela 17. Degradação de pireno (\%), valores reais e codificados da matriz do Delineamento Composto Central Rotacional (DCCR) com 2 variáveis, no total de 12 ensaios pelo fungo C. alba CBMAI 1346.

\begin{tabular}{cccc}
\hline Ensaios & $\begin{array}{c}\text { 1. Extrato de malte } \\
\left(\mathbf{g} \cdot \mathbf{L}^{-1}\right)\end{array}$ & 2. Peptona $\left(\mathbf{g} \cdot \mathbf{L}^{-1}\right)$ & Degradação (\%) \\
\hline $\mathbf{2}$ & $-1(0,330)$ & $-1(0,132)$ & 27,44 \\
$\mathbf{3}$ & $1(0,367)$ & $-1(0,132)$ & 29,03 \\
$\mathbf{4}$ & $-1(0,330)$ & $1(0,167)$ & 39,05 \\
$\mathbf{5}$ & $1(0,367)$ & $1(0,167)$ & 37,41 \\
$\mathbf{6}$ & $-1,41(0,325)$ & $0(0,350)$ & 34,32 \\
$\mathbf{7}$ & $1,41(0,375)$ & $0(0,150)$ & 32,65 \\
$\mathbf{8}$ & $0(0,350)$ & $-1,41(0,125)$ & 34,08 \\
$\mathbf{9}$ & $0(0,350)$ & $1,41(0,175)$ & 39,41 \\
$\mathbf{1 0}$ & $0(0,350)$ & $0(0,150)$ & 43,68 \\
\hline $\mathbf{1 1}$ & $0(0,350)$ & $0(0,150)$ & 45,32 \\
\hline $\begin{array}{c}\text { Controle } \\
\text { negativo }\end{array}$ & $0(0,350)$ & $0(0,150)$ & 51,09 \\
\hline
\end{tabular}

Tendo em vista que todos os valores de degradação do Delineamento Composto Central Rotacional (DCCR) foram menores que os valores apresentados pelo delineamento fatorial fracionado $2^{4-1}(61,59 \%$ para o ensaio 2 e $94,17 \%$ para o ensaio 6), o ensaio 6 deste último delineamento (contendo $0,350 \mathrm{~g} . \mathrm{L}^{-1}$ de extrato de malte, $0,150 \mathrm{~g}$. $\mathrm{L}^{-1}$ de peptona, $0,3 \mathrm{~g} \cdot \mathrm{L}^{-1}$ de extrato de levedura e $\mathrm{pH}$ 7.0) foi repetido para a validação da otimização do processo de degradação através do delineamento experimental. A atividade enzimática de lacase, MnP e LiP também foram avaliadas no ensaio de validação e os resultados obtidos estão apresentado na Tabela 18. 
Tabela 18. Degradação de pireno (\%) e atividade enzimática do fungo C. alba CBMAI 1346, obtidos pelo ensaio validado (ensaio 6 do delineamento fatorial fracionado $2^{4-1}$ ).

\begin{tabular}{|c|c|c|c|c|c|}
\hline \multirow[t]{2}{*}{ Ensaio } & \multirow[t]{2}{*}{ Degradação } & \multicolumn{2}{|c|}{ Com adição de pireno } & \multicolumn{2}{|c|}{ Sem adição de pireno } \\
\hline & & Lacase $\left(\mathrm{U} . \mathrm{L}^{-1}\right)$ & $\operatorname{MnP}\left(U . L^{-1}\right)$ & $\begin{array}{c}\text { Lacase (U. } \mathrm{L}^{-} \\
\left.{ }^{1}\right)\end{array}$ & $\operatorname{MnP}\left(U . L^{-1}\right)$ \\
\hline 6 & $94,17 \%$ & 1,28 & 100,32 & 4,23 & 114,17 \\
\hline
\end{tabular}

A atividade da enzima lignina peroxidase (LiP) não foi detectada em ambas as condições de ensaio. Tanto a lacase quanto a MnP apresentaram valores de atividade enzimática maiores na condição sem adição de pireno. No entanto, a produção de $\mathrm{MnP}$ foi similar para as duas condições estudadas (com e se a presença do HPA), sugerindo que o pireno não inibiu a produção da enzima e que a mesma pode estar envolvida no processo de degradação deste composto pelo fungo C. alba CBMAI 1346.

\subsection{Identificação dos metabólitos formados durante a degradação de pireno pelo fungo Chaunopycnis alba CBMAl 1346 em condição otimizada pelo delineamento Fatorial Fracionado $\mathbf{2}^{4-1}$}

O fungo Chaunopycnis alba CBMAI 1346 foi submetido ao delineamento experimental para a otimização da degradação de pireno. A validação foi realizada com base nos ensaio 6 do delineamento Fatorial Fracionado $2^{4-1}$, para o qual foi obtido $94,54 \%$ de degradação de pireno (Tabela 15). Na validação, a porcentagem de degradação foi de $94,17 \%$ e a condição deste ensaio está apresentada na Tabela 19.

Tabela 19. Validação da degradação de pireno (\%) pelo fungo Chaunopycnis alba CBMAI 1346, obtidos pelo delineamento fatorial fracionado $2^{4-1}$.

\begin{tabular}{cccccc}
\hline Ensaios & $\begin{array}{c}\text { 1. Extrato de } \\
\text { malte }\left(\mathbf{g} \cdot \mathbf{L}^{-1}\right)\end{array}$ & $\begin{array}{c}\text { 2. Peptona } \\
\left(\mathbf{g} \cdot \mathrm{L}^{-1}\right)\end{array}$ & $\begin{array}{c}\text { 3. Extrato de } \\
\text { levedura }\left(\mathbf{g} \cdot \mathbf{L}^{-}\right.\end{array}$ & $\begin{array}{c}\text { 4. } \mathbf{p H} \\
\mathbf{1}\end{array}$ & $\begin{array}{c}\text { Degradação } \\
\text { (\%) }\end{array}$ \\
\hline $\mathbf{6}$ & $1(0,350)$ & $-1(0,150)$ & $1(0,300)$ & $-1(7,0)$ & 94,54 \\
\hline
\end{tabular}

A avaliação dos resultados de degradação de pireno pelo fungo $C$. alba CBMAl 1346 antes (em MA2 \%) e após a aplicação dos ensaios dos delineamentos experimentais (Plackett-Burman, PB20 e Fatorial Fracionado, FF12), evidenciaram a 
eficácia da estratégia de delineamento experimental (Figura 28). O maior valor de degradação de pireno (ensaio 6 do FF12) foi de 94,54\%, cerca de 1,5 vezes maior do que o resultado de degradação inicial obtido em meio líquido MA2 \% (66,58 \%). O resultado da validação $(94,17 \%$, Tabela 19$)$ foi bastante similar ao anteriormente obtido no ensaio 6 do FF12 (94,54\%), confirmando o potencial do fungo para a degradação do HPA estudado.

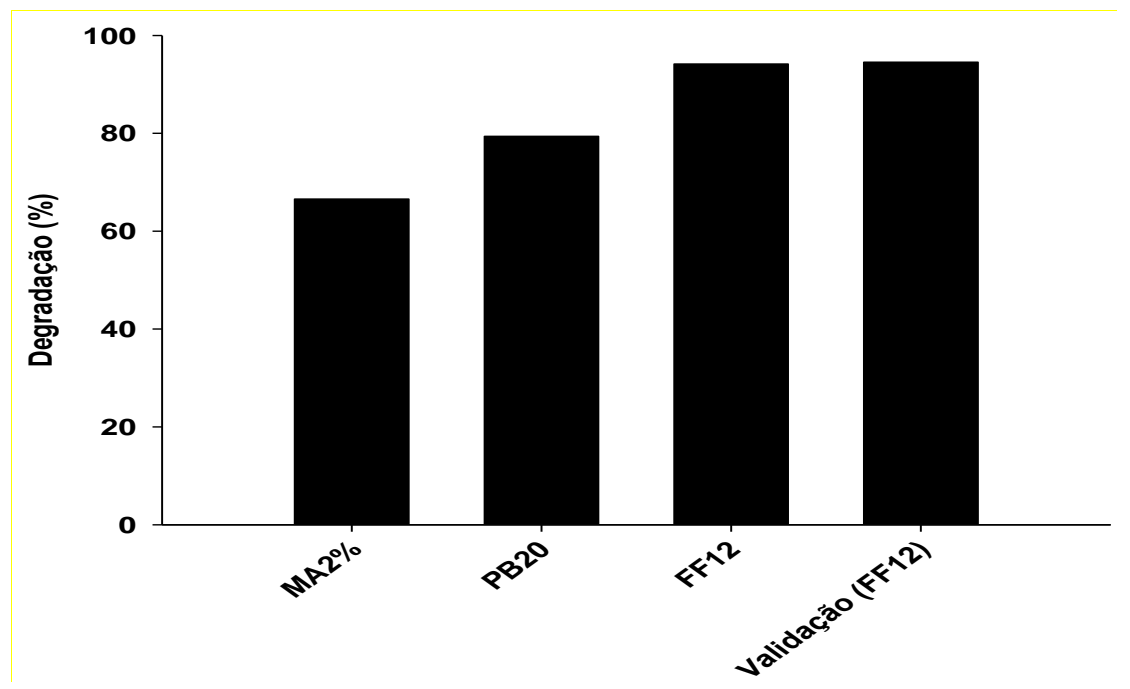

Figura 28. Evolução da degradação (\%) de pireno pelo fungo C. alba CBMAI 1346 nos ensaios propostos antes e após os delineamentos experimentais.

Do ensaio validado foram feitas réplicas que foram submetidas a análises de identificação de metabólitos a partir da degradação de pireno através de cromatografia gasosa (CG-EM). Na Figura 29 está apresentado o cromatograma expandido no intervalo de $t_{R} 8$ min a 18 min no modo Scan, na degradação do pireno pelo fungo $C$. alba CBMAl 1346 após 7 dias de cultivo, nas condições do ensaio validado. 


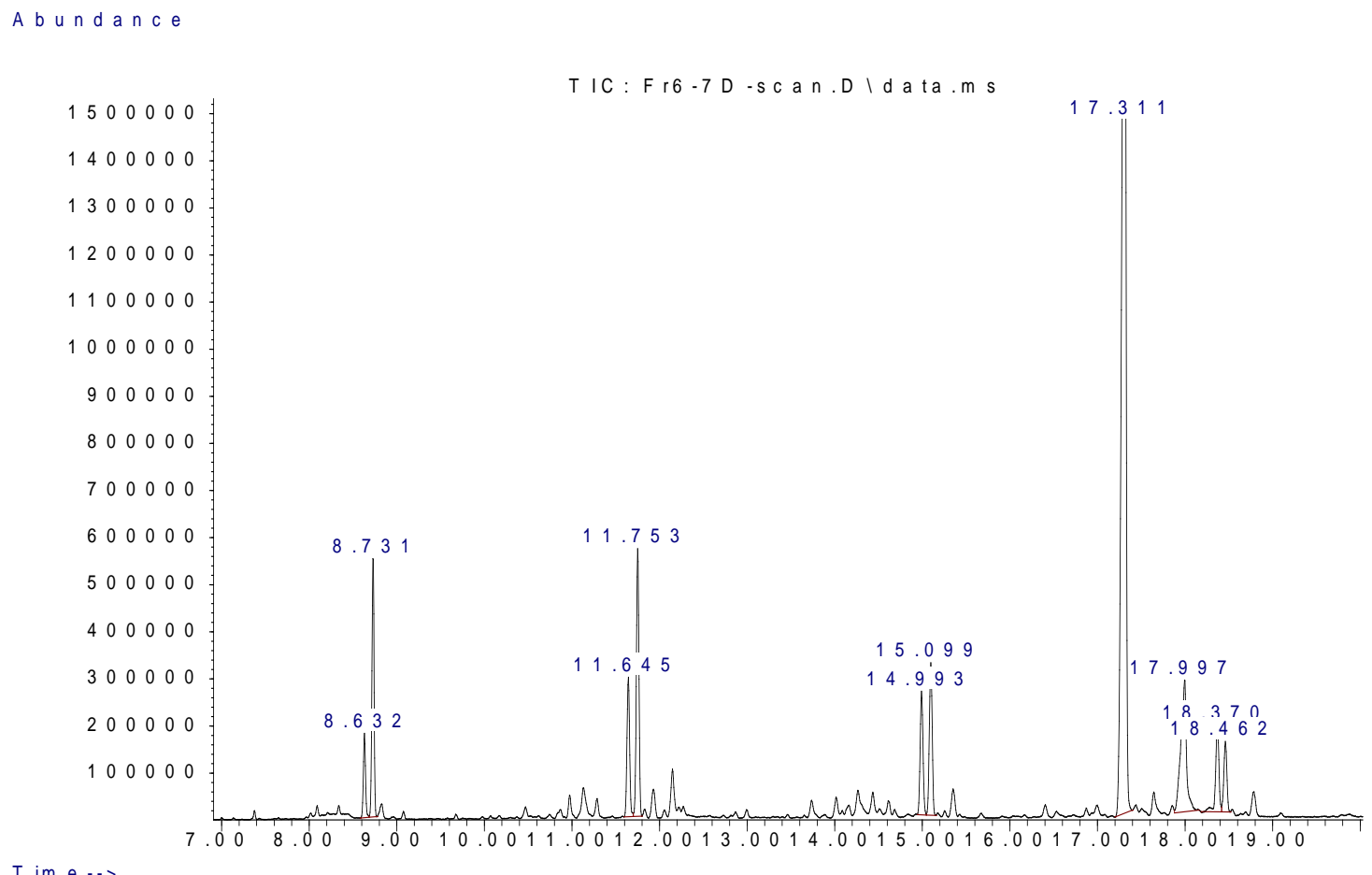

Figura 29. Cromatograma expandido ( $t_{R}$ de $8 \mathrm{~min}$ a $18 \mathrm{~min}$ ) modo $S c a n$ do produto de degradação do pireno pelo fungo $C$. alba CBMAI 1346, após 7 dias de cultivo, nas condições do ensaio validado.

Na Tabela 20 são apresentados os metabólitos resultantes (íons moleculares detectados) que foram obtidos pelo modo de varredura completa (Full Scan), no intervalo de 40-600 m/z (LUAN et al., 2006) a partir da degradação de pireno pelo fungo C. alba CBMAI 1346, na condição validada (Tabela 20). 
Tabela 20. Identificação dos metabólitos formados a partir da degradação de pireno pelo fungo Chaunopycnis alba CBMAI 1346 no modo de varredura completa (Full Scan): tempo de retenção $\left(t_{R}\right)$ e características da espectrometria de massas.

\begin{tabular}{ccccc}
\hline Picos & $\mathbf{t}_{\mathbf{R}}(\mathbf{m i n})$ & $\begin{array}{c}\text { Íons } \\
\text { moleculares } \\
(\mathbf{m} / \mathbf{z})\end{array}$ & Compostos sugeridos & $\begin{array}{c}\text { Abundância } \\
\text { relativa (\%) }\end{array}$ \\
\hline $\mathbf{1}$ & 8,632 & 224 & Ceteno (1-Hexadeceno) & $1,35 \%$ \\
$\mathbf{2}$ & 8,731 & 226 & Hexadecano & $4,06 \%$ \\
$\mathbf{4}$ & 11,645 & 252 & Octadeceno & $2,58 \%$ \\
$\mathbf{5}$ & 14,993 & 280 & 5-eicoseno & $2,72 \%$ \\
$\mathbf{6}$ & 15,099 & 282 & Eicosano & $3,13 \%$ \\
$\mathbf{7}$ & 17,311 & 101,202 & Pireno & $33,34 \%$ \\
& 18,370 & 326 & Álcool behênico $(1-$ & $2,12 \%$ \\
& & & docosanol) & \\
\hline
\end{tabular}

Todos os metabólitos encontrados no perfil cromatográfico da degradação de pireno pelo fungo C. alba CBMAI 1346 foram compostos de cadeia alifática (aberta), sugerindo que o fungo estudado atacou as moléculas do pireno, um hidrocarboneto policíclico aromático de quatro anéis (Figura 28). Uma vez que as cadeias carbônicas da maioria dos compostos encontrados possuem maior número de carbonos que o composto parental, esses compostos devem ter sido supostamente formados por condensação de moléculas menores quebradas pelo ataque das enzimas envolvidas neste tipo de degradação (NOVOTNÝ et al. 2004, WANG et al., 2009; ANASTASI et al., 2009). Da Figura 30 à Figura 36 são apresentados o perfil cromatográfico e a respectiva estrutura química de cada composto encontrado resultante da degradação de pireno pelo fungo $C$. alba CBMAI 1346, após 7 dias de cultivo, na condição validada. 


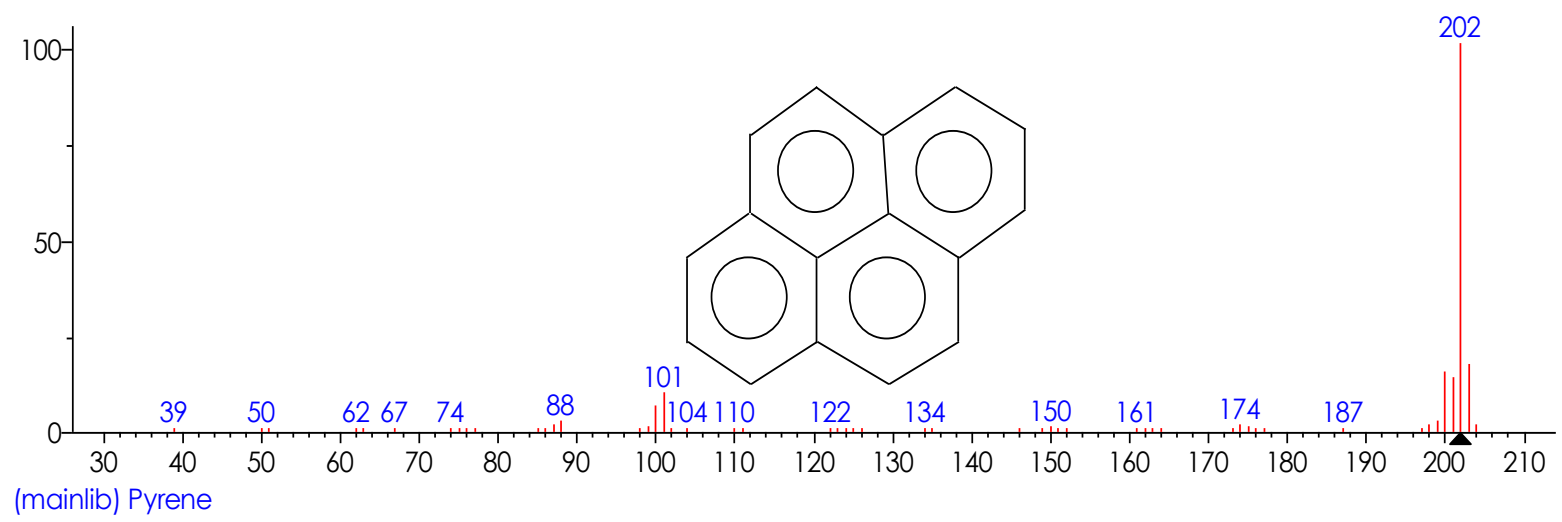

Figura 30. Espectro de massas do composto estudado pireno $-M M=202\left(\mathrm{C}_{6} \mathrm{H}_{10}\right)$ e sua respectiva estrutura química.

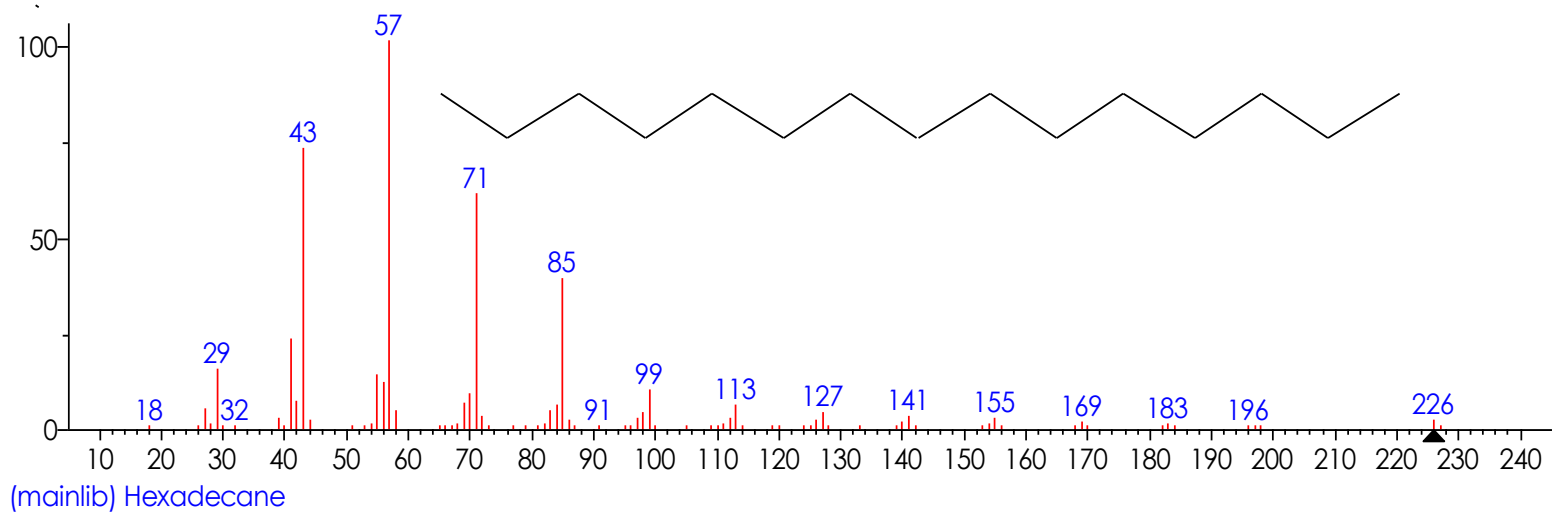

Figura 31. Espectro de massas do composto hexadecano - $M M=226\left(\mathrm{C}_{6} \mathrm{H}_{34}\right)$, composto encontrado como metabólito formado a partir da degradação de pireno pelo fungo $C$. alba CBMAI 1346, após 7 dias de cultivo, na condição validada, e sua respectiva estrutura química.

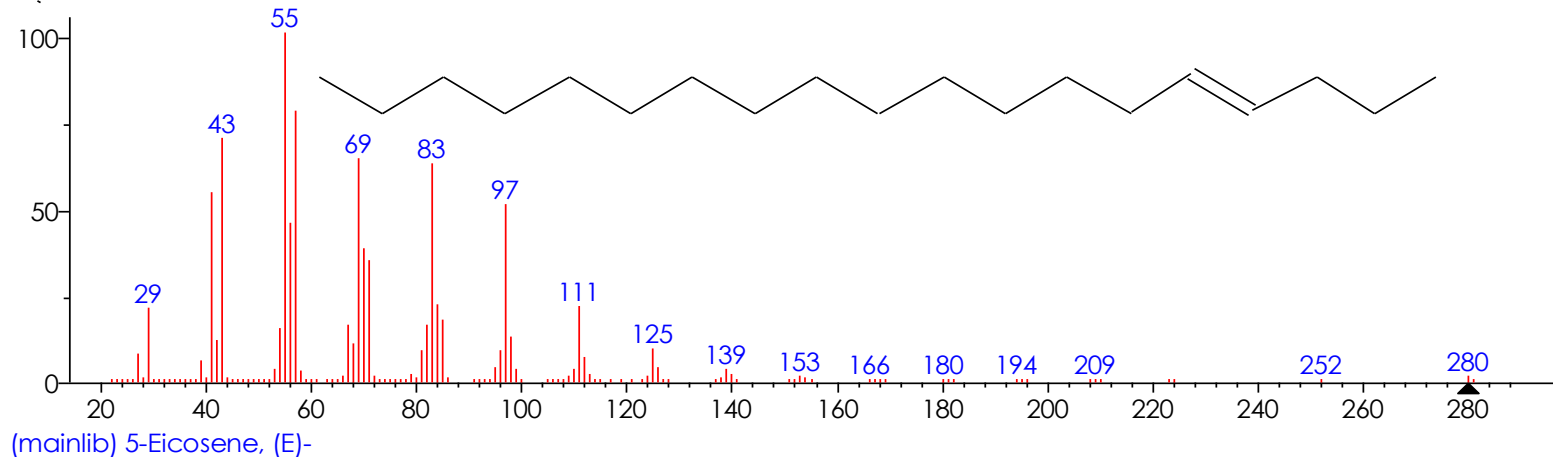

Figura 32. Espectro de massas do composto 5-eicoseno $-\mathrm{MM}=280\left(\mathrm{C}_{20} \mathrm{H}_{40}\right)$, composto encontrado como metabólito formado a partir da degradação de pireno pelo fungo $C$. alba CBMAI 1346, após 7 dias de cultivo, na condição validada, e sua respectiva estrutura química. 


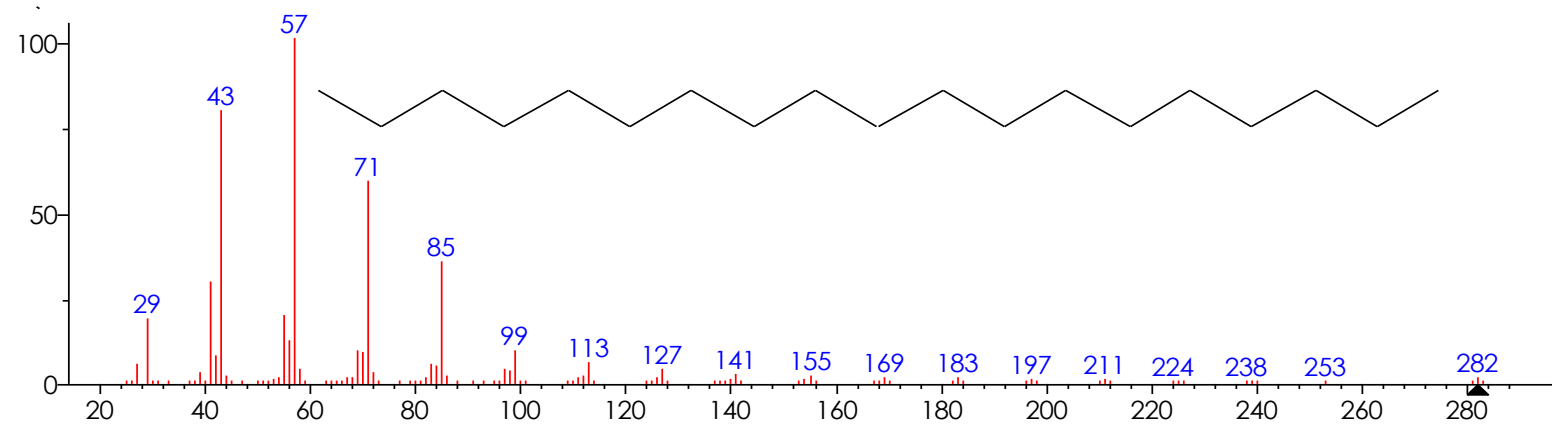
(mainlib) Eicosane

Figura 33. Espectro de massas do composto eicosano $-\mathrm{MM}=282\left(\mathrm{C}_{20} \mathrm{H}_{42}\right)$, composto encontrado como metabólito formado a partir da degradação de pireno pelo fungo $C$. alba CBMAI 1346, após 7 dias de cultivo, na condição validada, e sua respectiva estrutura química.

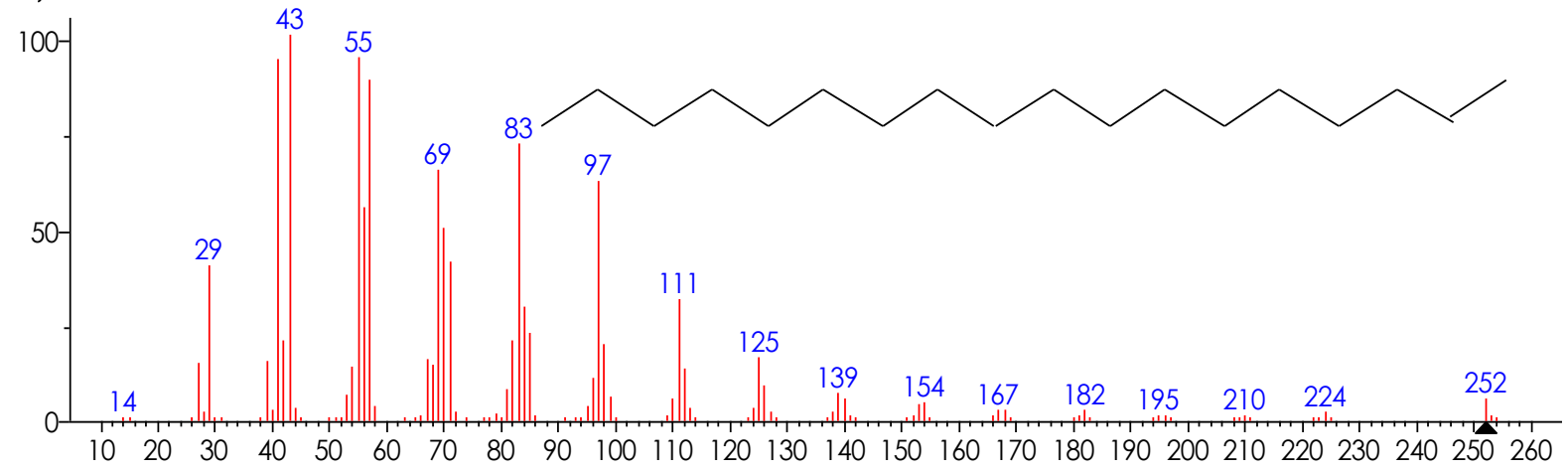
(mainlib) 1-Octadecene

Figura 34. Espectro de massas do composto octadeceno - $M M=224\left(\mathrm{C}_{18} \mathrm{H}_{36}\right)$,, composto encontrado como metabólito formado a partir da degradação de pireno pelo fungo $C$. alba CBMAI 1346, após 7 dias de cultivo, na condição validada, e sua respectiva estrutura química.

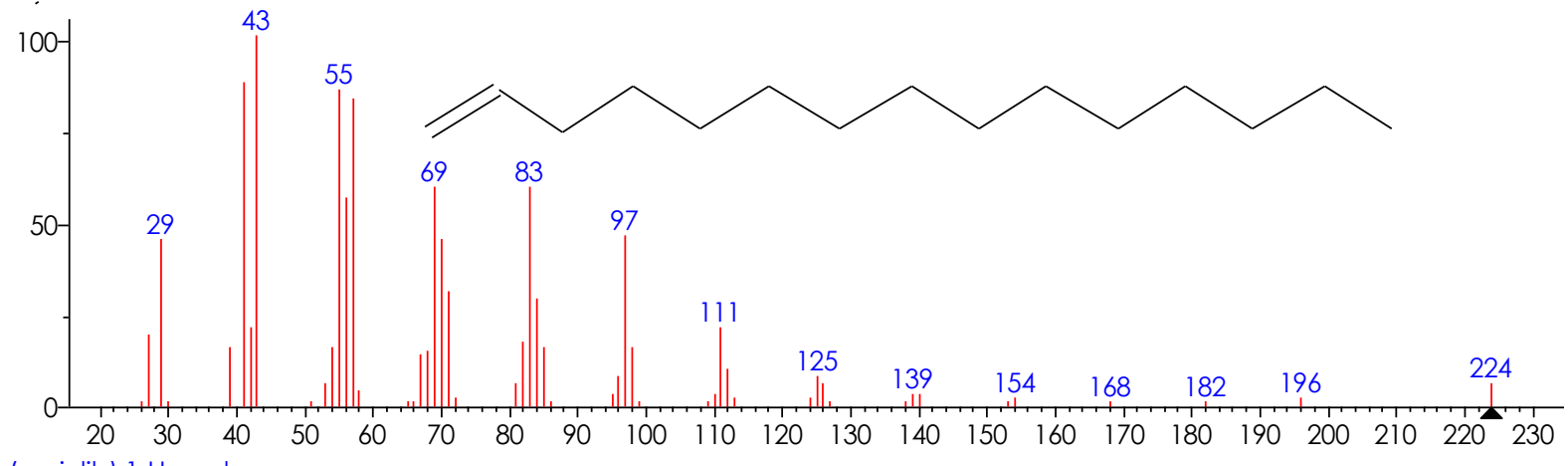
(mainlib) 1-Hexadecene

Figura 35. Espectro de massas do composto ceteno (1-hexadeceno) - $M M=224\left(\mathrm{C}_{16} \mathrm{H}_{32}\right)$, composto encontrado como metabólito formado a partir da degradação de pireno pelo fungo C. alba CBMAI 1346, após 7 dias de cultivo, na condição validada, e sua respectiva estrutura química. 


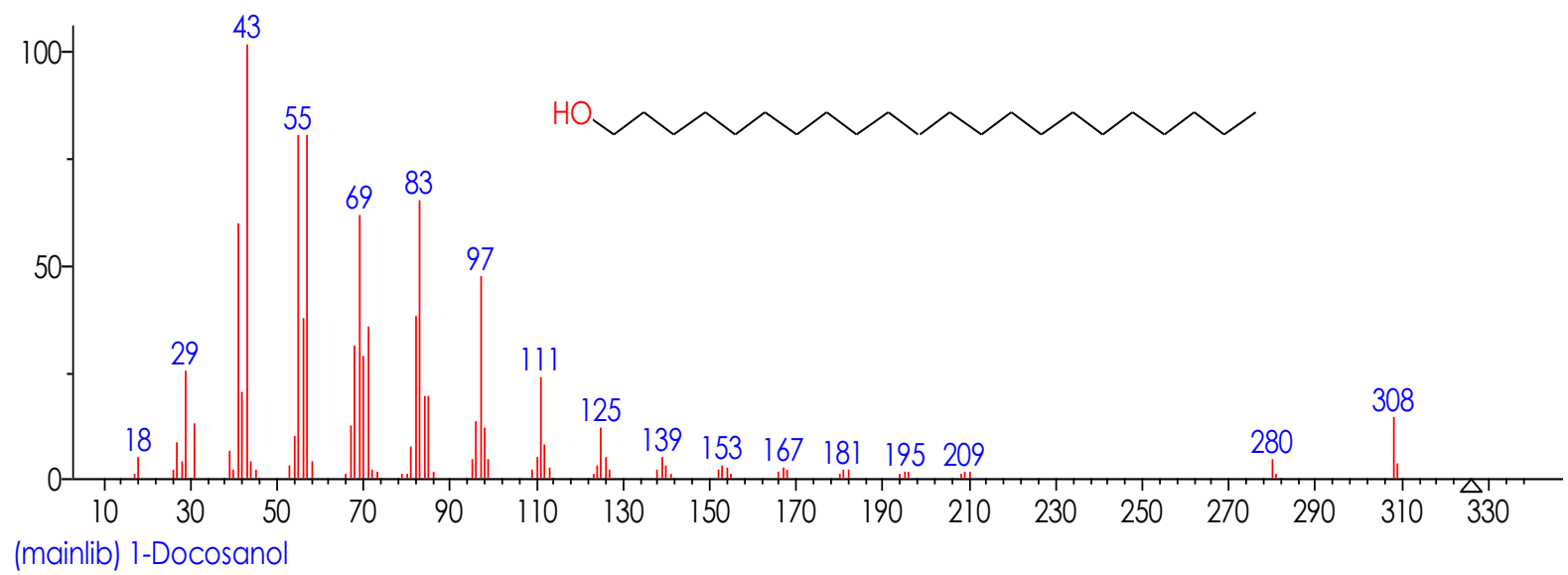

Figura 36. Espectro de massas do composto álcool behênico (1-docosanol) $-\mathrm{MM}=308$ $\left(\mathrm{C}_{22} \mathrm{H}_{46} \mathrm{O}\right)$, composto encontrado como metabólito formado a partir da degradação de pireno pelo fungo $C$. alba CBMAl 1346, após 7 dias de cultivo, na condição validada, e sua respectiva estrutura química.

Os resultados de degradação e identificação dos metabólitos gerados durante o processo degradativo são promissores e revelam o potencial biotecnológico do fungo C. alba CBMAI 1346 em degradar hidrocarbonetos policíclicos aromáticos. Além das altas porcentagens de degradação em condição salina, os metabólitos gerados (cadeia alifática) demonstraram a capacidade do fungo em quebrar os anéis aromáticos da molécula do pireno, na condição validada (Tabela 19).

Em estudo reportado por Bezalel et al. (1996), fluoreno e dibenzotiofeno foram oxidados a compostos alifáticos em vez de anéis aromáticos por Pleurotus ostreatus, sendo o pireno foi metabolizado predominantemente a pireno trans-4,5diidrodiol e 9,10-antraquinona.

Cabe destacar que as análises anteriores de identificação de metabólitos gerados na degradação do pireno (seção 5.9), resultaram na identificação de metabólitos com anéis aromáticos (mono-hidroxifenantreno, dihidroxipireno, hidroxipireno) na condição inicial utilizada (MA2 \%). Estes resultados sugerem que as condições aplicadas no delineamento experimental fatorial fracionado favoreceram a quebra dos anéis aromáticos da molécula de pireno. 


\section{CONCLUSÕES}

A partir dos resultados obtidos pode-se concluir que:

- A metodologia de triagem utilizada (qualitativa e quantitativa) foi aplicada com sucesso, permitindo a seleção de fungos de origem marinha produtores de lacase;

- Os resultados das atividades ligninoliticas sugerem que os corantes IB, RBBR e PS podem atuar como indutores da produção de lacase, MnP e LiP, pois para alguns dos fungos estudados, as atividades destas enzimas na presença dos corantes foram significativamente superiores às atividades nos ensaios sem o corante;

- A produção de enzimas ligninolíticas na presença dos HPAs pireno e benzo[a]pireno, foi de maneira geral maior do que a produção na ausência dos dos HPAs, indicando o possível envolvimento destas enzimas na degradação desses poluentes ambientais;

- A aplicação do delineamento experimental na otimização do processo de degradação de pireno pelo fungo selecionado $C$. alba CBMAI 1346 foi eficiente, uma vez que houve um aumento de cerca de 1,5 vezes (33 \%) na degradação do HPA pelo fungo, atingindo $94,54 \%$ de degradação (resultado confirmado após o experimento de validação do delineamento experimental).

- O método utilizado para a identificação dos compostos formados durante a degradação de pireno pelo fungo C. alba CBMAl 1346 (GC-EM no modo Scan), indicou a presença de compostos tóxicos e não tóxicos (lactona) nas análises preliminares. Os íons detectados no modo SIM revelaram a presença de hidroxipirenos, que são os principais metabólitos da degradação de pireno reportados em literatura. A identificação dos compostos formados durante a degradação de pireno a partir do ensaio validado (GC-EM no modo Scan) resultou na identificação de compostos de cadeias abertas, sugerindo que nas condições do ensaio, uma rota diferente do que a utilizada em meio líquido MA2 $\%$ deve ter sido utilizada pelo fungo. Estes resultados evidenciam o ataque às moléculas do pireno pelo fungo de origem marinha estudado.

- Os fungo isolado de esponja marinha C. alba CBMAl 1346 pode ser considerado um recurso genético relevante para aplicação biotecnológica em processos de degradação de compostos poluentes ambientais em condições salinas, uma vez 
que em $35 \%$ de salinidade (água do mar artificial), o fungo foi capaz de degradar cerca de $95 \%$ do HPA pireno. 


\section{REFERÊNCIAS}

ANALYTICAL METHODS COMMITTEE, AMCTB. Experimental design and optimization (4): Plackett-Burman designs. The Royal Society of Chemistry, n. 55, 2013.

ABBONDANZI, F.; CAMPISI, T.; FOCANTI, M.; GUERRA, R.; IACONDINI, A. Assessing degradation capability of aerobic indigenous microflora in $\mathrm{PAH}$ contaminated brackish sediments. Marine Environmental Research, v. 59, p. 419434, 2005.

ANASTASI, A.; COPPOLA, T.; PRIGIONE, V.; VARESE, G. C. Pyrene degradation and detoxification in soil by a consortium of basidiomycetes isolated from compost: role of laccases and peroxidases. Journal of Hazardous Materials, v. 165, p. 12291233, 2009.

ARANTES, V.; MILAGRES, M. F. The synergistic acyion of ligninolytic enzymes (MnP and Laccase) and $\mathrm{Fe}^{3+}$-reducing activity from white-rot fungi for degradation of Azure B. Enzyme and Microbial Technology, v. 42, p. 17-22, 2007.

ARGUMEDO-DELIRA, R.; ALARCÓN, A.; FERRERA-CERRATO, R.; ALMARAZ, J. J.; PEÑA-CABRIALES. Tolerance and growth of 11 Trichoderma strains to crude oil, naphthalene, phenanthrene and benzo[a]pyrene. Journal of Environmental Management, p. 1-9, 2010.

ARORA, D. S.; GILL, P. K. Comparison of two assay procedures for lignin peroxidase. Enzyme and Microbial Technology, v. 28, p. 602-605, 2001.

ASGHER, M.; AZIM, N.; BHATTI, H. N. Decolorization of practical textile industry effluents by white rot fungus Coriolus versicolor IBL-04. Biochemical Engineering Journal, v. 47, p. 61-65, 2009.

BAMFORTH, S. M.; SINGLETON, I. Bioremediation of polycyclic aromatic hydrocarbons: current knowledge and future directions. Journal Chemical Technology and Biotechnology, v. 80, p. 723-736, 2005.

BAUGHMAN, G. L.; WEBER E. J. Transformation of dyes and related compounds in anoxic sediment: kinetics and products. Environmental Science Technology, v. 28, p. 267-276, 1994.

BONUGLI-SANTOS, R. C.; PASSARINI, M. R. Z.; RODRIGUES, M. V. L.; DURRANT, L. R.; SETTE, L. D. Avaliação do potencial biosurfactante de fungos filamentosos associados a cnidários marinhos com atividade de degradação de HPAs. Microbiologia in Foco, v. 7, p. 12-17, 2009.

De acordo com:

ASSOCIAÇÃO BRASILEIRA DE NORMAS TÉCNICAS. NBR 6023: informação e documentação: referências: elaboração. Rio de Janeiro, 2002. 
BONUGLI-SANTOS, R. C.; DURRANT, L. R.; SETTE, L. D. Production of laccase, manganese peroxidase and lignin peroxidase by Brazilian marine-derived fungi. Enzyme and Microbial Technology, v. 46, p. 32-17, $2010 a$.

BONUGLI-SANTOS, R. C.; DURRANT, L. R.; SETTE, L. D. Laccase activity and putative laccase genes in marinederived basidiomycetes. Fungal Biology, p. 863872, $2010 \mathrm{~b}$.

BONUGLI-SANTOS, R. C.; DURRANT, L. R.; SETTE, L. D. The production of ligninolytic enzymes by marine-derived basidiomycetes and their biotechnological potential in the biodegradation of recalcitrant pollulants and the treatment of textile effluents. Water, Air \& Soil Pollution, v. 223, p. 2333-2345, 2012.

BRINK, H. J. M.; GORCOM, R. F. M. VAN; HONDEL, C. A. M. J. J. VAN DEN; PUNT, P. J. Cytochrome P450 enzyme systems in fungi. Fungal Genetics and Biology, v. 23, p. 1-17, 1997.

BUGNI, T. S.; IRELAND, C. M. Marine-derived fungi: a chemically and biologically diverse group of microorganisms. Natural Product Reports, v. 21, p. 143-163, 2004.

CERNIGLIA, C. E.; HEITKAMP, M. A. Microbial degradation of polycyclic aromatic hydrocarbons (PAH) in the aquatic environment. In: VARANASI, J. L. (Ed.). Metabolism of polycyclic aromatic hydrocarbons in the aquatic environment. Boca Raton, Flórida: CRC Press, 1989. p. 41-68.

CERNIGLIA, C. E. Fungal metabolism of polycyclic aromatic hydrocarbons: past, present and future applications in bioremediation. Journal of Industrial Microbiology and Biotechnology, v. 19, p. 324-333, 1997.

CERNIGLIA C. E.; SUTHERLAND, J. B. Bioremediation of polycyclyc aromatic hydrocarbons by ligninolytic and non-ligninolytic fungi. Britsh mycological society symposium series, fungi in bioremediation. In: Gadd, Z. (Ed.). London. Cambridge University Press, p. 136-187. 2001.

CIULLINI, I.; TILLI, S.; SCOZZAFAVA, A.; BRIGANTI, F. Fungal laccase, cellobise dehydrogenase, and chemical mediators: combined actions for the decolorization of different classes of textile dyes. 2008. Bioresource Technology, v. 99, p. 70037010, 2008.

CHEN, H.; WANG, M.; SHEN, Y.; YAO, S. Optimization of two-species whole-cell immobilization system constructed with marine-derived fungi and its biological degradation ability. Chinese Journal of Chemical Engineering, v. 22, n. 2, p. 187192, 2014.

COUTO, S. R.; RIVELA, I.; MUÑOZ, M. R.; SANROMÁN, A. Ligninolytic enzyme production and the ability of decolourisation of Poly R-478 in packed-bed bioreactors by Phanerochaete chrysosporium. Bioprocess Engineering, v. 23, p. 287-293, 2000. 
D'SOUZA, D. T.; TIWARI, R.; SAH A.; RAGHUKUMAR, C. Enhanced production of laccase by a marine fungus during treatment of colored effluents and synthetic dyes. Enzyme and Microbial Technology, v. 38, p. 504-511, 2006.

DA SILVA, M.; PASSARINI, M. R. Z.; BONUGLI, R. C.; SETTE, L. D. Cnidarianderived filamentous fungi from Brazil: isolation, characterisation and RBBR decolourisation screening. Environmental Technology, v. 29, p. 1331-1339, 2008.

DENG, J.; CARBONE, I.; DEAN, R. A. The evolutionary history of cytochrome P450 genes in four filamentous Ascomycetes. BMC Evolutionary Biology, v. 7, p. 1-22, 2007.

DIWANIYAN, S., KHARB, D., RAGHUKUMAR, C., KUHAD, R. C., CHANDER, R. Decolorization of synthetic dyes and textile effluents by basidiomycetous fungi. Water, Air \& Soil Pollution, v. 210, p. 409-419, 2010.

DURÁN, N.; ESPOSITO, E. Biodegradação de lignina e tratamento de efluentes por fungos ligninolíticos: atualização. Microbiologia ambiental. In: Melo, H. L. e Azevedo, M. O. (Eds.). CNPMA/EMBRAPA, p. 303-338, 2008.

EICHLEROVÁ, I.; HOMOLKA, L.; NERUD, F. Ability of industrial dyes decolorization and ligninolytic enzymes production by different Pleurotus species with special attention on Pleurotus calyptratus, strain CCBAS 461. Process Biochemistry, v. 41, p. 941-946, 2006.

EICHLEROVÁ, I.; HOMOLKA, L.; BENADA, O.; KOFRONOVÁ, O.; HUBÁLEK, T.; NERUD, F. Decolorization of Orange $G$ and Remazol Brilliant Blue $R$ by the White rot fungus Dichomitus squalens: Toxicological evaluation and morphological study. Chemosphere, v. 69, p. 795-802, 2007.

FERNANDES, T. C. C. Investigação dos efeitos tóxicos do biossurfactante ramnolipídio e suas implicações quando usado na biorremediação de águas contaminadas por petróleo. 2011. 101 f. Tese (Doutorado) - Universidade Estadual Paulista, Rio Claro, 2011.

GAO, H.; WANG, Y.; ZHANG, W.; WANG, W.; MU, Z. Isolation, identification and application in lignin degradation of an ascomycete GHJ4. African Journal of Biotechnology, v. 10, n. 20, p. 4166-4174, 2011.

GIANFREDA, L.; RAO, M. A. Potential of extra cellular enzymes in remediation of polluted soils: a review. Enzyme and Microbial Technology, v. 35, p. 339-354, 2004.

HADIBARATA, T.; TACHIBANA, S.; ITOH, K. Biodegradation of $n$-eicosane by fungi screened from nature. Pakistan Journal Biological Science, v. 10, p. 1804-1810, 2007.

HADIBARATA, T.; KRISTANTI, R. A. Identification of metabolites from benzo[a]pyrene oxidation by ligninolytic enzymesd of Polyporus sp. S133. Journal of Environmental Management, v. 111, p. 115-119, 2012. 
HALL, T. A. BioEdit: a user-friendly biological sequence alignment editor and analysis program for Windows 95/98/NT. Nucleic Acids Symposium Series, v. 41, p. 95-98, 1999.

HAMMEL, K. E. Extracellular free radical biochemistry of ligninolytic fungi. New Journal of Chemistry, v. 20, p. 195-198, 1996.

HAO, O. J.; KIM, H.; CHIANG, P. C. Decolorization of wastewater. Critical Reviews in Environmental Science and Technology, v. 30, p. 449-505, 2000.

HARITASH, A. K.; KAUSHIK, C. P. Biodegradation aspects of polycyclic aromatic hydrocarbons (PAHs): a review. Journal of Harzadous Materials, v. 169, p. 1-15, 2009.

HATAKKA, A. Lignin-modifying enzymes from selected white-rot fungi: production and role in lignin degradation. FEMS Microbiology Review, v. 13, p. 125-135, 1994.

HERNÁNDEZ-LUNA, C., E.; GUTIÉRREZ-SOTO G.; SALCEDO-MARTÍNEZ, S., M. Screening for decolorizing basidiomycetes in Mexico. World Journal Microbiology and Biotechnology, v. 24, p. 465-473, 2008.

HILDEN, K. S.; BORTFELDT, R.; HOFRICHTER, M.; HATAKKA, A.; LUNDELL, T. K. Molecular characterization of the basidiomycete isolate Nematoloma frowardii b19 and its manganese peroxidase places the fungus in the corticioid genus Phlebia. Microbiology, v. 154, p. 2371-2379, 2008.

HOEGGER, P. J.; KILARU, S.; JAMES, T. Y.; THACKER, J. R.; KUES, U. Phylogenetic comparison and classification of laccase and related multicopper oxidase protein sequences. FEBS Journal, v. 273, p. 2308-2326, 2006.

HWANG, H. M.; SHIN, X.; ERO, I.; JAYASINGHE, A.; DONG, S.; YU, H. Microbial ecotoxicity of 1-hydroxypyrene and its photoproducts. Chemosphere, v. 45, p. 445451, 2001.

HYDE, K. D., SARMA, V. V.; JONES, E. B. G. Morphology and taxonomy of higher marine fungi. Marine Mycology: A Practical Approach. In: Hyde, S. and Pointing, J. (Eds.).Hong Kong. Fungal Diversity Press. p. 172-204, 2000.

JUHASZ, A. L.; NAIDU, R. Bioremediation of high molecular weight polycyclic aromatic hydrocarbons: a review of the microbial degradation of benzo[a]pyrene. International Biodeterioration \& Biodegradation, v. 45, p. 57-88, 2000.

JUNGHANNS, C.; KRAUSS, G.; SCHOLOSSER, D. Potential aquatic fungi derived from diverse freshwater environments to decolourise synthetic azo and anthraquinone dyes. Bioresource Technology, v. 99, p. 1225-1235, 2008.

KIMURA, M. A simple model for estimating evolutionary rates of base substitutions through comparative studies of nucleotide sequences. Journal of Molecular Evolutionary, v. 16, p. 111-120, 1980. 
KIRK, T. K.; FARRELL, R. L. Enzymatic 'combustion': the microbial degradation of lignin. Annual Review Microbiobiology, v. 41, p. 465-505, 1987.

KOHLMEYER, J.; KOHLMEYER, E. Marine mycology. The higher fungi. New York: Academic Press, 1979.

KUWAHARA, M.; GLENN, J. K.; MORGAN, M. A.; GOLO, M. H. Separation and characterization of two extracellular $\mathrm{H} 2 \mathrm{O} 2$-dependent oxidases from ligninolytic culture of Phanerochaete chrysosporium. FEBS Letters, v. 169, p. 247-250, 1984.

LAMBERT, M.; KREMER, S.; STERNER, O.; ANKE, H. Metabolism of pyrene by the basidiomycete Crinipellis stipitaria and identification of pyrenequinones and their hydroxylated precursors in strain JK375. Applied and Environmental Microbiology, v. 60, n. 10, p. 3597-3601, 1994.

LUAN, T. G.; YU, K. S. H.; ZHONG, Y.; ZHIU, H. W.; LAN, C. Y.; TAM, N. F. Y. Study of metabolites from the degradation of polycyclic aromatic hydrocarbons (PAHs) by bacterial consortium enriched from mangrove sediments. Chemosphere, v. 65, p. 2289-2296, 2006.

MAGRINI, M. J. Degradação de HPAs e produção de enzimas ligninolíticas por fungos basidiomicetos derivados de esponjas marinhas. 2012. 99 f. Dissertação (Mestrado) - Universidade Estadual de Campinas, 2012.

MENEZES, C. B. A.; BONUGLI-SANTOS, R. C.; MIQUELETTO, P. B.; PASSARINI, M. R. Z.; SILVA, C. H. D.; JUSTO, M. R.; LEAL, R. R.; FANTINATTI-GARBOGGINI, F. ;OLIVEIRA, V. M.; BERLINCK, R. G. S.; SETTE, L. D. Microbial diversity associated with algae, ascidians and sponges from the north coast of São Paulo state, Brazil. Microbiology Research, v. 165, p. 466-482, 2010.

MESTER T.; TIEN, M. Oxidation mechanism of ligninolytic enzymes involved in the degradation of environmental pollutants. International Biodeteroration Biodegradation, v. 46, p. 51-59, 2000.

MORGENSTERN, I.; KLOPMAN, S.; HIBBETT, D. S. Molecular Evolution and Diversity of Lignin Degrading Heme Peroxidases in the Agaricomycetes. Journal of Molecular Evolutionary, v. 66, p. 243-257, 2008.

MOSMANN, T. Rapid colorimetric assay for cellular growth and survival: Application to proliferation and cytotoxicity assays. Journal of Immunological Methods, v. 65, p. 55-63, 1983.

NOVOTNÝ, C.; SVODODOVÁ, K.; ERBANOVÁ, P.; CAJTHAML, T.; KASINATH, A.; LANG, E.; SASEK. V. Ligninolyti fungi in bioremediation: extracellulas enzyme production and degradation rate. Soil Biology \& Biochemistry, v. 36, p. 1545-1551, 2004.

OSTERHAGE, C. Isolation, Structure Determination and Biological Activity Assessment of Secondary Metabolites from Marine-derived Fungi. Tese 
(Doutorado). 2001. 150 f. Gemeinsamen Naturwissenschaftlichen Fakultät, Alemanha, 2001.

PASSARINI, M. R. Z. Estudo da degradação de hidrocarbonetos policíclicos aromáticos (HPAs) e da produção de antimicrobianos por fungos filamentosos isolados de invertebrados marinhos. 2008. $107 \mathrm{f}$. Dissertação (Mestrado) Universidade de São Paulo, São Paulo, 2008.

PASSARINI, M. R. Z.; RODRIGUES, M. V. N.; SILVA, M.; SETTE, L. D. Marinederived filamentous fungi and their potential application for polycyclic aromatic hydrocarbon bioremediation. Marine Pollution Bulletin, v. 62, p. 364-370, 2011 a.

PASSARINI, M. R. Z.; SETTE, L. D.; RODRIGUES, M. V. N. Improved extraction method to evaluate selected PAHs degradation by marine fungi grown in fermentative medium. Journal of the Brazilian Chemical Society, v. 22, p. 564570, 2011b.

PASSARINI, M. R. Z.; SANTOS, C.; LIMA, N.; BERLINCK, R. G. S.; SETTE, L. D. Filamentous fungi from the Atlantic marine sponge Dragmacidon reticulatum. Archives of Microbiology, v. 195, p. 99-111, 2013.

PEIXOTO, R. S.; ROSADO, A. S.; TAKETANI, R. G. Bioprospecção da diversidade microbiana cultivável e não cultivável. Microbiologia Ambiental. In: Melo, M. e Azevedo, L. (Eds). CNPMA/EMBRAPA, p. 83-106, 2008.

POINTING, S. B.; PELLING, A. L.; SMITH, G. J. D.; HYDE, K. D. Screening of basidiomycetes and xylariaceous fungi for lignin peroxidase and laccase genespecific sequences. Mycology Research, v. 109, p. 115-124, 2005.

RAEDER, J.; BRODA, P. Rapid preparation of DNA from filamentous fungi. Letters in Applied Microbiology, v. 1, p. 17-20, 1985.

RAGHUKUMAR, C.; RAGHUKUMAR, S.; CHINNARAJ, A.; CHANDRAMOHAN, D.; D'SOUZA, T. M.; REDDY, C. A. Laccase and other lignocellulose modifying enzymes of marine fungi isolated from the coast of Indian. Botanica Marina, v. 37, p. 515-523, 1994.

RAGHUKUMAR, C.; CHANDRAMOHAN, D.; MICHEL, F. C.; REDDY, C. A. Degradation of lignin and decolorization of paper mill bleach plant effluent (BPE) by marine fungi. Biotechnology Letters, v. 18, p. 105-108, 1996.

RAGHUKUMAR, C.; SHAILAJA, M. S., PARAMESWARAN, P. S.; SINGH, S. K. Removal of polycyclic aromatic hydrocarbons from aqueous media by the marine fungus NIOCC\# 312: Involvement of lignin-degrading enzymes and exopolysaccharides. Industrial Journal Marine Science, v. 35, p. 373-379, 2006.

RAGHUKUMAR C.; D'SOUZA-TICLO D.; VERMA A. K. Treatment of colored effluents with lignin-degrading enzymes: an emerging role of marine-derived fungi. Critical Reviews in Microbiology, v. 34, p. 189-206, 2008. 
REDDY, C. A. The potential for white-rot fungi in the treatment of pollutants. Current Opinion in Biotechnology, v. 6, p. 320-328, 1995.

RODRIGUES, M. I.; IEMMA, A. F. Planejamento de experimentos e otimização de processos. 2. ed. Campinas, SP: Casa do Espírito Amigo Fraternidade Fé e amor, 2009. 359 p.

SALEEM, M.; ALI, M. S.; HUSSAIN, S.; JABBAR, A.; ASHRAF, M.; LEE, Y. S. Marine natural products of fungal origin. Natural Product Reports, v. 24, p. 11421152, 2007.

SETTE, L. D.; OLIVEIRA, V.; M.; MANFIO, G. P. Isolation and characterization of alachlor-degrading actinomycetes from soil. Antonie van Leeuwenhoek, v. 87, p. 81-89, 2005.

SETTE L. D.; PASSARINI, M. R. Z.; DELARMELINA, C.; SALATI, F.; DUARTE, M. C. T. Molecular characterization and antimicrobial activity of endophytic fungi from coffee plants. World Journal of Microbiology \& Biotechnology, v. 22, p. 11851195, 2006.

SHARY, S.; RALPH, S. A.; HAMMEL, K. E. New insights into the ligninolytic capability of a wood decay ascomycete. Applied and Environmental Microbiology, v. 73, n. 20, p. 6691-6694, 2007.

SHLEEV, S.; PERSSON, P.; SHUMAKOVICH, G.; MAZHUGO, Y.; YAROPOLOV, A.; RUZGAS, T.; GORTON, L. Interaction of fungal laccases and laccase-mediator systems with lignin. Enzyme and Microbial Technology, v. 39, p. 841- 847, 2006.

STAT SOFT, INC. STATISTICA for windows (computer program manual). Tulsa, OK: Stat Soft, Inc. 2325 East 13th Street, Tulsa, OK 74 104, 1995.

SZKLARZ, G. D.; ANTIBUS, R. K.; SINSABAUGH, R. L.; LINKINS, A. E. Production of phenol - oxidases and peroxidases by wood-rotting fungi. Mycologia, v. 81, p. 234-240, 1989.

SZLINDER-RICHERT, J.; NERMER, T.; SZATKOWSKA, U. PAH metabolites in European eels (Anguilla anguilla) as indicators of $\mathrm{PAH}$ exposure: different methodological approaches. Science of the Total Environment, v. 496, p. 84-91, 2014.

THOMPSON, J. D.; HIGGINS, D. G.; GIBSON, T. J.; CLUSTAL, W. Improving the sensitiviy of progressive multiple alignment through sequence weighting, positionsspecific gap penalties and weight matrix choice. Nucleic Acids Research, v. 22, p. 4673-4680, 1994.

TIEN, M.; KIRK, T. K. Lignin-degrading enzyme from Phanerochaete chrysosporium: Purification, characterization and catalytic properties of unique $\mathrm{H} 2 \mathrm{O} 2$ requiring oxygenase. Proceedings of the National Academy of Science USA, v. 81, p. 2280-2284, 1984. 
TORTELLA, G. R.; DIEZ, M. C.; DURÁN, N. Fugal Diversity and use in decomposition of environmental pollutants. Critical Reviews in Microbiology, v. 31, p. 197-212, 2005.

VERMA, A. K.; RAGHUKUMAR, C.; VERMA, P.; SHOUCHE, Y. S.; NAIK, C. G. Four marine-derived fungi for bioremediation of raw textile mill effluents. Biodegradation, v. 21, p. 217-233, 2010.

WANG, G. Diversity and biotechnological potential of the sponge-associated microbial consortia. Journal of Industrial Microbiology and Biotechnology, v. 33, p. 545-551, 2006.

WANG, C.; SUN, H.; LI, J.; LI, Y.; ZHANG, Q. Enzyme activities during degradation of polycyclic aromatic hydrocarbons by white rot fungus Phanerochaete chrysosporium in soils. Chemosphere, v. 77, p. 733-738, 2009.

WEBB, J. S., NIXON, M., EASTWOOD, I. M., GREENHALGH, M., ROBSON, G. D., \& HANDLEY, P. S. Fungal Colonization and Biodeterioration of plasticized polyvinyl chloride. Applied and Environmental Microbiology, v. 66, p. 3194-3200, 2000.

WESENBERG, D.; KYRIAKIDES, I.; AGATHOS, S.N. White-rot fungi and their enzymes for the treatment of industrial dye effluents. Biotechnology Advance, v. 22 , p. 161-187, 2003.

WILD, S. R.; JONES, K. C. Polynuclear aromatic hydrocarbons in the United Kingdom environment: a preliminary source inventory and budget. Environmental Pollution, v. 88, p. 91-108, 1995.

WONG, D. W. S. Structure and action mechanism of ligninolytic enzymes. Applied Biochemistry Biotechonology, v. 157, p. 174-209, 2009.

ZAHARIA, C.; SUTEU, D. Textile Organic Dyes - Characteristics, Polluting Effects and Separation/Elimination Procedures from Industrial Effluents - A Critical Overview, Organic Pollutants Ten Years After the Stockholm Convention - Environmental and Analytical Update. In: Puzyn, L. (Ed.). Stockholm. InTech. 2012. p. 55-85. 